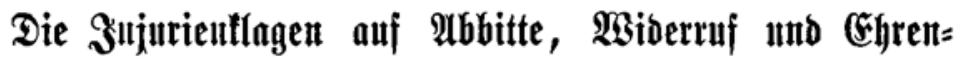

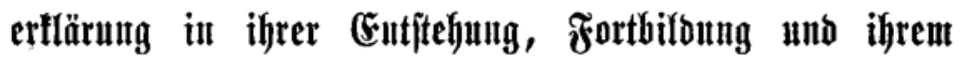 Berfall.
}

Sin Beitrag zur Befdidate bes beutident Strafredts

bont

fagern Dr. jur. C. v. Eallemrodt,

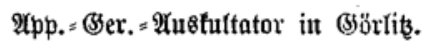

Ueber Den Uriprung der Snjurienflagen auf âtbbitte, Miderruf und (5h)rencrflärung find bie Meinungen ber Bjelehrten jeit gerauts mer 3eit fehr controbers - und (wie wir hier gleiđ) hinzufügen fönnen) Jurdjgängig falfof. - Mit oer fđton frühe eintretenden

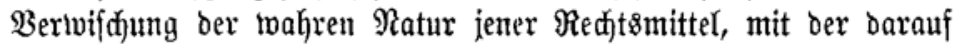
forgenden $\mathfrak{B}$ ermengung derfelben und ber $\mathfrak{B}$ eimifjunt heterogenter

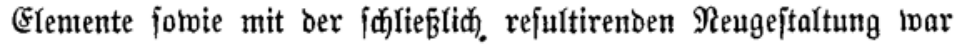

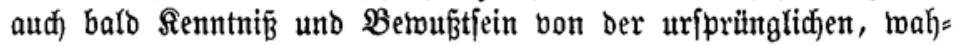
ren Entjtehung berjetben bei $\mathfrak{B o l f}$ und Bielehrten - bei Theo:

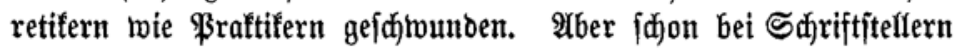
des [pätejten Mittelalters zeigt fïh ein $\mathfrak{B}$ emühen biefen Rlagen eine pofitivere und hiftorif d fejter befitimmte (5rundlage zuzumeifen als ben reibigen usus fori totius Germaniae, in bem fie bas Snjtitut ausgebildet und eingebürgert fanden. Man jah fith baher

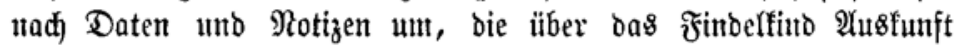
geben follten. $\bigcirc b$ und ino bieje fich vorfaltoen - ober ob die

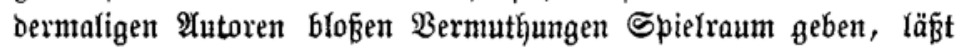


fich heute fidwer ermitteln. Sedenfalls find bie aufgeiftellten $\mathfrak{A n}=$ gaben nirgends burd betweifende Belegftellen begründet, und bie vielfadjen erheblicten Differenzen, bie unter ihnen herrichen, flögen uns nothlwentig bon borne herein Miįtrauen gegen bie Şaltbar: feit jeder einzelnen von ignen ein. Diefe mantgetnde Uebereinjtim:

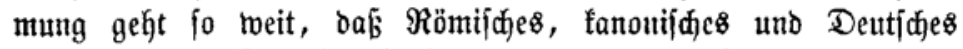
Red)t wedffeltweife haben herbalten und fid als Erzenger ein und

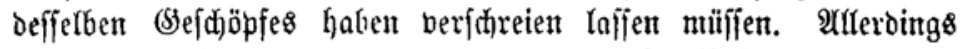
lag nothwentig einer ober ber anderen biejer Behauptungen et

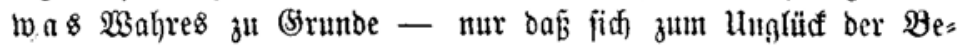
hauptende jelbjt beffen nidft betwugt twerden fomnte, weil er meder auf Thatfadjen, uod) auf übergentgende Conjefturen funte.

Bsic förnen zur Erteinjterung ber Ueberfidjtfidfeit bie aufige=

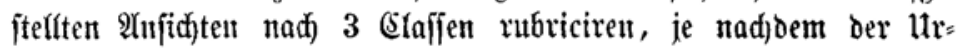

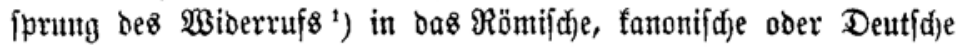
Redft berlegt tworben ift.

I. - Bon biefen zählt mun unzweifelhaft bie erf́tere bie toes

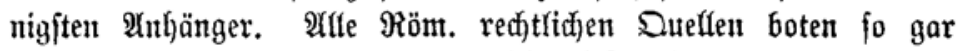
feinen $\mathfrak{A n}$ halt, baß bie Unhaltbarfeit diefer Şypotheje zu augen= füllig fein mußste. Nur Briffonius hat aus ben Ed)riften meh=

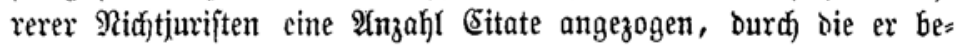

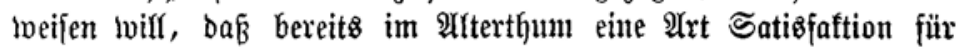
fugefügte Sniurien in Form einer bem Beleibigten bon Seiten

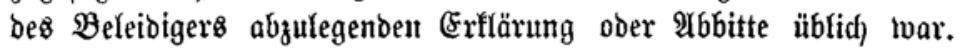
Diefes Faftum fann zugegeben werden; indeffen ift eine joldje Boridrift des Bohlanjtandes, eine folche Moralforderung, wie jie fich leidjtlid) in ber Sittenlehre eines jeden civilifirten $\mathfrak{B o l f e z}$ wie=

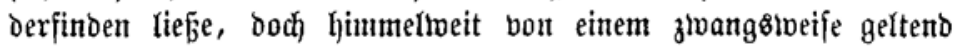

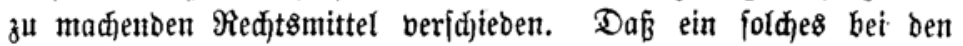
Römern etwa bereits formulitt erfdienen, ift entidjieden in arbrede

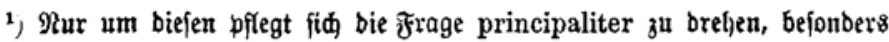

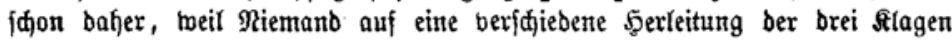

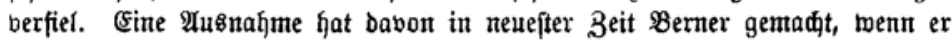

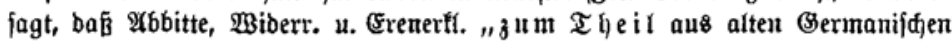

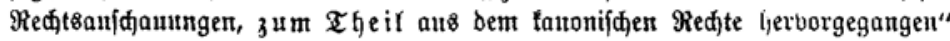

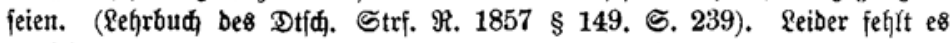
an jeber tweiteren Begrüntoung ber auвgefprod,enen Эoee. 
fu ftellen. $D b$ bies bagegen Brififonius ${ }^{2}$ ) hat berfechten wollen,

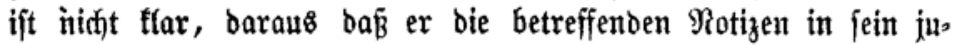
ribifaces Werf aufnahm, follte man es moht folgern. Sebenfalls gab biejer Umitand fpäteren Scribenten 2 fula Semährşmann zu beziehen. Freilid toar aud fagon früher hier unb ba ber SHlaube, als fundire bie actio ad palinodiam in

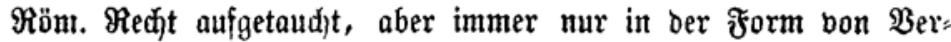
muthungen ausigefprodien toorben.

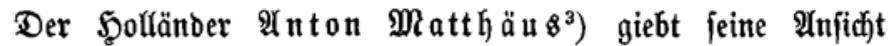
bahin $\mathfrak{a b}, \quad$ $a \mathfrak{B}$ er menigftens bie Beranlaffung zu bem fpäteren Redttmittel in ber bei (Sried)en und Römern gebräudhlichen Sitte

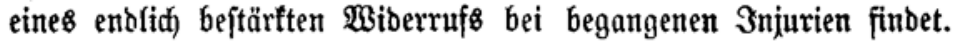
Die Erffärung, wie biejer (Sebraud) zu einem flagetweife geltend zu madyenden 3lwange erhoben worben, ifft gleid) oberflädjlid, ge= walt fam, unmotibirt unb unhaftbar. ${ }^{4}$ )

(Sanz in ähnliđjer Weije mie Matthäus (prid)t fiđh fpäter

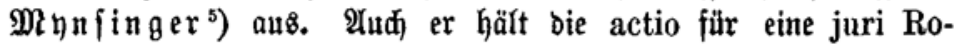
mano incognita, fudjt aber fundamentum uno rationem actionis in jure communi.

(Endidy bürfte nod) Marquarous Freheru 8 ) zu nennen fein, ber fid in feinem beachtenstwerthen tractatus de existimatione bereits auf bie 'formula recantationis' bezieht, bie fich in ben Adelphis Terentii befinden folf.

II. - Э. F. $\mathfrak{B}$ öhmer ${ }^{7}$ ) war e8, ber zuerft mit aller (Fnt=

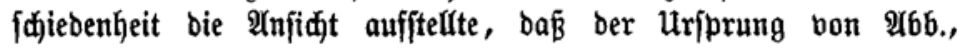

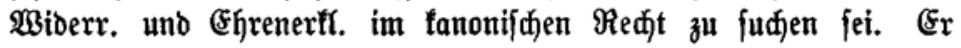
hat fid, wie mir fpäter fehen twerben, auf ber ridtigen Spur bes

2) De formulis Lib. VIII. no. XVIII. - Die ફ̧auptftellen fint: BYautus, Amphitr. Act. III. Sc. 2. V. 42. - unb Terentius, Adelph. Act. II. Sc. 1. V. 8. - Bie menig fie betweifen, liegt auf ber \$anb.

s) 2 (nt. Watţäu\&: De criminibus ad libr. XLVII et XLVIII Dig. (script. 1644). In libr. XLVII Tit. IV cap- 3 no. 7.

4) Idem 1. c. - - Cum autem tenaces multi propositi atque injuriae essent, eo tandem descensum, ut petente actore, judex cogeret reum injuriam verbis factam contrariis verbis retractare.

o) Joach. Mynsinger a Frundeck: Apotelesma, sive corp. perf. schol. ad Instit. - ad $\S$ in summa Tit. de Injuriis.

-) Marquardus Freherus; Tractatus de existimatione. Basil. 1591.

$\left.{ }^{\boldsymbol{r}}\right)$ Jus eccles. prot. lib. V. lit. $26 \S 1$. 
funben, aber er beging ztwei Fehfer: er troflte zu biel betweijen,

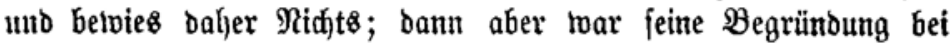

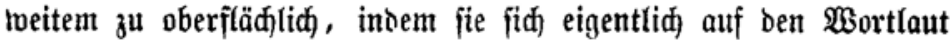
einer eingigen Stelle auts dem Defret ${ }^{3}$ ) ftüz̧te. (B)eforgt find $\mathfrak{B}$ öh $=$ mer auf feiner, lventigitens zum Theil ridftigen $\mathfrak{B a h n}$ Wenige. 3u nennen iijt mohl nur $2 \mathfrak{e b} e r,{ }^{9}$ ) der indeffen, feiner Sacfe

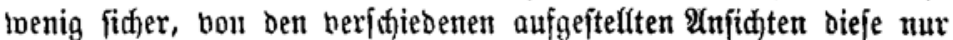
für bie "annehmbarjte" erflärt. Demnädift hatte ت̈id) aud $\mathfrak{S} e f f=$

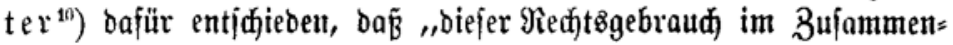

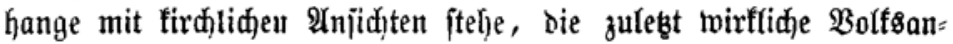
jiđjt twurben," jedod) ift er ipäter reider mieber babon abgegangen, und hat in ber 3 ten Pluflage feines Rehrbuds bem Bermanifichen Ređ̧te allein Bugeitänoniffe gemadjt.

III. - Die Sdjriftiteller ber neueften Zeit endidd nun haben mit Berhorrescirung aller fremben $\mathfrak{B}$ ejtanbtheile bem äd,t germa= nifden Redfte alfein bie Urheberid)aft unfres Rechtsిmittels bin.

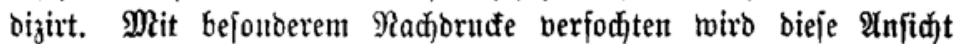
bon $\Re$ öft $\left(i\right.$ it. $\left.{ }^{1 t}\right)$ Reiber berwirft er Ridtigez mit Faljđem zu ¡đ̆nell auf bloken äukeren Sdjein. Weun er befjauptet, baß erít auf bie Autorität bon $\mathfrak{B} i \zeta_{b a}$ und $B r i m m$ hin ",bem germanis fden Red,t bie ihm gebührente (Ehre gegeben" worben fei, fo

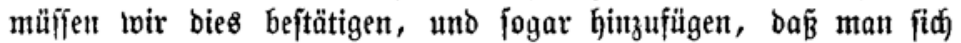
bon ba an nur an bie ",ifutoritäten" hielt, ohne fid) ein eigenes Urtheil zu bilden. Dagegen milffen bir bejtreiten, daß̧ Sdifter und Dreyer die Erjten getejen fein follen, bie einen "ridftigeren Blid“" (o. h. im Röptlin'finen Sinne) berriethen. Bereits Şein.

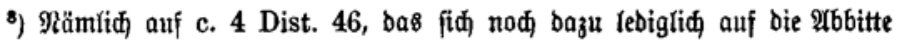
bezieft. Das Rähere toeiter unten.

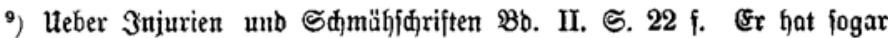
mit glüđflidjem Sđarfbliđ ben Bufammenthang mit ber ßönnitenz entbeđt, wobon fid bei $\mathfrak{B}$ öhmer Ridhts finbet, ber in Bsegentheil bon einer faljhen આunalyme ausgeht.

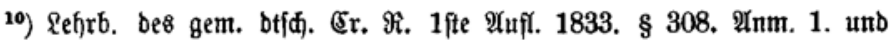
ebenio nod) im nenten अrdjib 1839 ऽ. 244.

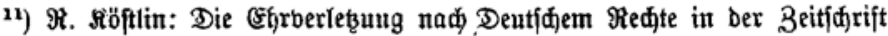

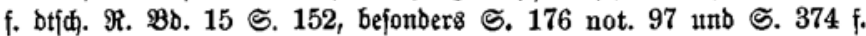


necciu ${ }^{12}$ ) hatte bon ber intereffanten und widjtigen Stelfe in bem Rangobarbifden Sejes Notiz genomuten und int Anhalte-an fie bie palinodia als einen deutichen (sebrauch bezeidnet.

2(ud) Scaltau ${ }^{13}$ ) giebt in feinem glossarium bereits 2 Ur: funben aus ben Sahren 1353 unb 1354, in benen bon einem

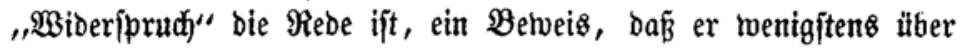
bas AYter bes (sebraud)s in Deutjhyland informirt war. - Einen bebeutenderen 2(pparat bietet $\Re \circ g g e^{14}$ ) aus den Borfiredyten bar. Ein anores Berbienfit fant ihm nidjt zugefproden weroen, benn er fteht fo rathlos bor "biejer auffalfenden ânmenoung von

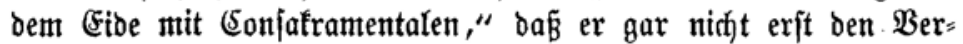
jứ) einer Deutung Diefes Räthfers unterninmt. - Eine Menge Material findet fid enblidf bei Dfenbräggen, ${ }^{15}$ ) hauptfäd)lid in Belegiteflen aus jutweizerifden $\Re$ ed)ten.

Die bißger Brenannten fino nur bie Saauptbertreter ber brei

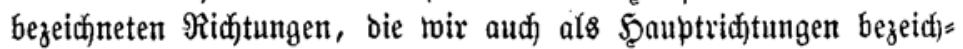
nen müffen. Daneben fehlt ez nidgt an folden, bie jid. entweder

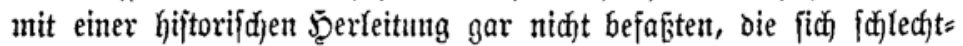
hin auf ben usus forensis bezogen, ober bie endlid ohne tiefere

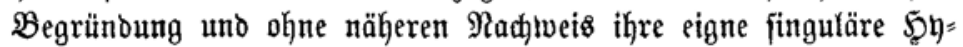
pothefe aufítellten. Es gentitge einige berfelben zu nenten.

(5onzalez Tellez ${ }^{16}$ ) und (5obarrubia ${ }^{17}$ ) Yeiten die actio ad palinodiam aus Spantien her; Daffertbe thut $\mathfrak{T} \mathfrak{h}_{0}=$

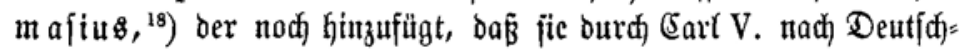
lano berpflangt fei. Die Einführung burd biefen Raijer beftätigt

12) Elementa jur. Germ. p. II. pag. 90. sg. Driginelf ifft afferbings feine Bezugnahme resp. Berufung auf $\mathfrak{T}$ acitıs. Germ. cap. 21. „suscipere inimicitias patris seu propinqui necesse est. Nec implacabiles durant."!!

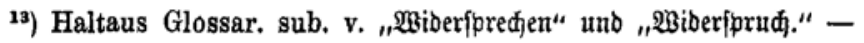

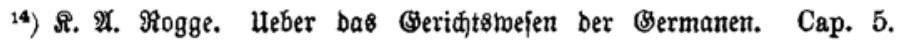
not. 7. ธ. 195.

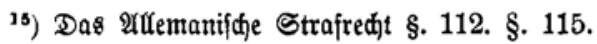

16) In cap. $23 \mathrm{X}$ dr sent. et re jud.

17) Didacus Covarruvias a Leyva. Resolutionum variarum libri III. Cap. XI. no. 1.

${ }^{18)}$ Diss. de act. injur. § 19. 
übrigens auch $\left.\mathfrak{M y n f i n g e r , ~}{ }^{19}\right)$ wogegen $\mathfrak{B a r t h o l o m a ̈ u ~} \mathfrak{B l} a^{\prime}=$

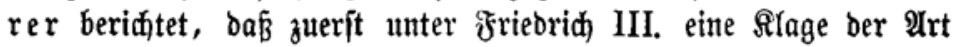
berhandelt fei, und dem fabliefit fich Marqu. Freheru $8^{20}$ ) an,

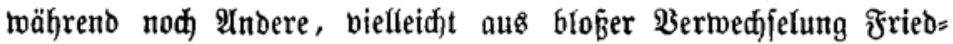
rid, II. nennen.

\section{Cap. I.}

\section{Die sfirenerklärung.}

Es ift bis auf bie neneften Beiten hin eine afltäglidje $\mathfrak{B} e=$

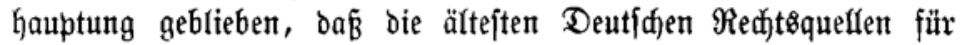
fein Eapitel bes Strafred to fo bürftig flöffen, als für bas ber

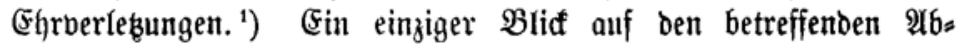

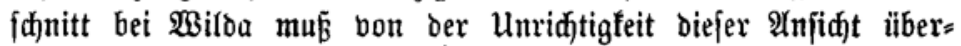
zeltgent.

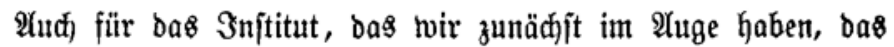

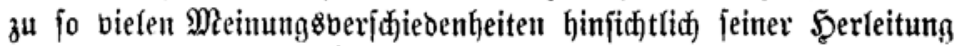
Anlaß̧ gegeben hat, für die Ehrenerflärung, finden wir bereit\&

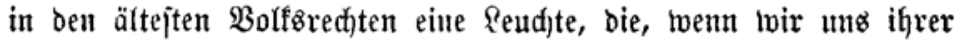
nur besienen wollen, jede Dumferlyeit zu zerftreuen und vofffom= mente silarheit zu beridgaffent geeignet ift.

Die Strafe ber Snjurie nad) norbijd)em, [peziefl Rortwegifdem Rec)te ijt bie Friedlojigfeit ${ }^{2}$ ) in ihrer miprünglichen (Sejtalt und Bedentunt. Sht Stelle berfelben, als jie einen beränderten Shas rafter auzunehmen und nur nod anf bie fdjwerjten Berbrechen

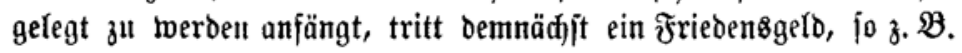

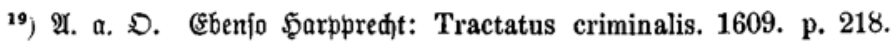
de Injur. borjüglid ad $\S$. in summa. Darüber bgr. unten cap. IV. not. 1.

$\left.{ }^{20}\right)$ Frreheruв a. a. D. § 4. Deళgl. Laurentius Kirchov; Respons. sive Consil. Tom. V. Consil. IX. no. 32.

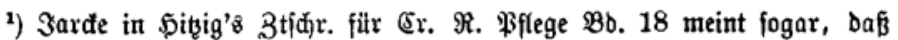

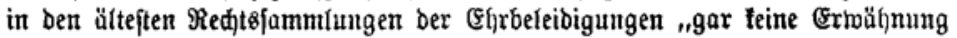

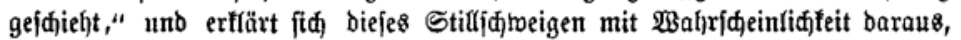

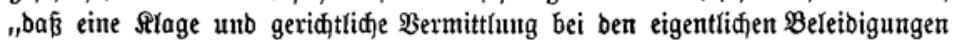
Der Ehre, ber Sitte nađh, nidjt ftattgehabt habe." (?!)

2) $\mathfrak{B i l b a}$ S. 787. 
im Gulathings-(Sefez bon 4 Marf Silfber. Sebod) erfolgte bieje Friebloserflärung nidut unbedingt, jonbern vertwandelte fid in eine $\mathfrak{B u B z}$ ahlung, went ber Beflagte bie gerichtlidje Erflärung ablegte,

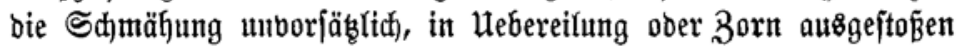
fu haben, ${ }^{3}$ ) und die Unbefdoltenheit bes Snjuriirten auf foldhe Beife zugeftano. Dieje Erflärung wurbe in Forın einez burch

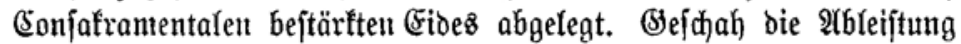
auf (Srund förmliderer Berweigerung nidyt, fo trat nut bie Silage resp. Berurtheilung auf frieblojigfeit oder auf bas fdipere Frie: bensgelo ein. Bejondere Beaçtung verbienen $\left.{ }^{4}\right)$ :

Guta-Lagh (ed. Schildener).

cap. 51 (G. L. 39). § 1. Einem Mann find 4 Borte unbulo=

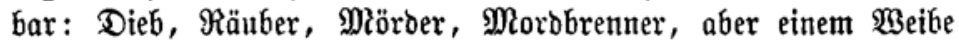
find untulbbar 5 Morte: Dieb, Mörber, Bergiftung (?) Ehyebruad) (?) uno Morobrenner.

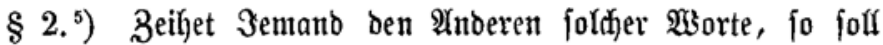

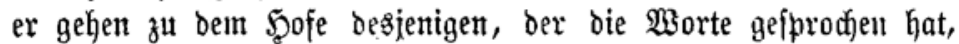

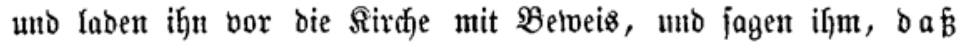

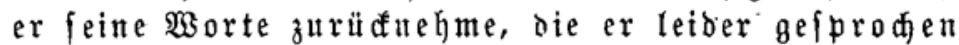
in (5) emith serwegung oder Betrunfenteit.

$\S 4$. . . Berntag er bas nidyt (zu läugnen) fo büßje er je= nem 3 Dere uno ehre ign bor ber Sirdje mit breier $\mathfrak{M a ̈ n}$. ner Eib.

§ 5. - Bef fuimpit einer ben anbern mit foldenen $\mathfrak{B o r t e n}$ bor bem ganzen Sirdffpiel, ober vor ber Dingberfanmlung oder irgeno

3) $\mathfrak{B}$ ilba S. 793 nennt biejeళ eitren $\mathfrak{B}$ iberruf. AUferbings liegt ber Sadje nad aud ein joldjex implicite in jener Ertlärnng; aber an ihnt bacite man

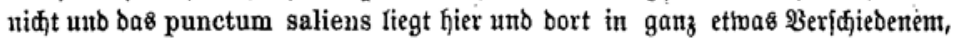
mie ftđ bemnäđfft ergeben wirb. Daher miliffen mir ber Sđärfe twegen ein für alle $\mathfrak{M a l}$ ben 2 (u\&brud $\mathfrak{B}$ Biberruf für ben hier fragliden $\mathfrak{A f t}_{\mathrm{ft}}$ bermerfen,

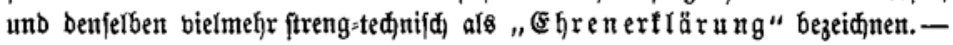

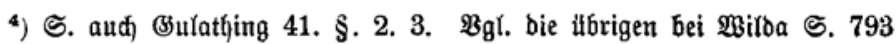
not. 1. citirten.

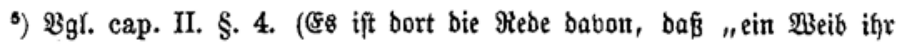
Rind berberbt hat."):

- - Eäugnet fie e\&, und fommt bie Sadje bor bie Dingmänner, unb trirb fte unịultbig, fo foll fie haben 3 Mart bon Demjentigen, ber ihn bie Sałje aufbutrbet, unb einen (Eib bes guten Bserü 4 t 8 bon 6 Männern. 
einer Bremeinheit, der bübe ihm 3 Mart unb ehre ihn vor ber Dingberfammlung mit 6 Männer cito.

$\mathfrak{A}$ lsbann :

Edictum Rotharis regis. a. 643. (ed. Baudi a Vesme). cap. $198 .{ }^{6}$ ) Si quis puellam liberam aut mulierem, qui in alterius mundum est, fornicariam aut strigam clamaverit, et pulsatus penitens manefestaverit per fororem dixissit, tunc preveat sacramentum cum XII sacramentalis suos, quod per fororem ipso nefando crimen dixissit, nam non de certam causam cognovissit, tunc pro ipsum vanum improperii sermonem, quod non convenerat loqui, componat solidos viginti, et amplius non calumnietur.

cap. $384 .{ }^{7}$ ) - Si quis alium Argam per fororem clamaverit, et neganer non potuerit, et dixerit, quod per fororem dixissit: tunc juratus dicat, quod eum Argam non cognovissit, et postea componat pro ipso injurioso verbo solidos XII.

Dieje auferorbentlid)e Itebereinftimmung zroeier Rofatrect)te, bon benen bas eine im Morben, Das anbre im Süben Europa's

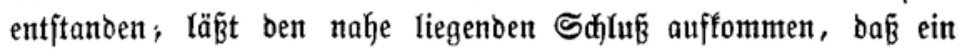
Red(t)gebraut(t, ber fid) hier mie bort fo beutlid) ausgeprägt findet, audj ben zwijden jeuten beiden fisentoen Böfferjafaften nidjt unbe= fannt getwejen fein mirb.

Ulebrigens fint beize citirte Stellen früher nidft allein be=

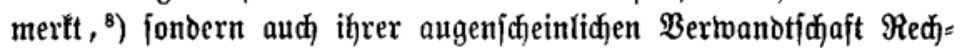

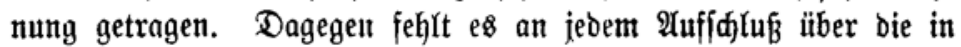
ihnen Yatenten Brunofäbse. - 9 uf einem ridtigen $\mathfrak{B}$ ege befano fitf, man fann fagen instinctive, $\mathfrak{T} x \mathfrak{m} \mathfrak{m}$ er. ${ }^{9}$ ) Aber er beutet nutr an, ohne auszuführen.

6) Dazıt Formula ad leg. 198 (Canciani V. p. 63). Petre te appellat Martinus, quod clamasti Aldam suam mundoaldam fornicariam. - De torto. - Si dixerit, quod dixerit per furorem, juret sicut lex commendat.

7) Dazu Form. ad leg. 389 (Canciani p. 74). - Arga foll freigling,

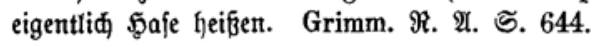

8) So 3. B. bon 5̨einneccius (Elem. jur. Germ. p. II. § 115) unb Rogge a. a. D. Selbft $\mathfrak{B}$.

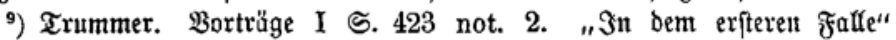
(näml. ment bie 3njurie in's Befidjt gefagt ift) "ftanb es ztwar bem Beleibigs 
Die Sadfe ift folgende:

Nidit jeber frebel einer beftimmten (Sattung auf bie bem (Befege nach Frieblofigfeit gelegt twar, zog bieje immer nady jid - wurbe ohne Beiteres alo Friebensbrud betradjtet. Bielmehr erforberte Der Begriff des Friebbrudjs eine beftimmte $\mathfrak{W}$ illen 8

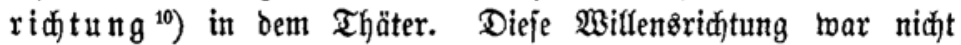

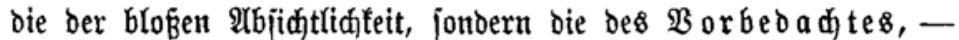
$\mathfrak{B}$ orjatze 8 . Die Queflen bezeidnen biejen dolus praemeditatus getö̈hnlich als ,berathenen Muth" (rathet radh) und "vorsate“;

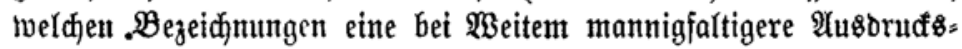

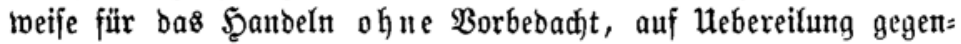
ïber jteht. So finden lvir in ben Queffen ben $\mathfrak{a f f e f t}$, astus animus, Zornmuth, Zorgemut, furor, ira in jtetein prägnanten Bsegen= fakze zur vorsate; ein (5tegenfag, auf beffen Bedeutjainfeit, mas

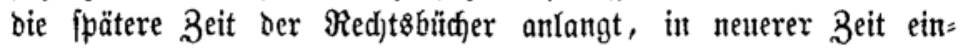
gehend aufmerffam gemadt iff. ${ }^{11}$ ) अ(ber fdjon früher ift haupt=

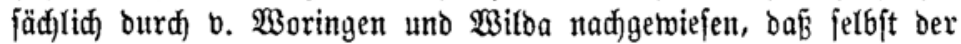
frïheren Stufe bes Strafrechts, auf ber bie Boltzrechte nod ftehen, eine foldhe Berüdfichtigung bes fubjeftiben Moments ber That, eine pindhologif he $\mathfrak{B}$ iurbigung ber Freiheit, als Borbedingung Des criminellen Unred)ts, uno ber biejelbe beftimmenden uno bejabrän= fenden Cinflüffe nidft fremb getwejen fei.

Brabe nun, to es fid barum hanbelte bem fpezififident Unter=

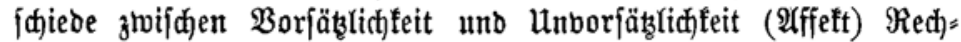

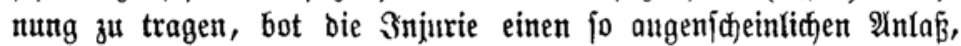
wie bielleidft twenig andere Delifte. ${ }^{2}$ ) Wie Yeidt twiro in (Erres

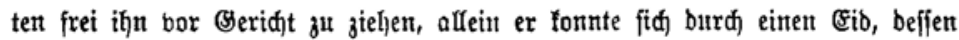

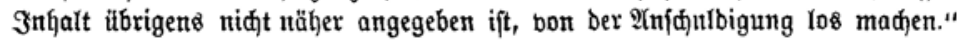
Not. 2. Es ift möglich, baß̉ in ber Formel beffelben bie erfte Spur ber fpäteren Ehrenertärung gefunben werben muß..."

10) $\mathfrak{B}$ iliba à. a. D. S. 272.

11) So 3. B. in ben treffliden $\mathfrak{B e r t e n t}$ bon Dienbrïggen (2tlemannifdes

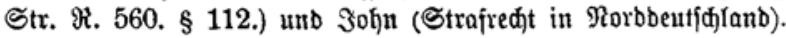

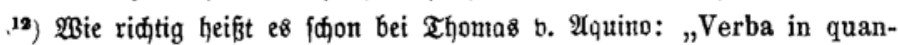
tum sunt soni quidam, non sunt in nocumentum aliorum, sed in quantum significant aliquid, quae quidem significatio ex interiori affectu procedit. Et ideo in pecatis verborum maxime considerandum videtur ex quo affectu aliquis verba proferat. Summa II. 2. Quaest. 72. art. 2 cf. Quaest. 73. art. 4). 
gung, 3orn, Uebereilung, ein unbebadytes Sd)mähtoort ausgejtogen

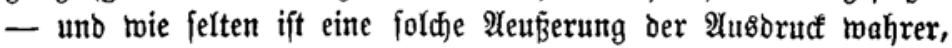
innerer Ueberzetgung. Die Эnjurie ift basienige Delift, zu weldem ber affeft am leidfeften hinreist. ${ }^{18}$ ) Das ift natürlich und - menisfida! Und eben weil bem jo ift, fo muß grabe hier ben natürficjen Eintwirkungen altf bie $\mathfrak{B i l l e n s f r e i = ~}$

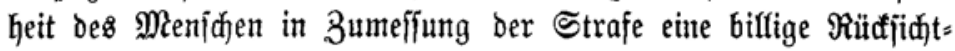

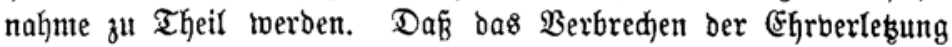
bereits in ben früheften Zeiten einer foldjen Beurtheilung unter= legen hat, betweijen bie Dueflen. ${ }^{14}$ )

Burbe auf bas Borthandenjein oder Fehlen bes $\mathfrak{B o r j a k g e s ~ b c i ~}$

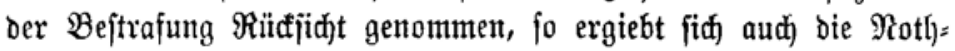

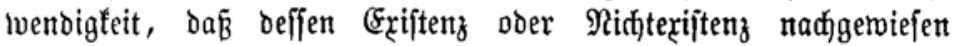
murbe. - Für bie $\mathfrak{A}$ rt und $\mathfrak{B}$ eife nut eben, wie diefer Radjweiß geliefert werden follte, geben bie Quellen $\mathfrak{A}$ ntweijung. Ueber bas Borhantenjein des Borjaz̧es fonnte Riemand mit Sid丸̣erheit ur= theilen, als ber Beleibiger felbft. Daher wurbe es ihm überlaffen jid) in bie bolle Strafe ber vorfäbstidjen Egrberlekzung zu fügen, -

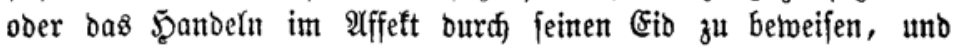
Damit einer gelinderen Beftrafung zu berfallen. Diefer Eio, wie er fidf zu biefem Btwed in ben Queflen borgefdrieben fittot, ift bie alte unt ädht=bentide Egrenerflärung, bie toie ans dem Siejagten erhellt, nidjt bas Mindejte bon eimer Strafe (oder gar (Ehrenftrafe) an fid hat, fondern in einer Proceb̧anolung, einem Beweism o du bejteht. Diefez twirb bem, ber bie oben angefühthren Stellen einer unbefangenen Prüfung untermirft, nidjt entgehen fönnen, ${ }^{15}$ ) aber es findet tweitere $\mathfrak{B e g r u ̈ n}$ ung unb $\mathfrak{B} e=$

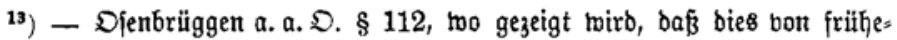
fter Beit anerlannt unb in ber Strafjumeffung berïlffidftigt ift. Bu bergleidjen finb bie bort angejït\}rten Statuten bon $\mathfrak{2}$ ppenzell, Freiburg, Obmalben $\mathfrak{u}$ a.

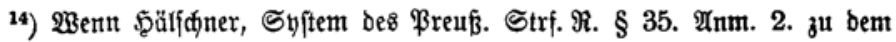
ธđ) In

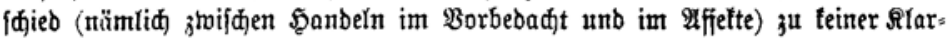
heit und Bebeutjamteit gelangt," - fo miberlegt fid bas f́,on aus bem Fols

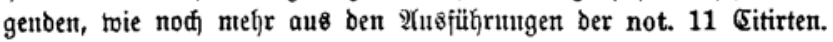

1s) - Diertwürbig ift, wie nahe Mande, 3. B. Sëptlin ber toahren (5x= lenntniß̧ tamen, ohne bod ben einen Sdjritt, ber fie bon berfelben fdeinbar

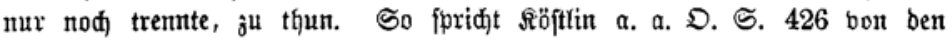
"Milberungsgründen" bei Strafbarfeit ber Snjutrien, und fommt babei aud 
ftätigung in ber Darfteflung fpäterer, Demmä(t)ft in Betrad)t łu ziehender Duellen.

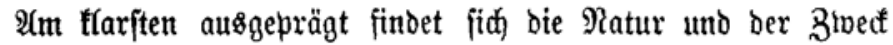
Der E⿹renerffärung in ber eit. lex Rotharis. Der Stäger flagt wegen einer $\mathfrak{B e r b a l i n j u r i e , ~ D e r ~ B e f l a g t e ~ b e r u f t ~ f i d ) ~ o h u e ~ b i e f e l b e ~}$

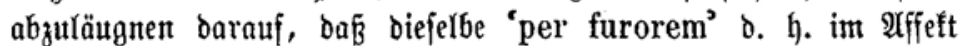

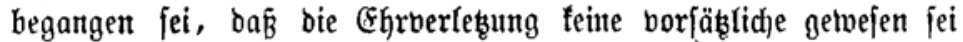
'quod eum Argam non cognovisset.' Rläger forbert un den Beflagten zur Betweizantretung diejer Behauptuty all, sicut lex commendat, nämlid mit 12 Eonfaframentalen. (Selingt dem $\mathfrak{A n}$. gejdultoigten diefer $\mathfrak{B}$ etweiz, fo hat er nur 'pro ipsum vanum improperii sermonem' oder 'pro ipso injurioso verbo,' bas boch immerhin unziemlidfer uno bertesenender $\mathfrak{B}$ eije gefproden war, 20 sol. zut zahlest, - jajwor er nidft, ober fiflug ber Bemeis in Rürfficht auf bie berlangte (sideshülfe fehl, fo trat (biez tönnen und müffen twir folgern) bie fdjwerere Strufe ber borjäbslidien Beleidigung ein. Die in ber lex fid findenten $\mathfrak{B}$ orte fornicaria, striga, arga fdpeinen nur af $\mathfrak{B}$ eifpiele befonder el)rentühriger Borte zu bienen, ohne anbere bon ber BSleidjitellung auszuld fliefien. Dagegen erflärt bie Guta Lagh nux ben beftimmten fleinen Sreis "unouldbarer Worte," die fpeziefl gentant fint als für ein ber= artiges Berfahren geeignet. ${ }^{16}$ ) Wahrfóneintich wurben fie als am meipten berleşeno betrad)tet, uno ftano nur auf ihnen, als ben fhlverften injuriöfen $\mathscr{2}$ euf

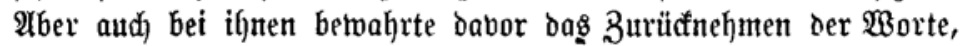
๖. h. Die (Exflärung, in Bemüthsbelvegung (per furorem) oder Betrunfenkeit gefprodjen zut haben.

auf ben impetus-dolus repentinus, für beffen Beriłđfidftigung er ganz riđftig auf bie lex Rotharis cit. unb anbre, unten zu erörternde Queflenftellen ber= weift. Dennod hält er bie Ehrenerllärung, unb jtoar mie fie fid bereits in

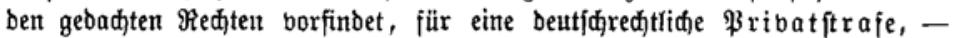
für eine "eigenthïmlidfe, bei leinem anbern Berbrecten borfommenbe $\Re e=$

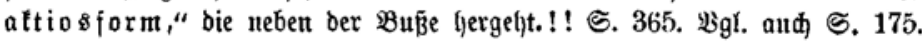

16) $\mathfrak{B}$ irba a. a. D. S. 788. "Frieblos foutte aber nad biefen normegi,

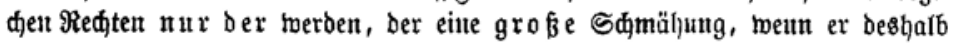
belangt murbe, nid)t zurïfnahm; that er bies, fo fam er mit Erregung ber vollen Buf̧e babon." - Bgl. bie Antologien im Bulathingggefetse und Birfes jarredt: S. 787-790. 
Was mun bie Natur bes fraglicten (Fibes anlangt, fo fann es nach dem (Bejagten foum begreiflid) erideinen, wie biejelbe ir = gento weldem 3 tweifel zu unterliegen bermag. E\& ift eben ein rein proceffutififjer (Eid. Nun fragt es fid allerbings, warum ex mit Eibeshelfern abgeleiftet toerben mupite, ba bod) zur Reinigung ber Unjfuldzeid genügte. Uno bod liegt die 2 nnthort nur in ei= ner ridjtigen Eonfequenz. Afflersings entzeht ber Bejdurdigte oer Regel nad) mit feinem alleinigen (Fibe ber peintidsen Befduldigung, ๖. h. wemn er bie That gänglich ablämynet. Das thut er aber im vorliegenden Falfe gar nid)t; er giebt vielmehr oie $\mathfrak{T}$ hat zu, und behauptet nux nod ein auf bie Strafbarfeit sinflun ausübendes Moment. Frreilid längnet er Damit inbireft bie Sdulto, twie fie ihm bon bem Rläger anfgebïrdet toirb. 230 mun ber $\mathfrak{A}$ ngegriffene mit bem Räugnen nod) eine pofitive Behauptung ber: bintet, bleibt er ztwar "Der Wahre" b. i. Dem Betweife näher, er muri aber (Eideshelfer itellen. ${ }^{17}$ ) Die jo jehr dibergirende $\mathfrak{A n z}_{\mathrm{z}}$ )h Der babei verlangten Eonfaframentalen fann uns nidt irritiren, wenn wir fehen twie oft überhaupt bie Bolfired)te in bergleiden mumerifaen $\mathfrak{A}$ ngaben autzeinandrgehen, uno twie fid erjt in viel fpäterer 3cit eine annäberno conjtante $\mathfrak{B r a z i} \&$ gebildet hat. $\mathfrak{A} u=$ fäfliger als bie ertwähnte Disharmonic zivijden verfdiedenen Bofferechten fann bie fdeinbar fidh in bem Tenor ein und beffel= ben borfindende eradftet merben. Die Guta-Lagh berlangt näm=

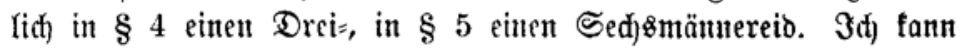
子ur Röjung biefes $\mathfrak{B}$ Bideripruchs nur eine Bermuthung auffitellen.

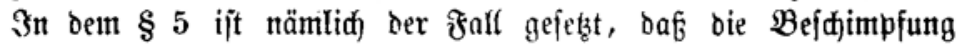
bor Dem ganzen Sirdipipiel oder ber Dingberjamımlung ftattgefunben hat. Run ftehen befanntlid Sirdje und Dingjtätte unter eillem be= jonderen Sdut - einem höheren Frieben; Daher mahridheinlich die größ̈ere $\mathfrak{B}$ edeutung, bie auf bas $\mathfrak{B}$ ergehen gelegt, bie ftärfere

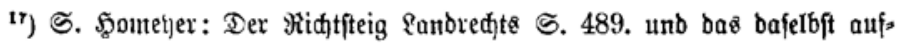

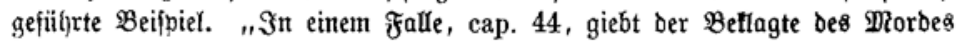

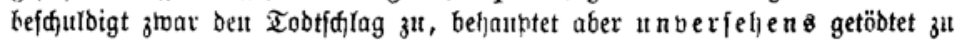
haben, roas ihm $\S 3$ nad) 2 nalogie von Sip. I. 64. jelbfiebent ju betweifen

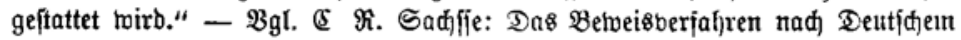
Recht D. M. A. S. 74 unb bie bort citirten Südermanland's Lagh, Manchelgab cap. 28. pr. " --- fo beruhe es auf 3mölfmanneneibe, toie dies verübt fei, mit $\mathfrak{B}$ illen ober a land's Lagh cap. 13. pr. 
Barantie, bie für bie Unborjäblidjfeit feiner Begehung berlangt murbe. Denn Sirche und Dingitätte raren boch Drte, ant benen nidht leidft Streit und F̧ader borfallen lonnte und burfte. E\&

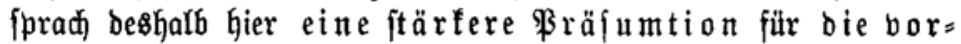
fätzlidue Beleioigung.

Die bisher ausgeführte unb in ber Şauptiade gewis wahre Ratur und Bedeutung bes (Ehreneibes hat Sdirbener ${ }^{18}$ ) gradezu negirt. Bielnehr findet er barin einen Modus, ben verletzten

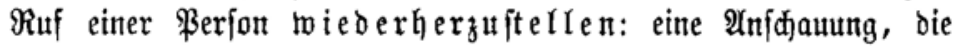
biefer Zeit getwif noch ferne lag, uno bie fid exft, wie wir fpäter fehen lverben, in einer ganz anderen Sphäre zu einem zunädjt burchaus beridjiebenen Snjtitut entmicfelte. Wie Sdjildener bie Sadje auffaģt, repräfentirt ber Eib, wo nidjt eine Strafe grabezu,

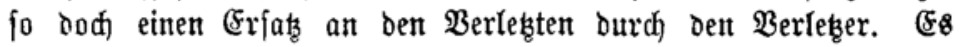
ift gar nidjt abzulehen, twie grabe auf biefem 2 sege bie (5ibes:

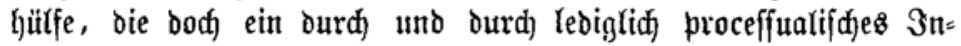
ftitut ift, eine Erftärung finden forf.

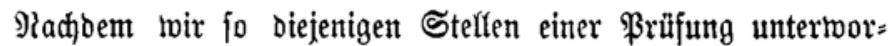
fen, bon benen wir ben meiften 2 Unfidjluz erwarten burften, da fie fic) ex professo mit unfrer Materie bejđjäftigten, uno beren Wort= laut fajon befonore Beadtung ouf fich zog, wirb es nun, ausges riijtet mit Den gewonnenen $\Re$ ejultaten, unire nädjite 2 ufgabe fein

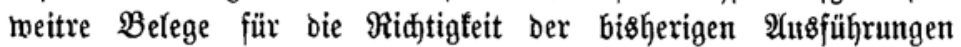
resp. Material für meitere Entıvicfelungen zu fudjen. Şier mirb unfere 2(ufmerffamteit zunädjit auf 2 Stelfen gelentt, auf bie be= reits Rogge hingetwiefen hat. (5\& find dies:

Lex Alamannorum Tit. 53.

$\mathrm{Si}$ quis filiam alienam desponsatam dimiserit et aliam duxerit, componat eam, quam desponsavit et dimisit cum quadraginta solidis, et cum XII sacramentalibus juret, cum

18) $\Im_{n}$ ber $\mathscr{X}_{118 g a b e}$ ber Guta-Lagh in ber Not. 12 zu Cap.II. "Durd

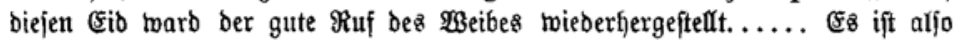

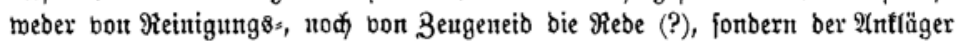

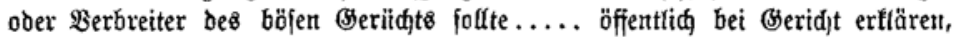

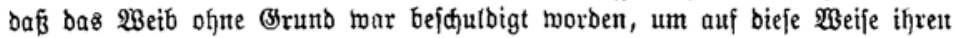

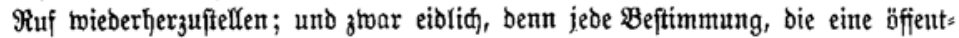

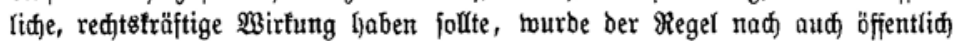
bejd)oren, namentlid bei (s)eridjt." 
$\mathrm{V}$ nominatis et VII advocatis, ut pro nullo vitio nec tentatam eam habuisset, nec vitium in illa invenisset, sed amor de alia eum adduxit, ut illam dimissiset, et aliam habuisset uxorem.

uno lex Bajuvariorum Tit. VII cap. $15 .{ }^{19}$ )

2lehnlidje Beftimmungen enthalten nod) andere (Sejese, wie

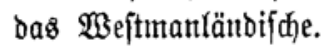

3mar mad)t aus bem hier geftifilderten Thatbeftand $\mathfrak{B}$ ildoa cin eigene Bergehen: "Weigerung bie Berlobte heimzuführen," meldfes er unter bie "Berletiungen ber Familienredyte unb ber Sittlidfleit" rubrizirt. Artlein wenn wir näher anf ben Sadjber= halt eingehen, fo zeigt fid, daß biefes ganze Delift nur unter ben Befichtopunft bon injuriöfen Şanblungen fäflt, uno baher auth con= fequenter $\mathfrak{B e i f e}$ proceffutifif eine ben 3njurien ganz analoge $\mathfrak{b} e=$ hantlung erfährt. Die einmal gefđjehene Berlobung nämlid fonnte nur ourd) Uebereinfunft ber (5ontrahenten oder bon bem Bräutigam einfeitig, auf (Sruno beftimmter, gefekslider (Srünte ${ }^{2 n}$ ) aufgehoben werben. Diefe Sründe find foldje, die dem $2 B$ etragen ber $\mathfrak{B r a u t}$ zur Rajt fallen. Sonnte der Bräutigaın betweifen, bá̧ feine Braut fich wirflich ber in Befes borgefehenten Sandlungsomeife idulbig gemacht habe, fo war ex bod entfidieden geredtffertigt und ftraflos. Somnte er aber feinen biejer Bründe borjdützen und nadiweijen, fo war er zunächit bem Bsejes megen unmotibirter Auflöfung ber Berlobung berfallen. (Es fragte fich nur nod): twas hatte ihn zut bem Brude jeines Berbältniffes betwogen? Satte es eine abjidts

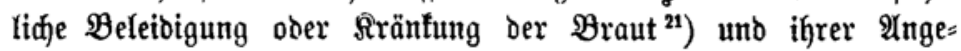

$\left.{ }^{19}\right)$ Si quis liber, postquam sponsaverit alicujus filiam liberam legitime, sicut lex est, et eam dimiserit, et contra legem aliam duxerit cum XXIV solidis componat parentibus, et oum XII sacramentalibus juret de suo genere nominatis, ut non per invidiam parentum ejus nec per ullum crimen eam dimisisset, sed propter amorem alterius alteram duxerit, et sit finitum inter illos, et postea filiam suam donet cui vult.

2o) Edict. Rotharis. 179. Si dixerit sponsus de sponsa sua quod adulterassit postquam eam sponsatam habuit, liceat parentibus eam purificare cum XII sagramentalibus..... Et si parentis, ut dictum est, eam mundare non potuerit de ipso crimen, tunc sponsus recipiat res suas quas dedit, et illa patiatur pena adulteric. $\mathfrak{B g l}$. cap. 180. 181.

21) Denn auf biefe fiel bod immer ein gemiffer Sdjatten zurüđ. Man bente ferbft an bie Berbültniffe ber heutigen Beit. Der mit Den fpeziellen $\mathfrak{B e r}$ * 
hörigen fein follen, ober trar bie Z3uneigung für ein anderes $\mathfrak{B e i b}$

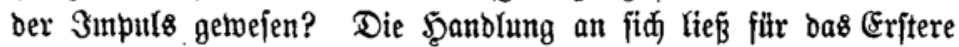
eine \$räfumtion auffommen. $\Im_{\mathfrak{n}}$ ihm $\mathfrak{l a g}$ aber bas Betwus̆te, Dolofe, Borbedacte. Wollte ber Beflagte fich beffen entledigen,

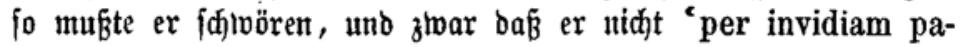
rentum' gehanbelt, unt aud feine $\mathfrak{B r a u t}$ "pro nullo vitio tentatam habuisset;' - joridern Daß̉ ber amor alterius bas Mcotib getwefen jei. Diefer amor, bie Reibenjafaft wirb bem Affefte bei andern 3njuriirungen gleidfgefteflt - eine Îtuffaffung, bie uns allerbings fern liegt. Wurbe biefer Eib geleiftet, fo tam ber $\mathfrak{B} e=$

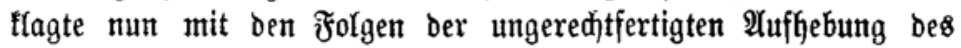
Berlöbniffes babon, während ifn fonft nod) die Antlage und $\mathfrak{B e}=$

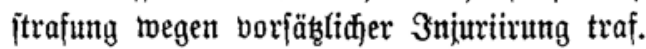

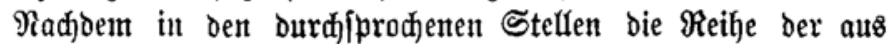
Den Boffsred)ten hierhergehörigen abgejd)loffen erifheint, handelt

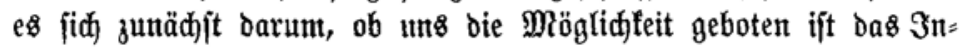
ftitut in ber Beftalt, in ber wir bisher fenten lernten, b. h. in feiner urfprüngliden Reinheit, nod) in ipätern Rechtsoent=

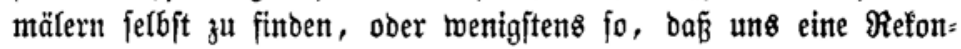
ftruftion gefingen tann. Und bies ift zu bejahen. Ramentlic) bietet uns eine Stelle einen merfwïrbigen $\mathfrak{A}$ nhalt, bie allein ges eignet wäre jeden Zroeifel an ber Ridutigfeit ber bisherigen Dar= ftellung zu bejeitigen. Es ipt:

Boslarer Statuten (ed. Böfden) S. 91. 3. 24-36. ${ }^{22}$ )

We deme anderen mid frevele in torne mit hastmude sunder vorsate wat dede edder up on spreke edder betege, dat om on syn liff, ere und gude gerochte ginge,

hältniffen unb Motiben unbefannten Menge muß̧⿻ boh immer ber Bebanfe

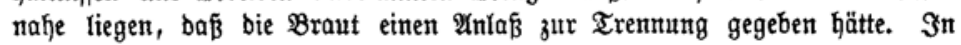

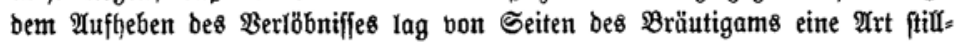

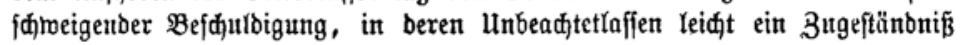
gefunden merben fonnte.

22) Befonders flar wirb bie Sache burd bie folgenden, Den Begenjatz bes handernden $\mathfrak{B}$ orte: We aver in hate edder mit vorsate unde mit vorbedachtem mode weme wat dede, edder up on spreke, dichtede edder beteghe, dat an syn liff ere und gode gerochte ghinge..... de scholde deme clegere boten.... unde dem vogede wedden.... dartho schal dat an deme rade stan, wu de om dat umme de vorsate keren wolden. 
des he up on nicht vullbringen konnde alse recht were, unde sek vorsate dar an entleddigen wolde, eff men dat van om esschede, de scholde dem clegere buten mid drittich schillinge unde dem vogede wedden sestich schillinge.

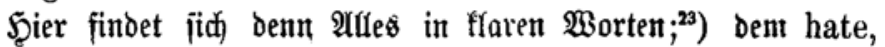
vorsate und vorbedachtem mode entgegengefegt ber torn, hastmude, bas \$annoeln sunder vorsate; die Strafe bes borjäbs= fidfen Bergehens höher als bie bes im affeft begangenen, nämlich

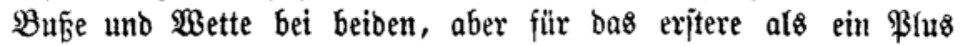
nod) eine arbiträre $\mathfrak{A}$ hnoung, beren $\mathfrak{B}$ erhängung „ an dem rade stat; ${ }^{*}$ Beweis enolid für bas Borhandenfein bes hastmude gegen das des vorsate: ber Eib. Denn mur bies fann bas "sich entleddigen" bedeuten.

Da haben wir bie Ehrenerflärung ber norbifđen Redjte und des Rongobarbijđjen in ihrem Urtypus, nur präcifer - man

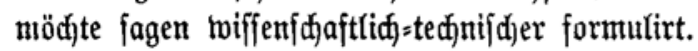

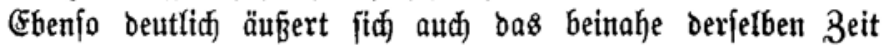
entitammte

Baierifaje Ranorecht $\mathfrak{A}$ rt. $61 .{ }^{24}$ )

Spridyt ainer bem andern an, er hab in gehaizzen ainen đüfjertin fun, ober einen huntfertin fun, ober einen merhen fun,

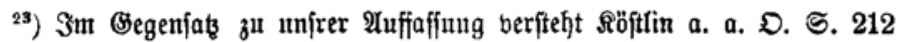
bieje Stelle bon ber relatiben $\mathfrak{S}$ njurie, unb glaubt in bem ermähnten

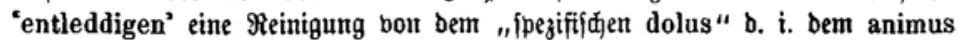
injuriandi 3 u finben. - Der a nimus ift aber fehr beftimmt bon frühefter Beit 3u bem Thatbeftanb jeber Snjurie gejorbert, unb ofme ihn findet ïber:

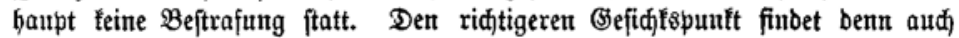
söp̧tlin felbjit auf 5.426.

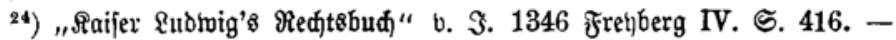
Damit ifit zu bergleidjen: Stabtred)t bon Fret)fing a. 1359. (Frenberg V. S. 175 ff.) - Behflagt ainer bem antern er hab in gehaiffen ainen posbidt ober ungetretw, oder er hab in berraten oder bercjaufft. Spridgt ber antwurtter, bie reb hab id in zorn getan, ungeberlidjen und bon dainer wahrheit nicht, baz gehört dain zeag über, toen er in fein (5fyr mieber geben hat, und forl man fein aib barum nemen, aber umb bie reb bie er getan hat, fo er ez Dem Beridgt peffere mit ainem pfunt piennig und an bie ftat $\frac{1}{2} \$ 8 \ldots$ etc.

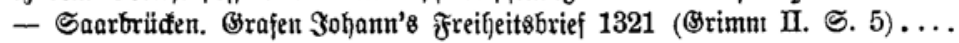
unb trol nit glauben, bas bas menjळe foliche mere, aljo es bie rebe hat ge= rett unb fie gejdiet in fyme zorn.... Dagegen fann eine andere Stelle 
ober twaz fo getaner biflicjer fidfelt wort ijt ..... : wirt er alfo überwunden, fo ijt ex bem gericht idjuldoig zwen und fibenkigig pfenning, .... und fol auth, ber, überwunden ift, bor off em (seridht pmere, daz er bie reb ungeberlid im zorn getan hab ... etc.

Şier ift ztwar für bie geforberte (E)renerflärung foheinbar bes reits ber Befichtspuntt ber Strafe maß̧gebend; aber eben aud nur fajeinbar; bieje nahe liegende Täufdung entjteht nur burch bie Wortfaffung. Denn mit Recht milffen mir bod) fragen: was ift

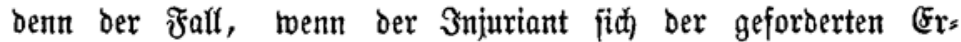
flärung soeigert? Die Strafgeinalt fann bod in ihrer Berur= theilung nicht ben 3wang aufferlegen bie Untwahrheit fu berfiçern! Ber bemmad bie Snjurie borfäblid) - 'geberlid) - zugefügt, ber fann aud) nidjt zu ber wiberfprechenden Erflärung genöthigt

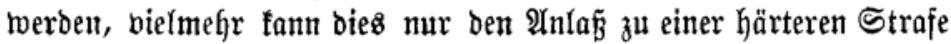
gebent. Die milbere Strafe ift aljo an bie Ehrenerflärung als an eine conditio gefmitpft. Darin ijt benn unberfennbar noch immer

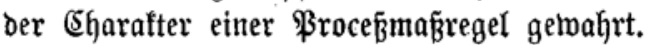

Dennod) ifit nidft zu läugnen, baj wir hier hart an ber Brenze eines Uebergangsitabiums jtehen, wo das Betoustfein bes wahren Sadjerhältniffes beridiminden unto einer neuen Theorie Blą̧ zlt madhen beginnt. Bebor wir aber biefe aflmählidje $\mathfrak{B e r}=$ fámelzung zum (Segenftand unfrer Unterfuctuutg nehmen fönnen, find nod) vorerift bie 2 (usigänge uno 9 nfangspunfte jener andern gedadyten Theorie aufzufudjen, twas in bem nädjiten Cap. ges ficheken foll.

Das bisher getwonnene Refultat läßst fid furz in Folgenbem recapituliren :

Die fogenannte Ehrenerflärung ift ein äđft germani=

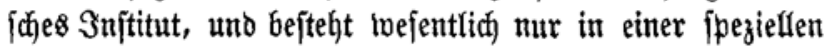

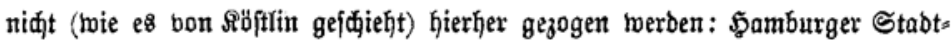
ređt. 1270. XII. 13. (Bei Rappenberg S. 71). Denn obgleiđ bem æort= Iaute nađ in unjere Materie eimjhlagentb, gejört fie in ber That nicht her. Die "vorsate' nämliđ, bon ber am Enbe bie Rebe ift, bezeidnet bort niđht bie Bsilfensbeptinmung, unjer heutiges "Borfatz," fonbern ein ferbftitündiges, mit

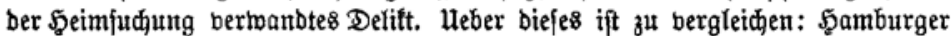
Stabtredt 1270. XI. 1. (Wat eyn vorsat sy) und gappenberg in ber (Finreitung S. $50 \mathrm{ff}$. 


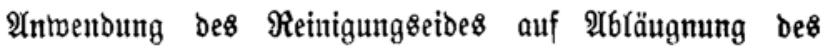
Borjakzes bei begangenen Snjurien. In biejer Bejtalt unb Bebeutung hat fid baffelbe jeboch nidft erhalten; biel= mehr läp̆t es fiđd in derfelben nur burd bereinzelte Belege bis in bas 14. 3ahrbundert berfolgen.

\section{Cap. II.}

\section{Der Öগiderruf und die Albbitte.}

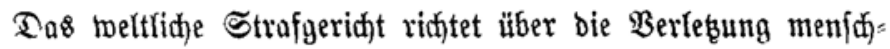
lidjer Satzungen, mag biefe mun als ein $\mathfrak{B e r g e h e n ~ g e g e n ~ b a s ~ e i n = ~}$ zelne Snoibibuum, oder als jtörender Eingriff in bie gefammte Recftsorbnung angefehen merben. Für bie Sirche ift diefer Bre= fid)tzpunft nidjt maßggebeno; bie Berlebung ber göttliđen Bebote bildet bas Berbredjen, weldez daher als Sünde erjdjeint. Der

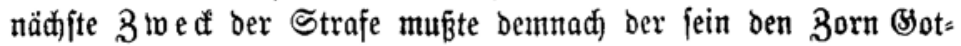
te\&, ber burdf bie Bjegehung ber Sïnde herborgerufen, zu berföh $=$ nen, um jo Bergebung der Sünden zll erhalten. Die Strafe in biefer bejtimnten Beziehung, auf biefen Zloet hin ijt bie $\mathfrak{B} u \mathfrak{B}$ e. So beftanden beitlidge und geiftlidje (S)eridjte $\mathfrak{A}$ nfangs jelbjtitändig neben einander fort; "beide berfolgten felbjtitäuroig unb unabhängig ifren eigenen $\mathfrak{B e g}^{1}$ ) und ifren eigentfümlichen (Befidtopuntt", bie einen bebienten fid als Mittel ber Strafe in Bsejtalt einez

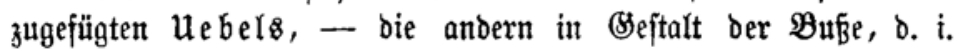
eines mit (5ott mieber berföhnenden Mediums, einer $\mathfrak{3}$ ohlthat für ben Berbrecfer. ${ }^{2}$ )

Befanntlid ift num bie firdflide Strafgered)tigfeitßpflege auf diefem $\mathfrak{B u n f t e}$ nidjt jtehen geblieben. 2(ber ihr uriprünglider (5ha= rafter hat fid jtets als ein (Element erhalten, und wenn in ben Fällen, to bie gefammte Alburtheilung und Beftrafung eines $\mathfrak{B e r}=$ brechens ber geifflicfen Eognition anheim fiel, bies (Element nidft

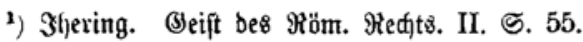

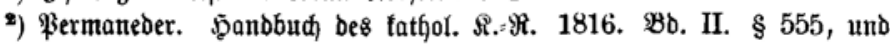
borzügl. § 809 . 
mehr fo unteridjeibbar zu Tage tritt, oa e8 mit ben ßrinzipien melttidier Strafe zufammengefloffen ift, fo bleibt es befto erfenn= barer $\delta a$, two bei einem delictum mixti fori bereits ber Staat ourch feinen Rid)ter ben Alnforberungen ber ftrafenden (Seredf= tigfeit (benitge gethan hat, bie Sirdje aber bie $\mathfrak{A}$ usgleidfung bes

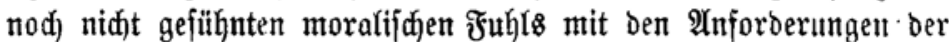
göttlititen (3)bote in foro conscientiae übernahm.

Die Tilgung Der Sünbe nun in ber göttlicten Bergebung und, bon bem oberwähnten Stanopuntt aus, - aud) bie Tilgung Dez Berbredjens, injofern biejes jtets zugleich Sünde ijt, Kezloedt nach ber fatholifiden Rehre daz Saframent ber Buke. Mit ber Entwidfelung berfelben fid, eingehenoer zu hejdjäftigen fann hier nicht der Drt fein. Es fragt jich nur ob bas 3njtitut ber poenitentia, gleid)biel in meldjem Entmidelungsiftabium für unferen ipezieflen 3 wed bertwerthbar iit? $\Im_{11}$ ber 2 (ntregung biejer Frage an biefem Drt liegt bereits ifre Beantwortung.

Itud hier müffen wir, wie oben bei der Şerleitung ber (Eh= renerflärung, in eine fehr frühe Zeit zutüforgreifen. Es jind bie

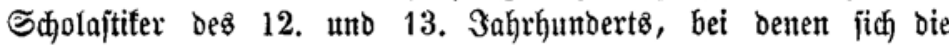

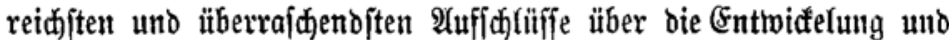
Bedeutung deв Widerruf borfinden, - ja bie wir als ङdjöpfer Des Snftituts betradften müffen. Es ifft un fo tounberbarer, bas biefe reidjen Quellen bisher unbeadtet und unberwerthet geblieben fino, als bereits freherus ${ }^{3}$ ) auf fte hingetwiefen hat. Die Sache verhält jïh) forgentermaßjen: Materia poenitentiae ijt ein Drei= fades : contritio cordis, confessio oris, operis satisfactio. ${ }^{4}$ ) Bon biefen fann aber naturgentäß nur bas Borhautoenjein ber reşten beiben an bie Sinnentwelt ber äuß̧eren Exidfeinung treten.

3) Marqu. Freherus. Tractatus de existimatione lib. II. cap. 9. § 4. - Seine felyr gründlidje arbeit führte ifin bem Stofie nad) bon ferbft zur

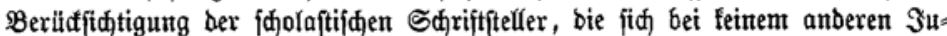
riften findet.

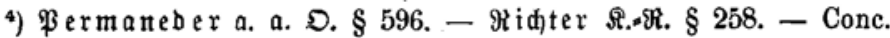
Trident. Sess. XIV. cap. 8. 9. - dist. 16. cap. 1. - $\mathfrak{A b a e l a r b}$ nennt für bie contritio bie poenitentia, alfo in engerem Simte. $\mathfrak{B g l}$. 3 . $\mathfrak{B}$. in feinter Ethica seu scito te ipsum Cap. XVII. ... Tres itaque sunt in reconciliatione peccatoris ad Deum, poenitentia scilicet, confessio, satisfactio. (Petri Abaelardi op. omn. ed. Cousin tom. I. p. 623). 


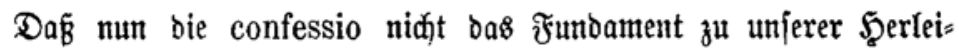
tung abgeben fann, fteft fejt. Es breibt alfo nur bie satisfactio. Dieje bejtelyt in ber Erfüllung ber vom Priefter aufgetragenen Buşmerte, beren $\Im$ nhalt und umfang bei ben veridjiebenen $\mathfrak{B e r}=$

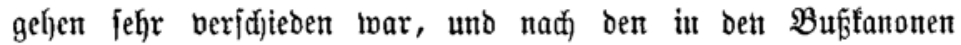
entlyaltenen betaiflirten Boridjriften geregelt wurbe. Borbebingung aber, uno getwifjermafen erfter uno integrirenter Beftantheil einer jeden satisfactio war bie Erjaţleiftung an ben Berleşten, injofern eine foldje nodh ausführbar war. Diejes ift oie restitutio, ${ }^{5}$ ) bie aber, twie gejagt, mit unter den Begriff ber satisfactio im weiteren Simme fällt. ${ }^{6}$ ) Diefelbe machte bei Detilten wie furtum, rapina etc. feine bejonbere Stgwierigfeit, bie ben Berluft eines materiellen (Sutes für den Berlekgten zur Folge ge= habt hatten, das in natura ober bod, bem $\mathfrak{B}_{\text {erthe nad }}$ rejtituir= bar twar. Dagegen tourde bie Sadje mif̧lid, wenn bas entzogene But rein ,intelfigibler" ober immaterieffer Natur toar. Diefe Bedenfen fonfolidirten fid frühe zu ber boftrineffen frage: utrum, oporteat restitui, quod quis non abstulit, ${ }^{7}$ ) bie fid mit gerin= gen Bariationen in ben $\mathfrak{B}$ erfen fajt alfer Scholajtifer erörtert uno eines Breiteren abgehandelt findet. Dabei ging man ber bamals allgemein üblidjen $\mathfrak{B}$ ehanblungsmeife in Dubitationen und Reppons fionen gemäß bon bem Saz̧e aus : Videtur quod non sit necessarium ad salutem, quod fiat restitutio. Quod enim est impossibile non est de necessitate salutis. Nun werden aber Fälle aufgezählt, in benen bie restitutio impossibilis ijt, wie z. $\mathfrak{B}$. wenn membrum vel vita bie entzogenen Büter fino. Darauf

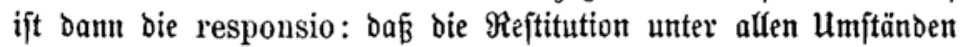
nothiwendig $\left.j^{2 i,}{ }^{8}\right)$ und lvenn id, quod est ablatum, non est re-

5) Şierilber bgl. int $\mathscr{A}$ Igemeinen: Petr. Qombarbus lib. IV. Dist. 16. -

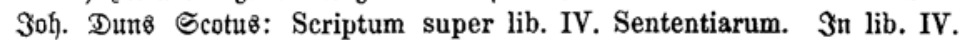
Dist. XV. per totum. - Thoma b. Aqquino. Sec. Sec. (Summa theol.) Quaest. 62. - Eajetanus in ben Poten bazu a. a. D. - Dominicus Soto: De justitiae et jure. lib. IV. quaest. 6. u. 7.-- நojtienfit: : Aurea Summa lib. V. Sit. de poenit. et remiss. No. 60. sq.

c) - Dieß zeigt Der Umítano, Dẩ die restitutio f́tet\& mit ber satisfactio abgehanbelt mirb. Sm entgeten Sinne fteht diefe jener gegenthber.

7) Ifom. थquin. 2. 2. quaest. 62. verb. quanto.

8) Thom. 2quit. 1. c. art. II. . . . Respondeo dicendum, quod restitutio, sicut dictum est, est actus justitiae commutativae, quae in qua-

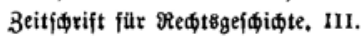


stituibile, per aliquid aequale debet fieri recompensatio, qualis possibilis est; fo foll für eine Beriftünmelung ein Seld: erfats jtattfinden u. f. f. Nun hat der Menfich breiertei Büter: bona animae, bona corporis uno bona exteriorum rerum. ${ }^{9}$ ) Bon diejen finto nur bie erjteren ourd) britte unentziehbar; bie rebeten beiben bagegent fino einer Entziebung fähig: unb eine fordje

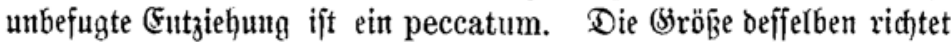

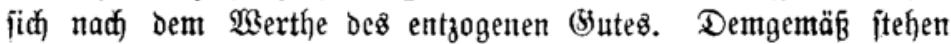
boran bie bona corporis uno dann erit forgen die bona exteriorum rerum. Unter biefen nimmt bie herborragendite Stelle bie fama ein, ${ }^{10}$ ) quae praeminet divitiis, eo quod propinquior est spiritualibus bonis. Bon biejem Standpuntt aus war e\& ein natïrlicfer Sdyritt zи fagen: et tenetur aliquis ad restitutionem famae, sicut ad restitutionem cujuslibet rei sub-

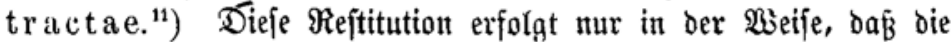

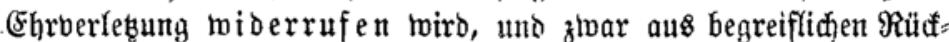

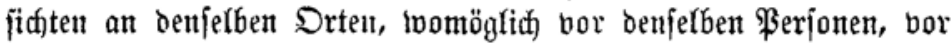
denen bie Diffamation jtatt gefunden hat. ${ }^{2}$ ) -

dam aequitate consistit. Et ideo restituere importat redditionem illius rei, quae injuste ablata est ..... quia justitia in aequalitate consistit.

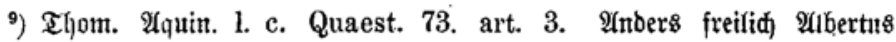
Maguı : Summa theol. p. II, tract. XVIII. Quaest. 117. (In opp. omn. Lugd. 1651. tom. XVIII.)

10) Wan ftitz̧t fid hiebei auf bie Sprïd)e Salomonis. (5ap. 22. ‥ 1.

11) Cajetanus in not. ad Thom. art. 2. . . . quia sicut homo est dominus aliarum suarum rerum exteriorum: ita est suae famae: Est enim fama inter exteriorabonahominis, quae possunt $a b$ invito a ufferi.

12) İußer unzähligen aubern Stellen feien ljier utr folgente nambaft ge= mađt: Alberti Magni tract. XVIII. Quaest. 117. Membr. II. art. 4. : . Dicendum quod ille, qui ex malignitate et deliberatione animoque docendi detraxit: quia aliter non impleret verbum Domini Rom. 6 . Sicut exhibuistis etc. ..., pro certo tenetur ad reparationem a pud eos apud quos detraxit. - Joh. Duns Scotus: Scriptum ad lib. IV. Sententiarum. In lib. IV. Dist. 15. . . . In primo dico quod oportet restituere famam retractando verbum suum vel quod imposuit et hoc ita publice sicut imposuit, quia aliter non servat justitiam in reddendo proximo quod suum est. - Henrici a 


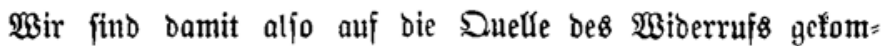
men, Der nad) bem (Frörterten umzroifelhaft als ein Probuft fd)o=

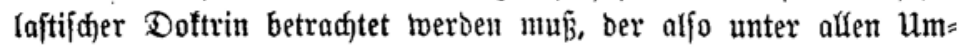
ftänden dem fird) lidjen $\mathfrak{B o d e n}$ entwadjen iit, und nidft bem bes

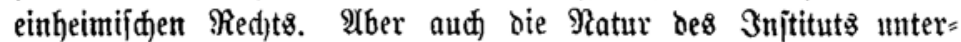
liegt nad) bem (Biefagten wohl faum nod einem Zloeifel. ${ }^{13}$ ) $3^{\mathrm{H}}=$ nüdjit darf nidjt bergeffent trerben, daß̧ in ber gegentwärtigen ßeriode

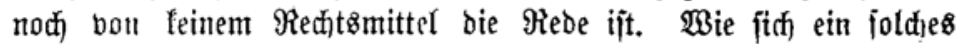
aus ben bisher betrachteten Elementen bildete, wirb ben Begen= ftand ber ipäteren Unterfudfung ausemaden. Sebenfalls fteht fo viel fejt, daß̉ bie restitutio, zut welcher auth der Wiberruf gehört, burdfans nid)t ben (Sharafter ber Strafe trägt, vielmehr Yediglid,

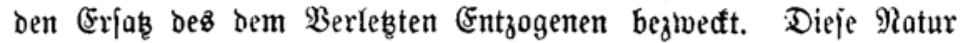
fann ourd) SReception bes 3njtituts in das forum externum nidjt fofort gänzlid verändert loorben fein.

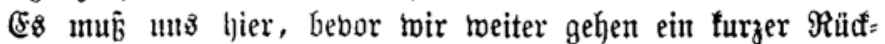
blicf gejtattet werden. Sn bent Sisherigen murbe ber (Segentitand in bem Bujtande bargejtellt, in loeldem er bei feinem Entivife=

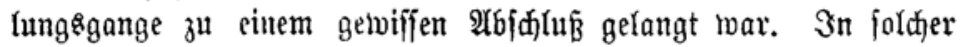
bolffommenten Durfdoringung und Berarbeitung bes Stoffes iteflt

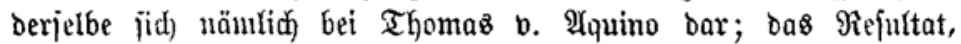
wie es oben gegeben murbe, beruht auf feiner Darfteflung. $\mathfrak{A} \mathfrak{l}=$

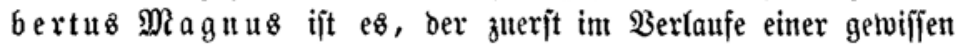
Sujuijtif fpezielf bas Erforberní für oen, weldher einen Arnoern in bouo famae damnificavit auf=

Segusio, Cardin. Hostiensis. Aurea Summa. lib. V. Tit. de poenitent. et remiss. No. 61. sub verb. quid de accusator. . . . . Obligantur tales non solum ad restitutionem pecuniae, sed etiam famae, quod hoc modo fieri debet, ut .... in locis, in quibus sentiet alium dicto vel facto suo infamatum, publice recognos cat errorem suum, et dicat, quod mentitum erat per os suum .... etc.

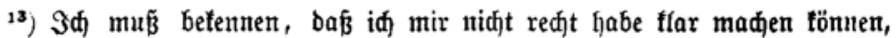

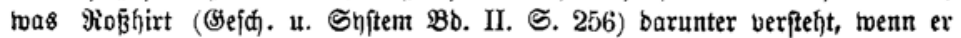
Den $\mathfrak{B}$ iberruj cine "geiftige (sompofition" nemnt, burd) bie man bie cen-

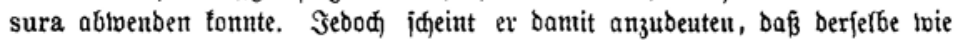

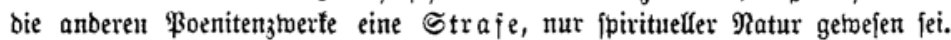
Diezs ift unridtig. Die censura twurbe alferbings burd ihn abgementet, ba erft uad ber restitutio bie poenitentia vera uno recta b. h. birffam voll= fithrt fein fann. 
ftellt. Zwar recurrirt er, twie alle feine Nadffolger; auf ben gro=

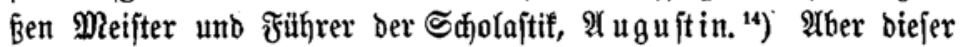
fann bod) füglich nur injofern in Betradt fomnten, alz er itber:

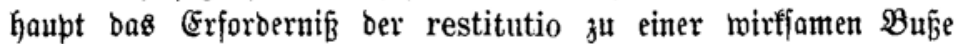
auffiteflt, ohne bos er auf bie Ânmenobarfeit diefes Dogmas bei

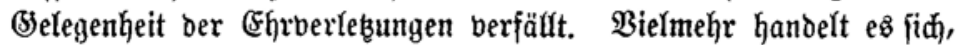
nach bem 'cum restitui potest' Darum, of Âguítin bie Egree

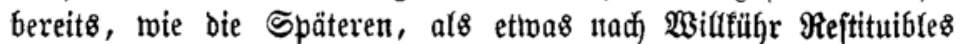
eracjtet habe, twas fich faum bermuthen läßt. $\mathfrak{A} u d$ f fann nidft aus ber in Derjelben Epiít. [päter fich findenden Stefle: „Qui vero contra jus societatis humanae furtis, rapinis, calumniis, oppressionibus abstulerit, reddenda potius quam donanda

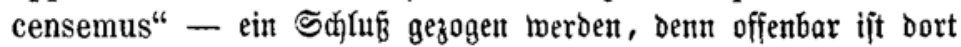
bon ben Fällen die Rede, too die calumnia den Berlujt eines materielfen \$utes zur ₹olge gehabt hat. Ohne weiteren $\mathfrak{A n}=$ halt zu haben, fönnen wir baher in Alugujtin nur hödjt mittelbar Den Begründer jener Egren=-Erakagleijtungs: Theorie finden.

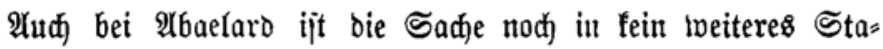
bium gerülft, uno jelbjt bei beın berüfmten Magister sententia-

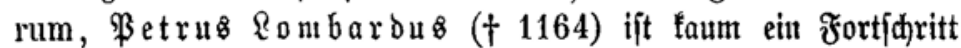
merfbar. ${ }^{15}$ ) 2ud er fordert $\Re e$ ítitution, to fie möglid ijt, erflärt aber bie $\mathfrak{B}_{\text {uBe }}$ ohne biefelbe, wo jene an fid nidjt möglid ift, für böffig mirffam. Unter ben Sadjen, bie nidft rejtituibel find nennt er 'vel oculum, vel vitam' offenbar nur beifpielshalber, und ob

14) Die oft angezogene Stelle ift in einem Intwortidjreiben $\mathfrak{A} u g u$ fin's an ben Macebonius, Das burd, eine İnfrage beffelben herborgerufen toar, enthalten unb lautet in ihrem Rernpuntte: - - - si autem veraciter agitur (scl. poenitentia), non remittetur peccatum, nisi restituatur ablatum: sed ut dixi, cum restitui potest. (August. ad Macedon. pro reis quomodo intercedendum. In opp. omn. per Erasmum Rotterdamum Basil. 1528. Tom. II. ep. 54).

16) Sententiarum lib. IV. Dist. XV. c. 5. in fin. - - : Demit enim injuste quis alicui quod restituere non valet, ut oculum, vel vitam et hujusmodi: et tamen si poenituerit peccati cum amore condignae satisfactionis veniam habet. Nec ideo quisquis putet, qui rem alienam injuste abstulerit, quam reddere potest: de illo peccato penitere ac veniam consequi, nisi restituat ablatum. Quamdiu enim res propter quam peccatum est non redditur, si reddi potest, non agitur poenitentia, sed fingitur. 
er bie fama mit zu ihnen reḑnet, oder nidjt, fönnen wir aus Ridts erfehen.

Sebenfalla gab biejer passus allein fpätern Rehrern, bie in

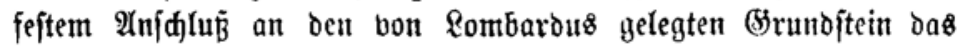
Syftem weiter auzbauten, Belegenheit einen cajuijtifden Ipparat anz̧utnüpfen, in bem bou $\mathfrak{A}$ nfang an auf bie ablatio famae eine

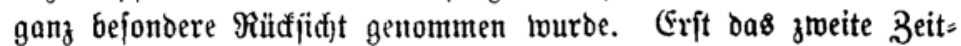
alter ber Sdjolajtif, heraufgeführt burd, das öffentlide Sehramt Der Dominifaner uno Franzisłaner in ßaris, jäugte Das Rind, Das (id) in ben $\mathfrak{B}$ erfen ber bisher genannten Autoren hödfítens in embryonifđen Formen zeigt, zu voller Selbjititänbigkeit auf.

Der Dominifaner Mrtbertus Magnus, Rehrer in \$aris uno jpäter in (ธöln $(\dagger 1180)$ ) Cieferte zuerjt in feinen Commentariis in libb. Sententiarum einen meitläufigen 21pparat zu Dem $\mathfrak{B}$ erfe Des ßetrits Romb., der mejentlich fid an baffelbe anfdyließend nur eine burd Spezialifinutgen uno Eajuiftit eriveiterte Stoffmaffe bietet. $\mathscr{A n}$ bie oben not. 15 citirte futrge Stelle antnitpfeno han= belt er eingehend ither bas $\mathfrak{W e j e n}$ Der restitutio. $\left.{ }^{16}\right)$ - Dabei unteridfeibet er eine redditio und eine compensatio, je nadjoem bie $\mathfrak{B}$ iedererftattung in natura, ober nur in 2 equibalent erfolgen fann. Dann ifit befonders widtig das, twas im 2 trtif. 43 folgt. (58 heifist bort:

Secundo quaeritur quid debeat restitui? Et haec est quaestio difficilis, cum enim restitui debeat res ablata, contingit a ufferri famam .... etc. .... Si dicas, quod non debet restitui fama. Contra: id quod possidetur, invitissime amittitur: fama autem clarius possidetur, quam aurum et argentum, ergo invitissime amittitur; ergo videtur quod maxime debet restitui.

16) Alberti Magni. In lib. IV. Dist. XV. Sententiar. (In opp. omn. Lugdun. 1651. tom. XVI.) Articul. 42-45. Эeber biefer \%rtiter behanbelt eine ber Fragen: Quid sit restitutio? - Quid debeat restitui et qualiter est restituendum? - Cui debet fieri restitutio? - Qualiter habent se opera restitutionis ad opera poenitentiae? $3 \mathrm{n}$ Bejug auf bie lełzte bes hauptet er, bas bie restitutio nidjt eine pars satisfactionis fei, fonbern fundamentum berfelben. Darilber ift bereits oben bie Rebe getwefen, aud ift nod) zu bergleidjen: Bonaventura in lib. IV. Dist. XV. Sentent. Quaest. 4. (An restitutio sit pars satisfactionis?) 
Dieje Deduftion trägt den Stempel des Driginären; auch

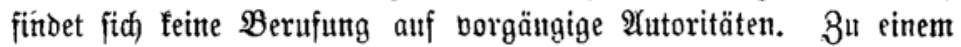
gewiffen Brade der Beptimntheit mun fid die Bermuthung, hier auf bie Quefle ber restitutio famae gejtofien zu jein jteigern, menn wir bas äugitliche $\mathfrak{B}$ cmühen jehen, dieje getwiffermagent neue

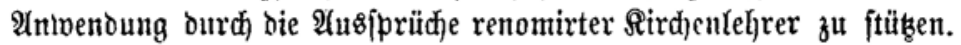
So hat beieronymus einmal gejagt: crudelis est, qui famam negligit. Šieran anfnüpfent wiro folgente etwas gefährliche (5on= fequenzen $=$ Brücte gefdjlagen:

Sed ille qui non exigit famae restitutionem, famam negligit: ergo est crudelis; ergo videtur, quod etiam haec injuria non debet remitti sine recompensatione; - ergo quilibet tenetur exigere talis rei restitutionem; ergo aliquis tenetur solvere, constat autem, quod non nisi qui abstulit, ergo ille restituere tenetur!!

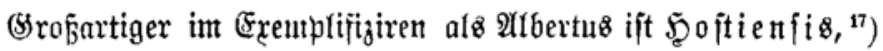

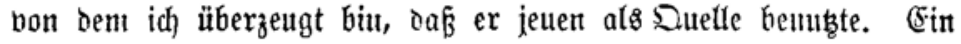
A6meid)en ift überhaupt bei beiden nur injofern borhanden, als Soptienfis mit einer munderbaren (Sründichfeit den Reftitutions: pmift fajt für jedes Delift bejonders uno einoringlid abhandelt.

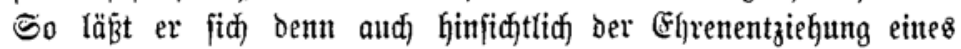
Breiteren aus. - Bemerfenstwerth ift bic fpejiefle Beziehung auf die geriduttlid)e Berläumoung, morïber in näd)jten (5ap. Dagegen muß̧ gleid) hier auf bie eminente Steflung hingetviefen werben, bie gerade biefer Sdyriftitefler in orr (Entmidfelung geidhichte unires

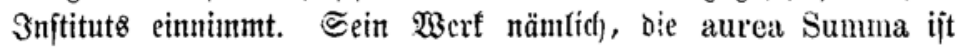
wejentlid) firchenred tliden Snftaltz. Damit ift ber (brund

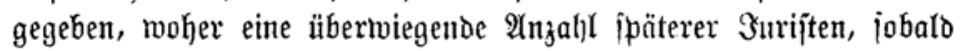

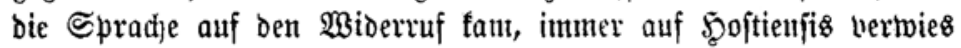
uno auf ihn refurrirte, mährend non ihnen, da jie jich mit theo=

${ }^{17}$ ) Henrici a Segusio Cardinalis (Hostiensis) Aurea Summa (etc.... Coloniae . . . 1612. Fol. Lib. V. tit. de poenit. et remiss. §. Quibus et qualiter, bejonders No. 61 sub verb. Quid de accusatoribus? - Die Summa ift um b. Jahr 1250 gefdrieben. - Dlan bergleide 3. B. Die genaue Uebereinftinnung einzelner Stellen a. a. $\mathcal{D}$ mit Alberti M. Summa theologiae Pars II. Tract. XVIII. Quaest. 117. Membri II. Artic. 4. Salutio ..... (In opp. tom. XVIII.) Sedenfalls ift bie Darftellung bei 5oftienfis

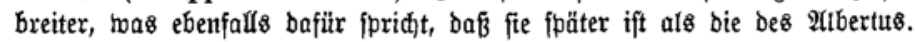




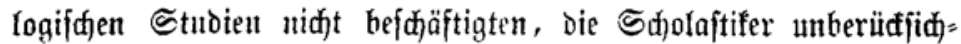
tigt blieben. Seoftienfiz hat in ber Rehre non der restituiio famae roie ïberhaupt in bon von ber poenitentia, satisfactio etc. nidyt

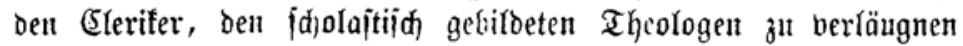

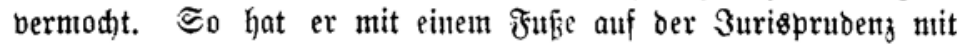
bem andern auf oer Theologie ftehend, bon ben Red)telehreen biel

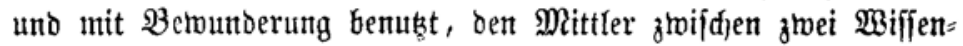
fa)aften gemadyt uno ein Degma ber einen in bie Prax̧iz ber an= Dern hinübergeleitet. Wie unfdjiner bies twar, ift einleudjtend.

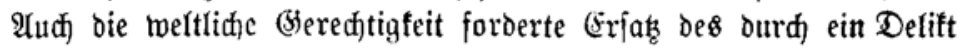
Dem Damnificaten (Entzogenen, und liefs denfelben burd) Eibifflagen gelteno madhen. E\& bedurfte alfo nur einer $\mathfrak{A}$ boption ber $\mathfrak{A}$ nficht,

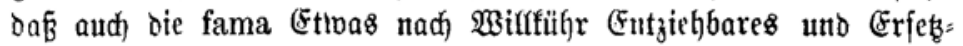
bares fei - uno bie Reception in bas meltlidje Redtt war als

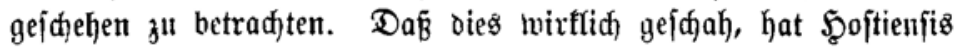
bemirft.

Wir find hier an einem Sirenzpunft unferer Entroifelungs: geldjidte angelangt, von to dic $\mathfrak{B}_{\text {ege }}$ Der Theologie uno ber $\Im_{\mathfrak{u}=}$ risprubenz auzeinandergehen. Unifre 9 unfgabe ift es natürlid nur

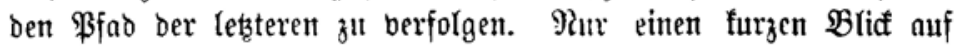
Den 2erlauf der Straß̄e zu werfen fei utts erfaubt, bie wir bisher mantern muß̧ten. Daß̧ bie Theologie auth noth fernerhin ihrem nunmehr untcr frembe Pflege gerathenen Sinbe Boridub leiftete, bas lehrt uns eine felbjt flïdtige Bead)tung ber fpätern theologis fichen Siteratur. Bci allen Eelebritäten ber fpäteren fdolaftifiten

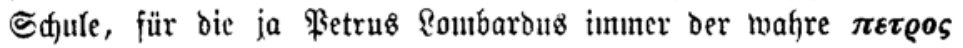
blieb, anf oem jie fortbaute, findet jid derfefbe (Hrmoggedante nur

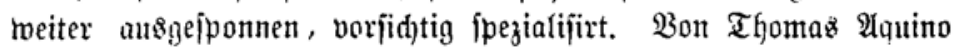

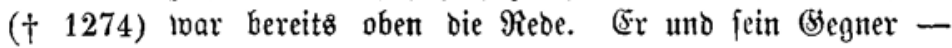
in was für Bunften aud immer ihre segren in Disharmonie ge= riethen -: in oem Buntte, der uns intereffitrt fitimmen jie jo

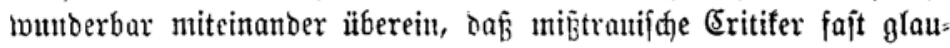
ben fönten, jie hätten einanoer mehr als benukgt. Es ijt natür=

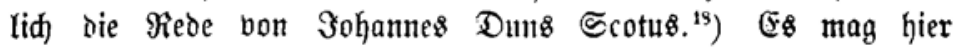

18) Ulm nutr eine 2 Infdjautung bon ber ïberans meitläufigen (Eafuiftit biefes

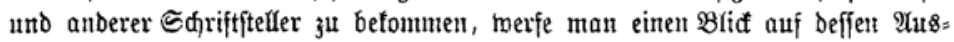
führung bes jragliden Themas it feinem Eommentar ad Lib. IV. Dist. XV. 
geniigen auf bie Coryphäen ein 21tgenmerf geridytet zu haben; viele

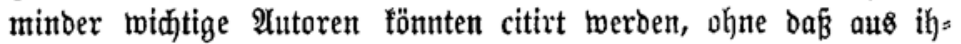

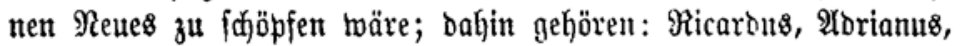
Sylbejter u. 2 . Sie afle fino jehr fleif̧ig benutst bon Dominicus Soto, ${ }^{19}$ ) Der infofern nicht ohne Эutereffe ift, als er ein Rejumć

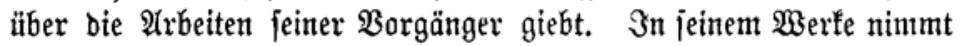
allein bie Unterfudung über famae uno honoris restitutio 6 enggebrutte Foliofeiten ein. Wir haben es hier um fo wentiger

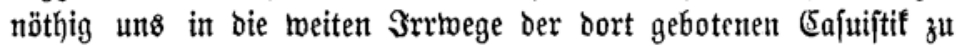
berlieren, als biejelbe jtets nur Eigenthum einer berfümmerten Doftrin geblieben, und nie aus ben biffleibigen @ḍriften ber moral= philofophirenden Sirchenlehrer in ben lehentigen, frifdtreibenden

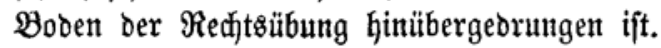

(5\& bleibt uns hier nođ Giniges über ben Uriprung ber $\mathfrak{A} b$, bitte hinzuzufügen.

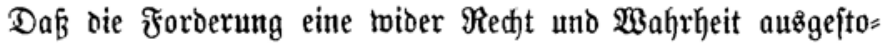
Bene Beleidigung als foldje bem Berlek̨ten gegenüber anzuerfennen und um beffen Sergebung zu bitten in ben Rehren ber Moral be= gründet fei, barf faum bezmeifelt merben. Bon biejen Bsefictto

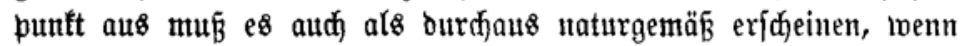
bei einem jeden gefitteten $\mathfrak{B o l f e}$ eine $\mathfrak{2}(6 b$ itte für angethane Sd)mad) (b. h. in untednifdem Sinne) etwas nidjt Ungetwöhulidjes ift. ${ }^{20}$ )

- Rom breiter if Cajetanus in not. ad Thom. II. 2. Quaest. 62 ef. Quaest. 73.

19) In Fratris (Dominici Soto) Segobiensis Theo (logi, Ordinis Praedica) tarum .......... Libri decem). De Justitia et Jure Antverpiae a. 1567 (ed. nov) Lib. IV. Quaest. VI. Art. 3. (Er ftellt an bie Spiz̧e ben Saz̧: Quod laesa fama non est de necessitate salutis restituenda, nisi quando contra justitiam aufertur. - Dazu erforbert er breierrei: Primum, ut fama vere fuerit ablata . . . Praeterea, ut alius famam obnubilet per justitiae delictum .... Tertio, quod qui laesus est, non alia via famam recuperaverit.

20) Damit findet bas feine Errebigung, was sriffonins: de Formulis lib. VIII. N. XVIII. anfüffrt. 2ggl. obent in b. Einteit. 
Mit befonderem Radjoruff fintet fid) abcr biefes (Bebot als eine uidft zurütufumeifente 2 nfforberung an bie Betwiffenspflicft in ber (chriftliden Sittenlehre, ${ }^{21}$ ) die ja burdilveg von bem (Bseifte ber Duldung und Delwuth fö̈n ourfibrungen ift. Eine Stefle Der heil. @djrift, unf bie dieferhalb ipäter oft recurrirt wurbe, ift Matthäi V. 23. 23-24. ${ }^{22}$ ) Sdjon 2 Auguf́tin ${ }^{23}$ ) bemerfte $z^{\text {th }}$ ber= felben: Poteris eum (fratrem) non simulato animo lenire, atque in gratiam revocare, veniam postulando, si hoc prius coram Deo feceris, - uno biefe Sehre trurde in ber frühejten

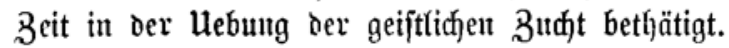

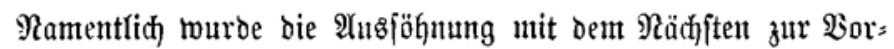
bedingung für Empfang ber (Eud)ariftia gemtadt, bohingegen na= türlid Der Beleidigte nud) Dem ,bergieb uns unjre Sdjuld, wie wir bergeben unfern Sduldoigen" zur (Extheitung oer gehörig nad)= gefudten $\mathfrak{B e r z e i f u n g ~ b e r p f l i d j t e t ~ w a r . ~ D e m ~ e n t i p r e d j e n t e ~ B o r = ~}$ fariften gingen it dic \$oententialen über. So j. $\mathfrak{B}$.

Poenitentiale Viniani ${ }^{24}$ ) 55 . Si quis rixam faciat de clericis aut ministris Dei, hebdomadam dierum poeniteat... et petat veniam a De o et proximo suo plena confessione et humilitate, et sic potest Deo reconciliare et proximo suo.

Ramentlid) wurbe das (J)ebot öfters für (Slerifer eingejđärft; nidft als ob es fid) nid)t and) auf bie Raien erftređt hätte (j. bie not.), fondern loohl deshalb, meil die (Heifttidsen jid) ber veniae postulatio einem \&aien gegentïber gerne entjiehen mod,ten, ba jie

21) Jos. Bingham. Origines sive Antiquitates ecclesiasticae (vertit Grischovius) 1729. vol. VIII. lib. 18. cap. 3. §. VI.

22) Darum twem but beine Babe auf bem 2Yltar opferft, unb wirft allba

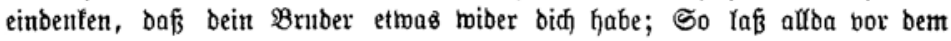
Altar beine (sabe, und gehe zubor hin, unb berföhne bid mit beinem Bruber; unt alobaun fomm' unt opfere beine Babe.

$\left.{ }^{23}\right)$ Augustin. De sermone domini in monte lib. I. cap. X. Später heifst es ebenba: Hoc est unum remedium, supplici animo veniam deprecetur, quod quisquis non fecerit, inanis jactantiae spiritu inflatur.

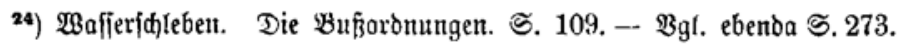
Pseudo-Beda c. XXXIV. Ci quis rixam fecerit clericorum aut monachorum, reconciliet $\mathrm{se}$ cum eis, quos lesit, et hebdomadam dierum peniteat. - ङ. 483. Poenit. Cummeani c. IX. §. 3. Fratrem suum furare maledicens, cui maledixerit pl ace at et VII. djes peniteat. 
barin eine größere Demüthigung uno ફ̧erabmürbigung if̧rer Stel= lung fahen. In biejem Sinne beftimmt das Concilium carthag. IV. (a. 398$)^{25}$ ) c. 57: Clericus maledicus maxime in sacerdotibus cogatur ad veniam postudandam, si noluerit, degradetur, nec unquam ab officium absque satisfactione revocetur! -

Bereits der Wortlaut diefer Stelle lehrt, Daß̧ satisfactio Daffelbe ift, mie veniae postulatio. Dies mur barum bemerft merben, meil nach der früherent Arsführung man bielleidyt geneigt fein fönte Stellen, in benen von satisfactio die Rede ift, ${ }^{26}$ ) jo $z^{\mathfrak{u}}$ berftehen, als ob in ihnen ein ફ̧inmeis auf ben $\mathfrak{B}$ iberruf läge. Derfelbe war aber zu ber Zeit, aus ber jente ftammen, twie man wohl mit Redft fagen fann, nod nidft "erfunden". Die Satis: faftion (bon ber twir ja nod heutigen $\mathfrak{T a g e s}$ reben) hat hier alfo ein mehr fubjeftibes Moment, o. h. e\& ift "dasjenige, was id bem 2 ntberen für die Sräntung, tweldhe bie アnjurie ihm zugezogen hat, leiften muß , um ihn felbft megen biejer ßränfung zu beruhi=

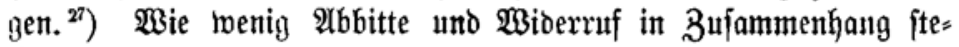
l)en ober gar bon einander abjängig finto, leutftet mun wohl bereits aus bem Befagten eitt. (Es fann aber aud aukerbem auf bie oben benukzten Sdyriftiteller verwiefen werben. Namentlid) zeigt bie betreffende Stelfe bei Şoftienfis, ${ }^{28}$ ) daß̧ wir es mit 2 boll =

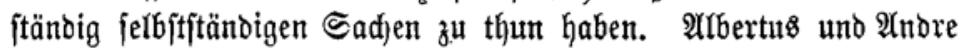

2s) Bei Regino (ed. Bafferfđjeben) lib. I. cap. 155. Bei Burdarb X. 66. Damn in Das Decretum Gratiani c. 5. Dist. 46 übergegangen. Man

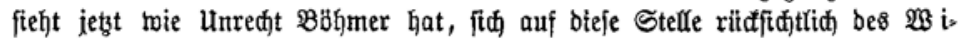
berruf zu bejiefen. Bgl. Bernh. Diaz be \&uco. Pract. crim. canon.

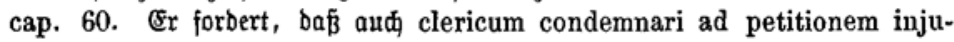
riati ... quam ita cautum sit . . et servari soleat in laicis.

$\left.{ }^{26}\right)$ 3. B. Regino lib. I. cap. 158. Si quis convicio vel maledicto vel etiam crimine subjecto laeserit aliquem, dignissima purgetur s at isfactio ne. - Poenitent. Pseudo-Theodori c. XI. §. 4. 5 (2Bafferfoleben ङ. 572) $\mathrm{Si}$ quis fratrem suum furore maledixerit, primo satisficiat ei, deinde VII dies peniteat . . - Qui verba asperiora in furore protulerit, primo satisfaciat ei, deinde ....

an $\mathfrak{B e b e r}$ a. a. D. II.

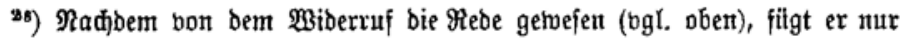
am Sd)luffe nod mie beiläıfig hinzu: Sed et ab infamato tenetur veniam postulare. 
gecenfen ber $\mathfrak{Y}$ bbitte gar nidt, mentigitens niđt $\partial a$, wo bom $\mathfrak{B i}$ berruf gerebet wirb. Mar bürfen wir freilid nidgt auf biel fpätere

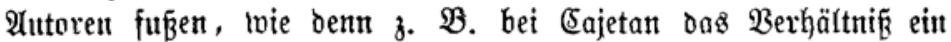

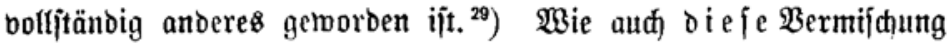
entjtanden - Inie man fpäter zul eitter Trenmung aus neuten $\mathfrak{M}_{0}=$ tiben uno bont neuen (Bsejidjtzpuntten fahritt - bas zu zeigen wirb

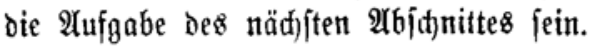

\section{Cap. III. \\ Die જூer}

Un uns nod einmal bie Elemente zu bergegentmärtigen bie wir in Bisherigen an ihren S.ueflen anfgefucht uno unabhängig von einander befunden haben, fo find es forgende:

1. Ein rein proceffualifder (Eio: 3 wed: Betweis ber $\mathfrak{U n}_{n}=$

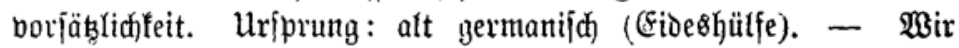

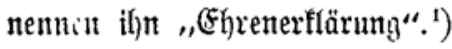

2. Eine öffentlide, ober twenigftens vor denfelben ßerionen, in deren Begentvart bie 3njurie zugefïgt, abgelegte Ertlärung: "mider bie $\mathfrak{B a h r h e i t ~ g e f p r o d j e n ~ z u ~ h a b e n " . ~ Z m e c t : ~ R e s t i t u t i o ~}$ famae $\delta$. h. Wiebererftattung Des entzogenen guten $\Re$ ulf als einer gleidfam fungibeln Sadje. Uriprung: die theologifd)=idjolajtifde Doftrin. - Es ift ocr Biderruf.

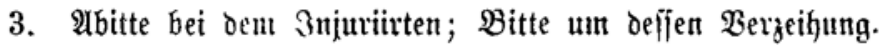

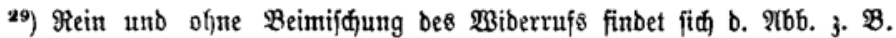
nod) in ber Summa confessorum beళ Sohanne be Friburgo Lib. II. tit. 15 Quaest. 99: Injurians etiam vel spoliator vel complices eorum semper debent humiliter postulare veniam ab his, quos offenderunt ne illi remaneant in rancore seu mala voluntate. -

1) Es gefdiebt nur einer conftanten Terminologie wegen. Durd bie

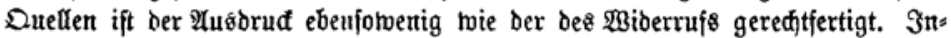

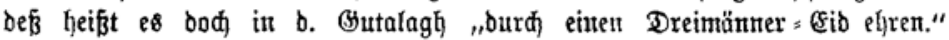

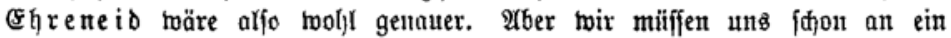
gebrüuđliđłes Bort halten. 
3med: Satisfactio (privata) laesi. - Uriprung: bie Sittenlehre fpeziell $\mathfrak{B o r j a j r i f t e n ~ b e r ~ d r i f t l i d e n ~ M o r a l . ~ - ~}$

Un\& intereffirt bor $\mathfrak{A}$ flem der sub 2 ertoähnte $\mathfrak{B}$ iberruf. Ridjt fobald war beffen Sdjöpfung erforgt, als er aud bereits

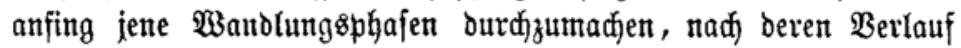
wir ihn in einem semande wieberfinden, indem wir als cinge= meihte unjre Mühe Gaben, bie alte Beftalt herauszuerfennen.

Das (Erfte mod)te fein, dą̧ Der todte Saz ber Doftrin in das Reben und in bie ßraxis Ginüberfpielte. Bunäajt tvirb er bon ben theologifd burchbildeten uno ben Rehren ihyer grofien Meiffter folgenten Elerifern aboptirt, von ben Beiffigern in foro

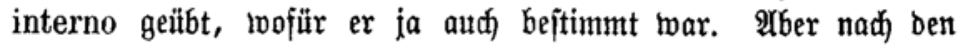
bereits oben bemerften Berbältniffen fonte es dabei nicjt bleibetr. Die restitutio ablati, als ein actus justitiae commatativae murbe auch in foro externo zur Beltung gebradjt. So ijit es ficher, dẩ auf Brund ber mehr uno mehr in ber Bolfsemeinung

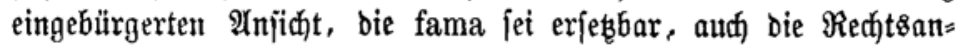
idalung zur (Entwifelung fam, wonad) jene restitutio (Etwas bon

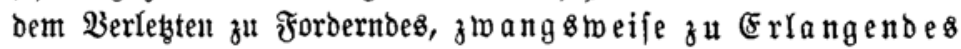
fei. Warum foflte ber Эnjuritirte ntidft feine fama vinbizirent fön= nen, ${ }^{2}$ ) wie ber $\mathfrak{B}$ eftohlene unb ber Beraubte bie res furtivae und vi ablatae. Warum follte er feinen Erfaks, twenn ein foldjer möglid) war von bem Umitande abhängig madjen, ob ber 3 nju= riant beidjtete, und ob ber Beicftiger igm bie restitutio anbefahl? Doer beliebige 3eit barauf marten?

(E\& fann alfo nidht befremben, wenn bie geiftlidjen (Seridyte aud in foro externo früher oder (päter ${ }^{3}$ ) eine foldje Slage auf

2) Didacus Covarruvias a Leyva: Resolutionum variarum libri III. Cap. XI. No. 4. - - Iustissimum tamen est, famae et honoris restitutionem fieri his, qui convitiis objectis ejus laesionem passi fuerint.

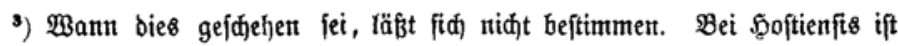

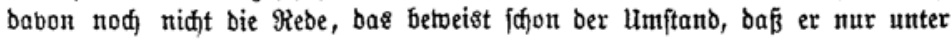
ber poenitentia Dabon Ganbelt, aber meber in bem Titel de injuriis und de maledicis et calumniatoribus babon bie ßebe iff, nod aud überhaupt einer Rlage auf restitutio gebađt ift. Niđht ganz unmöglid ift, baß̉ auf biejen

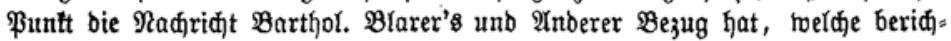

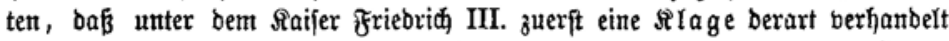
jei; und alsbann entbehrt jene Notiz niđjt jeber ছ̧altbarfeit. Nur muß̧ ents 


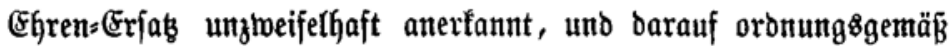
geurtheilt haber.

Denjelben hier gefdiftberten (sang hat entidjieden aud $\mathfrak{B e r n}=$ haro Diaz be \&uco bor 2 ugen, wenn er (Practica crim. canonica Cap. 60) fagt: - - ,Sed quis dubitat, quod justum sit et rationi naturali congruum, quod clericus, qui falsum crimen alicui imposuit, ex quo laesa est fama illius, dicat se mentitum esse, ut per hoc fama illi restituatur, maxime cum ad hoc teneatur tanquam christianus, et ad id a confessore etiam non petente injuriato, cogendus sit."

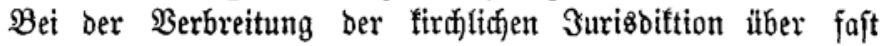
ganz Europa getwann biefer, auf einem perberjen Theorem exftan= bene Redftigebrauth eine unglaublidje Berbreitung. Wir finden ihn ficon frühe bon bem tiefiten Silben, b. h. bon Spanien,"

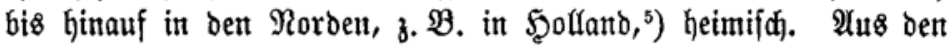
geiftlidjen Beridjten fand er feinen $\mathfrak{B e g}$ in bie weltliden. $3 d$ f glaube Bemeife Dafür beizubringen ift unnöthig, wenn twir anbers hoffentlidf in Dem Borigen zur Benẗge. betwiefen, bá er in bem (S)biete ber Sirche entitanden, und wenn wir auf bas unbejtreit=

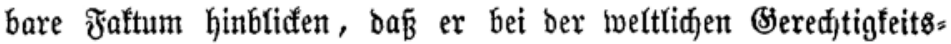
pflege in Uebung war. Wie mentig übrigens eine foldje Şerüber= nahme aus ben geiftlichen in bie weltlidjen (Seridjte etros Unges tröhnlidfes ober Singuläres trar, fo twurbe fie hier bod nod Durch bejonbere Berfälttifffe begünjtigt. Das હaamentorn fiel auf einen empfängliḑen $\mathfrak{B}_{\text {oden. }}$

Sn ben germanifđen \&änbern beftand nämlid, wie oben ge= zeigt, bon jeher ber sub 1 djaratterifirte Egrentio. - Bergegen=

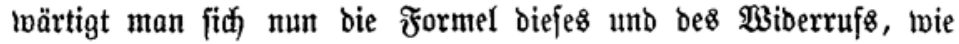
fie uns für ben reştern mit fo groß̧er Stenautigfeit bei ben Scho=

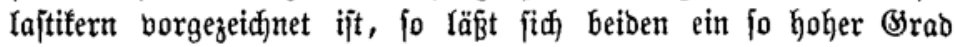

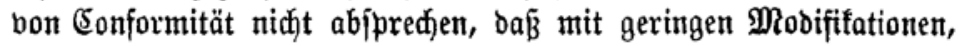

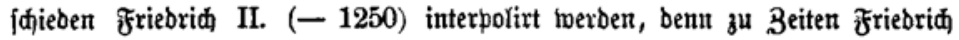

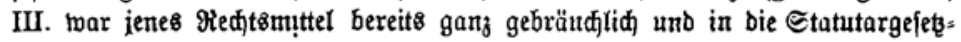
gebung bieler Srte itbergegangen. (5. unten).

4) (Eobarrubias a. a. D. $\mathfrak{B} .1$ - - Gouzalez Tellez Comment. ad c. 23. X. de seut et re judi. No. 3 .

s) J. B. Cannaert. Bydragen on de Strafrecht in Vlaenderen. S. 136 f. 
ober fogar nur mit einer ffeinen 9 Xbänderung in ber $\mathfrak{B}$ ortfajfung ber eine in ben anderen übergeken muB̃te. Uriprünglidi enthielt die Eghrenerflärung allerbings nur bie Behauptuntg:, id habe im Afffelt, ohne Borbebadyt gehantelt". Dagegen bei bem Widerruf lautete es: ,ich erfenne mein Unrecht an, idh habe gelogen." $\Im_{n=}$ Deß̧ folgente Betradjtung lwirb zeigen, wie leidyt bieje beiben Erftä= rungen mit einander berfdmelzen.

a. - Eine Snjurie, oder ber Bortwurf eines Berbređ̧ens insbejondere, ${ }^{6}$ ) wenn fie im Borne, in ber Trunfenheit 2 . began= gen wiro, enthält gemiß meiftens eine Untwahrheit. In ben ₹ä̆len, two bies nid)t ber Fall twar, mirb wohl aud) bie Frage, ob bie Scjelte in vorsate ober mit hastmude gejdjehen, gar nifjt zur Erörterung gefommen fein, benn bann wiro ber 3njuriant $e 8$ bor $=$ gezogen Gaben ben $\mathfrak{B}$ emeis ber $\mathfrak{B a h r h e i t}$ zu führen, woburd er ganz lesig. murbe, ${ }^{7}$ ) anitatt bie - wenn auch geringere - Strafe

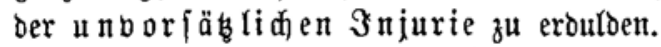

b. Andererfeits pflegt bod jebe Schnähung, bie einen un= ivahren Borwurf enthält, in Iffeft ausgejtogen zu werben. Radh biefen beiden (Sefidjtopuntten hin fano eine unmerffidje, gleidffam

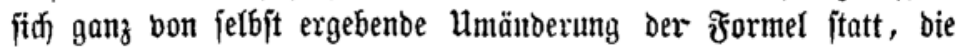
eine grö̧ere $\mathfrak{A}$ muäherung beider zur Folge hatte. - So modte einer:

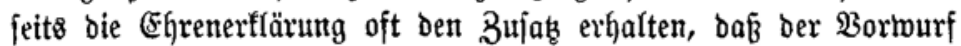
"bon feiner $\mathfrak{B} a$ ahrheit fei, “ anbererfeits aber ufancemäbig bem Widerrnf nod beigefügt werben, Daß̧ die Beleidigung ohnte böfe Abjitht und in Erregung borgefalfen jei, namentlid ba boch ber Biderrufende jelbjt feine Berjauldung baburch in etwas milberem sidjte barfteflte. - 2 nfangs beftant zwar nod eine grobe S(f)rante, die das 3neinanberflięen eo ipso unmöglid ntadjen muईte: unb diez war bie bei der Ehrenerflärung nothlwentige (Eibeshülfe. 2Ars aber erf́t biefe gefalfen, indem burd) bas $\mathfrak{Z}^{\mathrm{u}}$ fammentwirfen berfádiedenter Umptände, namentlid) aud auf $\mathfrak{B}$ etrei

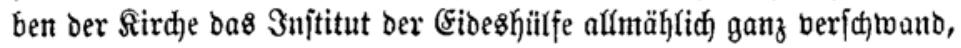

6) Darum hanbelt es fid bod meiftens. Bergl. oben Cap. I. bie cit. Stellen aus ber lex Rotharis („Fornicaria, Arga") ans bem (5) talagh c. 51 (bie unburbbaren $230 r t e)$ unb Softienfis a. a. D. - - ergo non dicat: Ego te tali facto infamaveram talem, specificando crimen.... etc.

7) $\mathfrak{B} i$ (ba S. 792. ("non potuerit comprobare, convincere"). - Dien= brïggen a. a. $\mathfrak{0 .} \S$. 113. 114. 


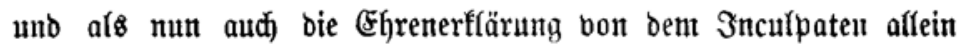
abgelegt wurbe - ba ijt es flar, wie eine Sonderung jener 3 njti= tute mehr uno mehr unmögfich inurbe. $\Im a$, noch andre (Sründe, bie bie Berjđunelgung begünjtigten, oürfen niđłt unerwähnt błeiben. Dic Ehrenerflärung, als proceffitualifojer $\mathfrak{B}$ organg hatte uriprüng= (id) gewi $\bar{B}$ nur vor Beriđht, in ber Dingberfanmulung ftattgehabt. Der W3iderruf war aflerbings ber Theorie nach nur bor benjenigen abzulegen, in Deren Begentwart bie Beffjimpfunt ftattgefunden, bei Deneut bie Berläumbung erfolgt war - furz in beren Alugen bie Eghre des Beleidigten geidjmälert ober entzogen fátient. Wo follte ber Widerrufende biefelben auffinden? Wufte er bod) oft nicht einunal genau anzugeben, wer gegentwärtig gemejen, zu twein bie Berläamoung zc. gebrungen twar! Sollte alfo ber Wiberruf nicft beliebige Mafe wiederholt werben, und bennodi eine grofie Unificjer: heit fortbejtehen, ob berjelbe nun auth aflen benen gegenüber $a b=$ gelegt fei, zu beren Renntníz er gelangent follte, fo toar es unjtreitig Das Sïrzefte einen Drt zu wählen, bon bem nid)t allein präjumirt werben burfte, baß̧ an ihm ber größste Theil ber erwadfenen $\mathfrak{B}_{e}=$ böfterung fích berfammelt fände, fondern ber einen fo hohen (s)rab

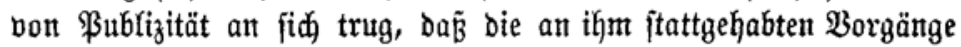
einer affgemeinen Berbreitung unterlagen. Scier bot fid naturge= mäß neben ber Sirdje (zur Zeit bes (5ottesbienjtes) aud bie Ding= berjammlung als hödfit paffend bar, unt in ber That finden wir biefe ftets als bie Stätten, an benent ber Widerruf geteiftet werben follte, fđon frühe angeiviefen, uno hier gerieth ber lestere aber. mals in Berïhthrung mit ber Eygrenerflärung.

Sehen wir enblid) auf ben beiberjeitigen Effett.

Burbe die Ergrenterffärung nid)t geteijtet, fo traf ben Sdjul, bigen eine härtere Strafe, nach altem Reutt jogar bie frieblofig= feit. Dem, ber ben $\mathfrak{B}$ iberruf verweigerte, fo lange berjelbe mur in faro conscientiae auferlegt trurde, orohte die Excommunifation

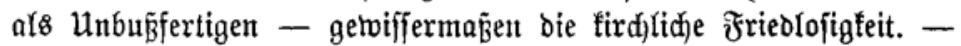
Wer bie (Ehrenerflärung Yeijtete, gab zu fid) Durd Reidenfjoft zu Ungerechtem haben fortreiß̄en zu laffen; wer miberrief (tellte fid felbjt als Rügner dar. Beides war eine Demüthigung - jum Minbejten eine Bef̧đämung, für ben Reiftenden ein $\mathfrak{U}$ ebel, alfo bod) eine Art Strafe. -

Man redne alles (Sejagte zufammen, uno bebenfe endid,

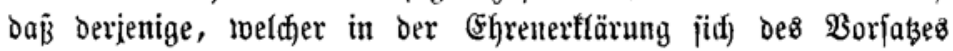


entredigt hatte, bemmädjt in Wiberruf nod) zur restitutio famae geztoungen twurbe -- unt man wito $c 8$ in ber That als hödfift

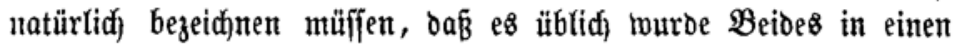
2fft zu zieken, uno bie Formel fo zu faffen, wie wir fie in ben Rernten bes Mittelalters fo oft finden. ${ }^{8}$ )

A. Den beutfdredftliden (5harafter mehr betwahrt, uno $\delta a=$ her bie Ehrenerflärung nod in ifrer antage erfennen laffen fol= gente Stellen:

Stadtred)t b. Zrenfing a. 1359 (Text bei Cap. I. a. (5. in not. 24).

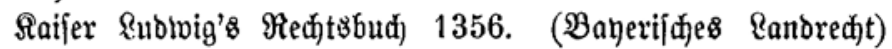
Art. 61. (ङ. ob Cap. I. a. (5.) uno Ârt. $64 .{ }^{9}$ )

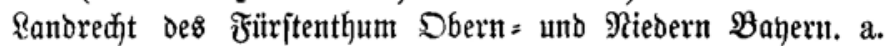

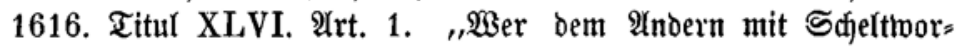
ten an fein (Ehr und glimpff redet, es betreffen foldje Wort (two fie twahr meren) Reib und Reben ober nit, fo er barumb in Redtt

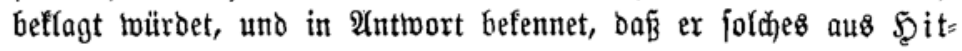
zigfeit bes 3orns gethan habe".... etc.

B. Den Widerruf uncorrumpirt geben: Sdinabenfpiegel. ${ }^{10}$ ) Cap. 110. Bon untgerechtem Frebcl. - Und fdjiltet ein Mann bent anbern, oder ftöfet ober wunbet er $\Im_{n}-$ un twil er püf= fen, $\delta a$ mant Ere erpiet ... . etc.

Rüdecfer Stabredft (Bei Hach $\mathfrak{A t h t h . ~ I V . ) ~ 2 ( r t . ~ 8 0 . ~ - ~ - ~ - ~}$ sundern alleine gebeden, dat deme beleidigten afdracht und ergetzlichkeit seiner ehre mit einem wedderrop beschehe...

Ruprecht v. Freysing. II. cap. 109 (ed. Maurer \$. 351).

Das ist ob ain man auf den anderen sait das jm an seinen leuttenn oder an sein er gat da sol er - - -

8) $\Im_{n}$ nur fehr menigen hat fich bie urfprünglidjè Pieinffeit zu exbalten vermođht, wie in ben Bjoslaer Statuten unb eitigen $\mathfrak{A}$ nbern, bon benten Cap. I. a. E. bie Rebe getwejen ift.

9) Der $\mathscr{A}$ rt. 64 ift faft gleidlautent mit bem Frenfinger Stabtred)t 1. c.

$\left.{ }^{10}\right)$ "Das beutide Raiferredt" bei Frehberg IV. Daffelbe aud toörtlid'

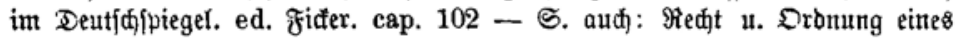

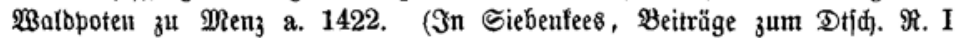
S. 51). bringt er es nit uff yn, fo muß er uff bie Sdjunbbanf ftehen und muß̧ ipred)en, maj er uff gefagt hat, $b a_{z} h a b$ er angelogen, unb bann fo ift er bem Mmtmann berballen - - etc. 
und mag er sein recht nicht gehaben er muss jm seinen schadenn abtuen und mus es wiederumb liegenn, als vor geredt ist vor dem gericht.

und biele Inbere, wie ${ }^{11}$ ):

Deffnung zu Tablatt. a. 1471 (Grimm I 231) -- - Item, wer der ist, - $-\ldots$ der dem andern sin er nympt und abschnytt mit worten - - - der sol dem sin er widergeben....

C. Die boflftänoige Berfd)melzung zeigen, auf eine uns nad) bem $\mathfrak{B i s h e r i g e n ~ h o ̈ d j i t ~ l e h r r e i d e ~} \mathfrak{B}$ eife:

Stabtredft von Frenfing (Frenberg V. 175).

Mr. 1. WBer uinen idilt. - Wehflagt ainer bem andern, er hab in gehaiffen ainen posbidat oder ungetretw.... Sprid)t Der antlourtter, bie Red han id in zorn getan ungebar= lidfen und bon wainer wahrheit nicht, baz gehört dain zeug über, wenn er int fein er wioer geben hat, uno fol man fain aib barumb nemmen, aber umb die Reb bie er gethan hat, Sol er ez bem (seridgt peffern mit ainem pfunt pfennig... ${ }^{12}$ ) 2 .

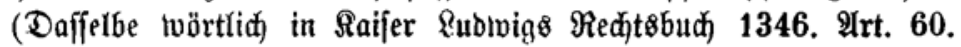
(Frenberg IV. 5. 416).

Saarbrüten. Brafen アohaun's Freiheits = Drief 1321 (ङrimm II S. 5).

_ — Wer ben anderen jufulbe merber, biep, farjaer, menneyber, ober bas folidjen reden glidjen modft, ${ }^{13}$ ) bas yemants

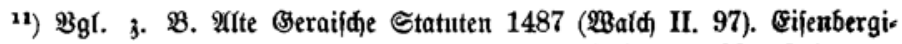
face Stat. 1610 (2Bald II, 253). - Eltbifler Weisthum 1383. (Brimm I. 547). - Acta Iudicii Duellici Noriberg. de a 1453 (Haltaus verb. „Wiber. (pru(d,").- Literae Henrici de Heimersheim a. 1353. (Dom. de Gudenus Cod. dipl. vol. II. p. 1129). - Statuten b. Rubolftabt 1594 (20ald V, 42). - b. Teudel (ebend. V, 175). - - ber Stabt Sdilaiz 1625 (baf. VIII. 76).

12) Dieje aufierorbenttid) interreffante Stelle lehrt Folgenbes: 1) Efren: extlärung und $\mathfrak{B}$ iberruf werben beibe erjorbert. 2) Die Ehrenertlärung mirb burd) ben einfaden (Eib ohne (Eibeshiliffe unb ohne Bezengniß geteiftet. 3) Reben ber restitutio famae tritt bie Strafe ber unborfätgliđen Snjurie eir.

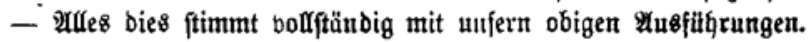

13) $\mathfrak{B g t}$. bie unbulbbaren $\mathfrak{B}$ orte in ber (Butalagh unb bie quinque verba,

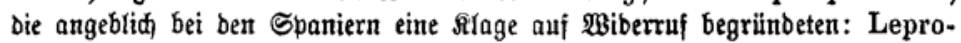
sus, Sodomita, Haereticus, Proditor, Cornutus (Covarruvias I. Cap. XI. No. 1.) Spunif́, füf)rt fie Gonzalez Tellez zu c. 23. X. de sent. et re judicata auf: Hereje, gafo, sodom etico, traidor, cornudo. His (fagt

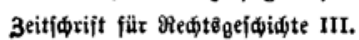


ere rurte, gejuce bas bor geridhte, uff ebme marfete, uf jaremefifen, ober da biel lube weren, ${ }^{14}$ ) wirt das geflagt und zubrachte mit zroeven twarbrechtigen luben, twer jofiche reoe out uff bemann, ber fol uns $X \boldsymbol{\beta}$ s und fol bie Worte toibder reden, wo er fie gerett hat, und aud in uffuer fertyen, bas bie bort nit ware finn, und tool nit glauben, das bas mentijice folidje mere, alfo es bie rede hat gerett, und fie gefdiet in fime forn. Der jolich flage nit zu bringen möd)te, oer jol uns zut befferonge $V \beta$ \&.

Betrachten wir bie angezogentell Queflenitellen, fo brängt jïđ uns im Refultat folgende Bemerfung auf, bie zugleich eine neue Unterftüküng für alles Bejagte bietet, infofern aus bem Borban=

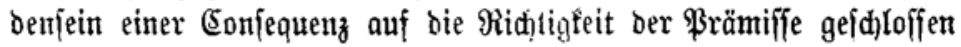
merben fann. Sn ben Recten nümlid, bie an Drten entítanben,

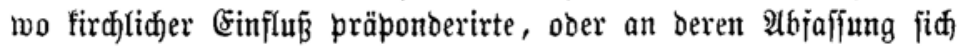
fogar Bjeijtliche bethätigten, ift ber $\mathfrak{B s i b e r r u f}$ zur alfeintigen ober Dberherridaft gelangt, fo in Deutidjipiegel, Schivabenipiegel, Rupredft $\mathfrak{b}$. Frenfing u. $\mathfrak{A}$. Dagegen hat jid anderwegen ber gute alte deutfidje Brauch ber (5hrenterflärung, mentigitens bod) zum Theil in feinem Redt behauptet, wie die (Soglarer Statuten zei=

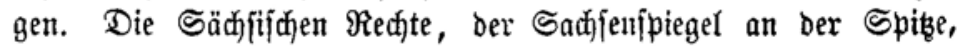
entharten Ridyts bon $\mathfrak{B i b e r r u f . ~ S i e ~ h a b e n ~ f i c h ~ t r e u ~ b e m ~ f t a r r e n ~}$ (Sonferbatizmus ihres $\mathfrak{B o l f e s}^{15}$ ) autf) hier bon jedent fremben (ETe= mente frei erhalten.

Covarruv.) etiam additur meretric is nomen et vitium foeminae ma-

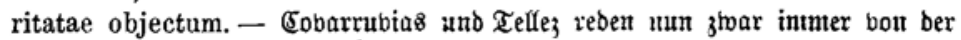
Palinodia, aber ber Bebante unb bie Frage liegt bod fehr nahe, ob eben biefe 5 Borte nidjt ben in ber (Sutalagh aufgefüt)rten corre\&ponbirend, Ehrener= tlärung ober Frieblofitgleit forberten. Itud) bie Uebereinftinumung ber Bahl untereftittżt biefe Şt)pothefe.

14) Die Gutalagh c. 51. §. 5. fagt: „bor Dem ganzen §irdfiptel ober ber Dingberfammlung ober irgend einer Bemeitheit -“".

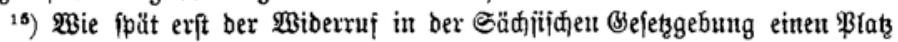
erfielt, werben twir unten erfałren. Bgl. vorläufig bie Ordinationes et Constitutiones Augusti, ducis Saxoniae. Pars IV. Const. 42. 


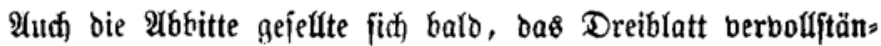
Digent, zu Egrenertlärung uno Biberruf. Dbgleid aber aud hier die Intiftände einer Affimilation ourchaus günjtig waren, fo ficheint

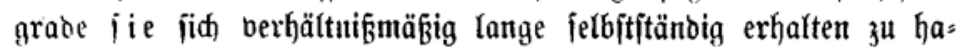

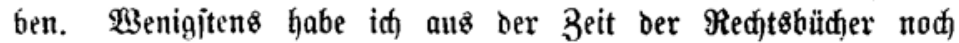
feinen $\mathfrak{B}$ eleg bafür aufafinden bermortht, bą̧ fie bem $\mathfrak{B 3 i d e r r u f}$

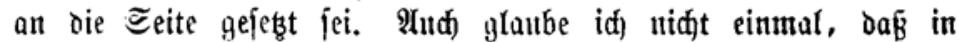
meltiichen (Serid)ten zu biefer Zeit fodon auf albbitte oft erfannt

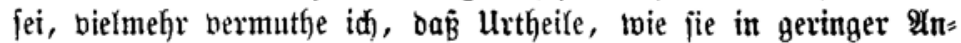
zahl in ber That vorliegen, meiftens von geifftiden Seridten aus=

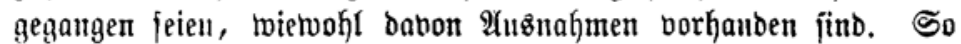

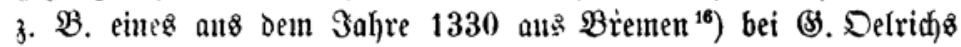
Samml. oer Bsejetzbücher ber fr. Stadt Bremen. S. 169. $\mathfrak{R r}$. 14) uno äfulid voul 3.1335 (a. ヘ. O. S. 193). Auch bies

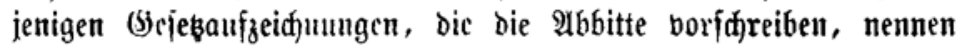
diefen alfeilt mo femnen uid)t ben $\mathfrak{B i d e r m i j .}{ }^{17}$ )

Bisher haben wir bell (stang ber Beridjmelyung bon ben brei uriprünglid, getrennten Elcmenten nur anf bem Bebiete ber eigent= lid,en $\Re$ c d)t

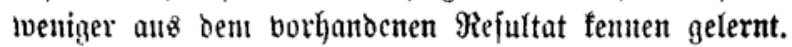

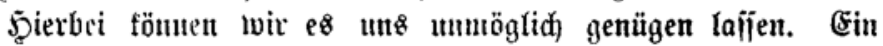
vollitändiges $\mathfrak{B}$ illo zu yetwinnen, bürfen lwir exít dann hoffen, wenn wir aud bie Thätigfeit ber $\mathfrak{B}$ iffenifgaft einer Betradftung und Srritit unterivorfen haben, und bejonders ift bies für eine Zeit nothpendig, wo nod Dottrin und Brazit in fo enger Berbinoung, in foldjer mectferfeitiger $\mathfrak{B}$ ceinfluffunty mit einander ftehen, wie Das gange Mittelalter und ber 2 nffang der neueren $\mathfrak{Z}^{\text {eit }}$ bies bei bem Strafred)t borzüylid ber Fall getwefen ift.

Ysir haben in dem Cap. II. furz gezeigt, wie bie theologi=

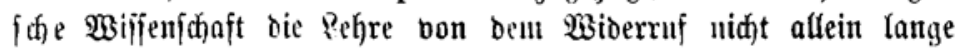

$\left.{ }^{16}\right)$ Ueberidrieben: Emenda illius qui alterum increpando dicit eum mentiri. (5z heißt: $--\ldots$ dat is gekommen up us johanne duckel - - to scedene unde scededen dat also: dat Wolf bidden scolde hermen hertogen ofte he de worte sic to hone hadde togen dat he eme de dar got vorgawe. - Der Fall ift infojern eigenthümlid, als eigents

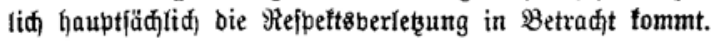

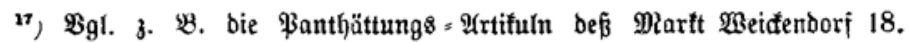

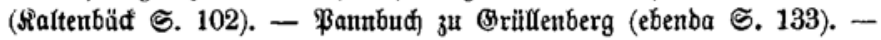


3eit nod als ihrem (s)ebiete angehörig betractete, fonoern aud

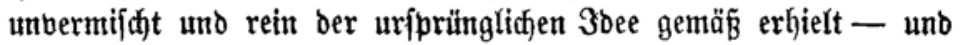
ausbiloete.

Aflein es murbe bort bereits bemerft, mie fid aud bie $\Im \mathfrak{u}=$ risprubenz bes Stoffes zu ihren Zloeeten bemädtigte. Der Uebergantg twurbe ourch Şoftienfis, einen bon ben Suriften hod)s geehrten und bielfach bentzten S(j)riftfteller bermittelt. Dennod) enthalten bie meiften Eriminaliften über unjer 3njtitut gar Nidts, und biefes barf aud) faum vertwundern. Bon ben bon ber Mitte Des 13. Эahrh. Kebenden bedeutenden Meijtern ift es jelbjtberitänd

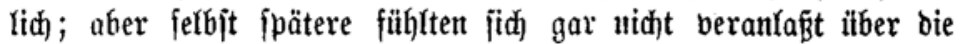
restitutio famae zul hanbeln, felbft menn fie ihnen befant unt bout ihnen a nerfant war, benn es twar ja das ein ßunft, ber, wie bie ganze Frage nad) Dem Sdjadenerfat, in bas (sibilredt

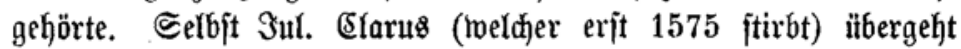
den Biderruf ganz mit Stillf(f)weigen, ${ }^{18}$ ) mährend ex ifgn bod fidjer fennen muß̧te, und erjt Bajarous, der zu ben Sententiae receptae beß Borigen Roten fajrieb, nimmt auf bie restitutio famae Rü̊ffidt.

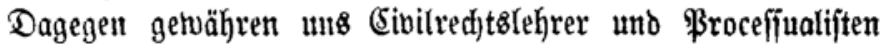

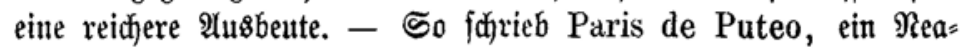
politanter, einten Tractatus de Syndicatu. Darin hanbelt er atth bon ber Stellung des judex in Sriminalproceffen, und babei bon ber compositio. „Compositio ift num aber nidft ettoa "Bube, “ wie jie in biefer Bebeutung fich gewölnnticher, namentfich in ben Bolfzredftent findet, fonbern (nađ) \$ariz eigner (Erflärung) trans-

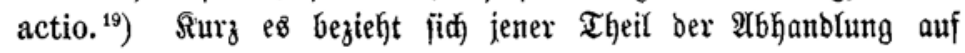

18) Dagegen finbet fich bei ifm nod ein mertwüroiger 2 ntulang an bie (Efrenerllärung. (Er fogt nämlid): (Sententiar. receptar. lib. V § Injuria $\mathfrak{N r}$. 16.) Quaero, quid si injurians dicat se poenitere et. quod dixerit aut fecerit calore iracundia numquid erit excusandus? (Er bes autmortet biefe Frage bahin, baß̧ eine milbere Strafe zuläffig fei! -) Bon bem $\mathfrak{B}$ iderruf ift hier bod moht nidjt bie Rebe, miemoht Bajarbus bie Stelle fälijafiç babon berfteht.

Die Sehre bou ber E⿹hrenertärung geh)ört, nađ ber oben bargelegten $\mathfrak{R a}$. tur ber leţteren, zunädft in den ( $r$ riminalproceßs - bann finbet fie aber aud in bem materiellen Strafredt eine Stelle, injofern es fid hier um eine Berühfidptigung bes Affetts bei ber $\mathbb{S}$ trafzumeffung handelt.

19) Paris de Puteo. Singularis tractatus in materia Syndicatus [In Volumen II] Tractatuum [ex variis juris civilis] Interpretibus [collec- 


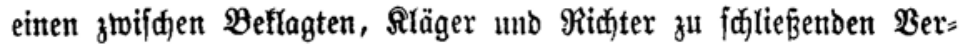
gleid) in Betreff begangener $\mathfrak{B e r b r e h e n , ~ m i t ~ e i n e m ~} \mathfrak{W}$ orte auf bie berildtigte, ifrer Zeit fo viel Untwejen berurjachende Rebigung ber Strafe. Bei berfelben handelte eв jiđd aud zunächit un eine satisfactio partis laesae, uno für die Ynjurie miro biefelbe in ber restitutio famae und veniae petitio gefunten, mit $\mathfrak{B c r u f u n g}$

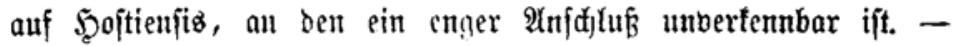
Ynoffen wirb uns dicje Stelle aus \$aris nod weiter unter Cap. IV befdäftigen. Sm (3)anzen ijt hier nur borläufig zu bemerfen, Dág ber (Eharafter der restitutio famae ztwar nidht gradezu ber= fanut ift, aber baßs fid) bod) bcreitz die Reigung fund giebt, in Der Ableiftung bes Wiberrufs eine Strafe zu finbent.

Dagegen finben twir bei bem nädjten Sdjriftfteller, in bem wir umferm Эnjtitut rieder begegnen, bereit eine unglaublidje $\mathfrak{B e r}$. mirrung uno eine perverfe Debuftion, bie uns in einem fonft braudbaren unb bielfad) betwutiderten $\mathfrak{B}$ erfe um fo unangenehmer berührt. (58 ift $\Re \circ b$. Maranta, ${ }^{20}$ ) auf beffen Argumentation wir ifhrer $\mathfrak{A} b$ fonderlidfét halber näher eingehen mitffen. (Er tommt nämlid auj bie satisfactio injuriae ${ }^{2 t}$ ) uno ftellt babei bie Frage, twenn auf einent $\mathfrak{W i b e r r u f}$ geflagt toürbe, ${ }_{n}$ an tale judicium dicatur criminale vel civile?"

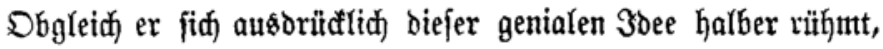

torum .. Lugduni 1549. gr. fol.] sub verb. Compositio n. 6 (a. a. $\mathfrak{O}$. fol. 368). Nam compositio et transactio idem sonant .... et compositio proprie est in pecunia quae infertur per delinquentem pro crimine. - Dirksen. Manuale Lat. verb. Compositio. § 2. Transactio, decisio. Qui cum adversario suo de compositione ejus criminis, quod intendebat, fuerit locutus fr. 6. Pr. ad s. c. Turpill.

$\left.{ }^{20}\right)$ R. Maranta: De ordine judiciorum, vulgo Speculum aureum et Iumen Advocatorum. Pars IV Distinct. 1.

${ }^{21}$ Loc. cit. no. 10. Sed juxta hoc quaero: quid, si agens actione injuriarum concludit injuriantem condemnari ad satisfactionem injuriae sive honoris, puta ut mentiatur, vel veniam petat, et famam restituat, ad quod tenetur injurians? - an tale judicium dicatur criminalevel civile? Hanc quaestionem non reperio tactam a b aliqu o, tamen inspectis his, quae supra dixi, posset aliquis dicere, quod iste dicatur civiliter agere, quia nihil venit applicandum fisco: imo illa satisfactio injuriae fit parti. Tamen ego te ne o contrarium, scilicet, quod imo tale judicium fit mere criminale. 
unto ferbftgefärlig bemerft, daß̧ er biefe quaestio noch fonft nir= gends erörtert fände (f. o. not. 21), fo hätte er twahrlidy feinen (S)rund gehabt, ben Brahler zu fipiefen, währento er ood in $\mathfrak{B a h y}=$ heit ein Unheilftifter worre. Seine $\mathfrak{A}$ uttorität war Beranlaffung,

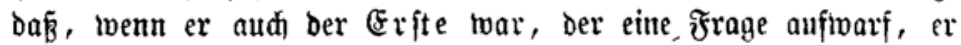
leiber nicht ber Reşte blieb, ber fich an ihre Beautwortung mad)te; vielntehr fann man fie bon ba ab bei jeben थ̂ttor, ber ïberhaupt ber Materie ertwähnt, breit getreten - ulo fogar mei. jtens ében io falfd entifjieden finden, wie es bei Maranta ber Fall ift. Sino bod, felbit bic friminalredtlidjen Eompendien uno

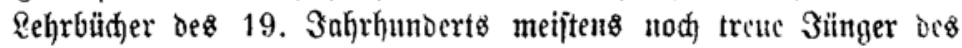
Maranta - allerdings ohne fich beffen bewufit ju jeitr. - -

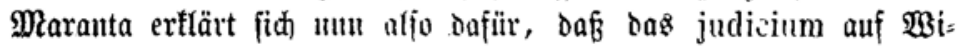
Derruf mere criminale ici. ${ }^{22}$ ) Wahrhaft betwundernoiwerth ijt aber bie Rogif, bie er zur Erreid)ung diefes Fiejultnts in Antwen= bung bringt. Die Siette jeiner $\mathcal{E}_{\text {d) }}(u$ fifolgerungen ijt näntid), in feinen eignen. Borten folgende:

Quia illa satisfactio injuriae dicitur poenla secundum Paris ${ }^{23}$ ) in verb. compositio; quia si est poena, cum non sit pecuniaria, nec amissio alicujus juris, de necessitate erit corporalis (!!). Nunc in proposito, si est (? - ) poena corporalis et descendit ex delicto, ergo causa est criminalis, quando imponitur .... poena inferenda parti in corpus ... unde cum hic inferatur poena in corpus, prout est satisfactio delicti: et descendit hujusmodi poena ex delicto, sequitur quod judicium est mere criminalis. ${ }^{24}$ )

22) Obgleid inn bod figon bie Borte restituere und satisfactio, bie er ja beibehält, eines Befferen hätten belehren tönnen!

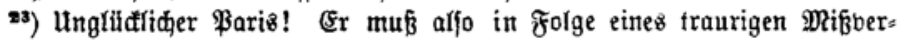

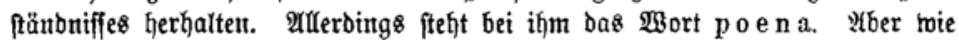
es gemeint ift, geht aus bem 3llfammenthang herbor: $)$ r. 8 - ies ift bon

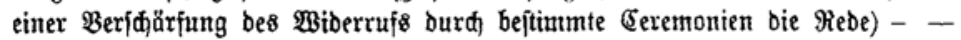
erit ergo satisfactio ista sic facta condecens delicto, et erit quasi poe n a corporalis, per quam tolletur injuria. - 2tlerbing eine elmas

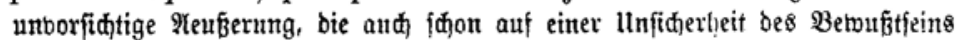

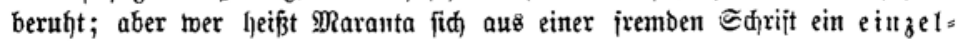
nes 28 ort herausgreifen, und barauf ohne jebe \$rilfung jortbanten?! -

Das ift bod mehr toie Nutoritätsglaube!

24) Dagegen Carpzov: Def. for. Pars IV Const. 42, def. II 9ir. 7 „jam vero recantatio sive palinodia corpus non afficit." 
(onfequenz: Die actio aestimatoria unt die ๔atisfattions: tlage fönnen nidht cumulirt twerden, quia cumnlaret (libellus) poenam civilem cum criminali, quae cumulatio non admittitur. - -

So Maranta. 21nore (belehrte fehen flarer. -

Эohanne $\mathfrak{B}$ berber ${ }^{25}$ ) berbreitet fid zwar jefr menig über ben einjd)tagenden $\mathfrak{B}$ unft, ober er giebt ein $\mathfrak{S}$ ( a g formular für den 3njuriirten, bas boflfommen anf rid)tiger Bajis conjtruirt ift. Der $\mathfrak{B}$ iberruf ift mit ocr actio aestimataria cumulirt.

Bon oen Deutfjen verbicnen $\mathfrak{B} u r m i e r$ und $\mathfrak{A}$ nor. (S) air genannt zu werben. Der eritere erflärt fidy ausorücflich für die

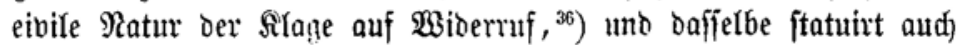
(3) a il, ${ }^{27}$ ) twietwohl er cin nidjt grade jehr fdjlagendez 2 rgument jut Şülfe nimmt. Er unterjtüßz̧t nämlich) bie (Sibilität ber Rlage

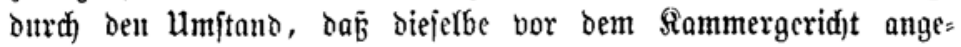
nommen und berhandelt merbe. Nun ijt das aber ein vertehrter

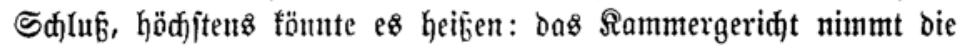
Silage an, to eif fic cibifer Matur ijt. Sm Srunde ijt jener $\mathfrak{B} e=$

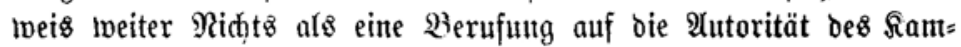
mergerid)ts, weldjes ebcujo urtheilt.

F̧iir mere reipersecutoria erflären bie actio ad palinodiam:

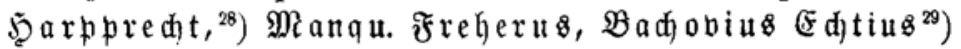
und $\mathfrak{A}$ troere.

25) Johannis Berberii : Aurea practica sive viatorium juris. Pars IV rubr, 1 de judiciis $\mathfrak{R r}$. 102 . - - et petit .... pro suorum nominis et famae redintegratione dictum reum ad publice dissonandum, profitendum et declarandum dicta verba diffamatoria et injuriosa fuisse per eum inconsulte (l) et contra veritatem dicta et prolata..... et ad solvendum actori summam praedictam mille librarum Turonen .... etc.

$\left.{ }^{26}\right)$ Bernh. Wurmbser ide Schafftalsshain) - Practicarum observationum libri II. lib. I tit. 46. Observ. $8---$ Sed in libello reclamationis nihil petitur fisco applicari sed parti agenti petitur restitui fama. Ergo est civilis. Cbenjo I tit. 9. Obs. 8.

${ }^{2 \boldsymbol{r}}$ ) Andreas Gail. Practicarum observationum libri II. - Lib. I. Obs. 64. 65. Bgl. Hartmann Hartmanni ab Eppingen Pract. observ. lib. II tit. 49. Obs. 3. -

28) Joh. Harpprecht. Tractatus criminalis Cap. de injuriis borzïgr. ad $\$$ in Summa.

$\left.{ }^{29}\right)$ Reinh. Bachovius Echtius. Notae ad disputationes Hieronymi Treutleri. Vol. II Disput. XXX Thesis 7 Lit. A. 


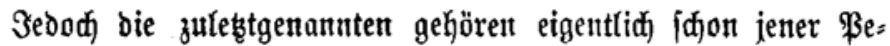
riobe an, bie uns in bem nädjten uno leşten (Eapitel zu betradten übrig bleibt. Wrir tönnen uns alfo hier bei bem $\mathfrak{B} e r(a f f e n$ der Doftrin nidft berheflen, wie wenig frudttbar fid ihre 2 sirffamteit für eine naturgemäße Behandlung unires Snjtituts bis zum $\mathfrak{A}$ = fange bes 16. 3ahrhunderts ertwiefen hat. Sie nahm die ihr bon einer fremben Wiffenffjaft oftroirte Soee willfägrig und ohne freie felbititänbige Sititif auf, und anftatt mit Sonberfion zu einer beffe= ren Erfenntnif́ ein im \$rinzip unhaltbares Theorem abzuftofen, fudten fie es burd bas Unterfifieben ungehöriger uno frember

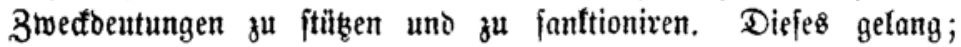
aber bie $\mathfrak{2}$ ufrectterhaltung eines ber Borzeit augehörigen uno nur auf moriden Pfeifern ruhenden (Sebtiudes wurbe mit einem theue= ren Breife erfauft, benn bie Wahrheit ift ein (Sut, beffen fid) bie

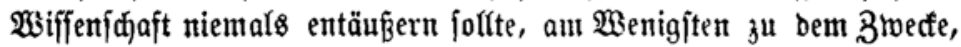
um zu verheimliçen, daß fie bereinjt einem 3rrthum verfalfen fei.

Was nun endlid bie Braxis anlangt, fo haben wir beren (Se)italtung am $\mathfrak{A n f}$ ange biefes Cap. fenten gelernt. ${ }^{30}$ )

$E_{8}$ bleift hier nod) ein Bunft zu erörtern, ber oben unbes rührt blieb, und abfidttid) hier bis zum Sd)lú vorbehalten mutroe. (58 hanbelt fid nämlid) unn eine unbefangene Betradtututg ber=

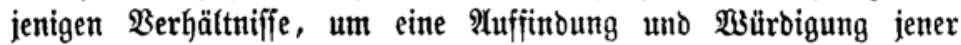
$\mathfrak{u m}$ ïänbe, bie geeignet waren bie Einbürgerung bes Widerrufs

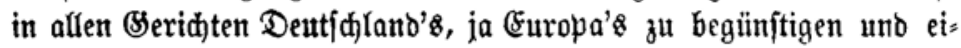
nen (sebraud) zu wahrem $\mathfrak{B o f f s e i g e n t h u m ~ z u ~ m a d i e n , ~ b e r ~ n i d t ~ b e r ~}$

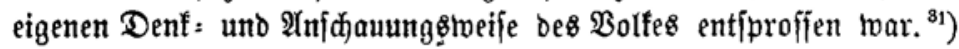

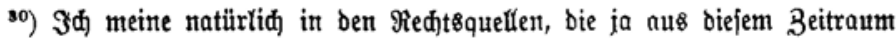
nod nirgenos ben Sharalter legislatorifijer Irbeiten an fid tragen, fonbern

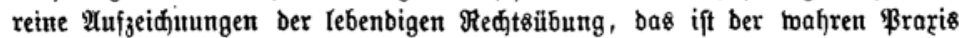
finb.

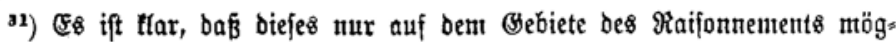
【iđ mirb. Die Quellen tönnen niđt Drt für Erräuterungen über $b a \& \mathfrak{B} a=$ rum? fein, fie lehren nur es ift fo; unb bie Sdjriftfteller ber (s) leidzeit haben ebenfalfs felten Beranlaffung fid Darïber auszulaffen. Daher fann eine

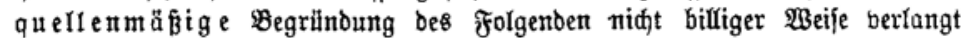

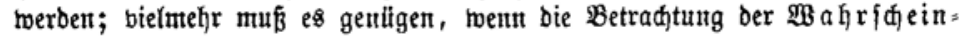
ridfeit und ber Blaubmitroigle it in Berildfidftigung bes allgemeinent

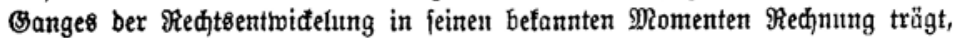
menn fie nidht $\mathfrak{T h a t f a d e n ~ m i b e r f p r i d g t ~ u n d ~ w e n n ~ r i d t i g e ~ C o n f e q u e n z e n ~ m i t ~}$ ber $\mathfrak{B}$ irflidfteit libereinftimmen! 


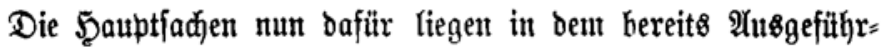
ten. Zuerít war es ber Bsetwiffenzzlwang in foro conscientiae,

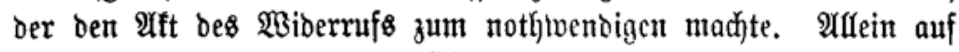
Brrund ber früher ïbliçen Ehrenerflärung tourbe die Alufnahme des neuen 3njtituts bei bem Boffe erleictert, das fogar bald, ber=

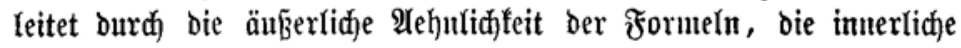

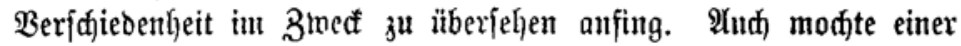
rohen $\mathfrak{A}$ njđanung auf ben erften $\mathfrak{B}$ ficf, ohne die Fähigfeit einer

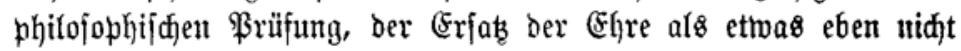
Unmöglidyes ober Widerfinniges vorfommen. Selbjt bas Betwuft= fein, bem Berurtheilten einen für ihn unangenehuten Bmang aufs zuerlegen, muß̧te die Forberming auf $\mathfrak{W i d e r r u f}$ zu etwas fehr (Bes $=$

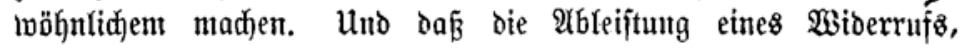

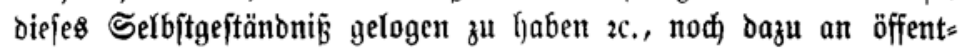
lidem Drte, in bem auf (Srund ridjterliden Befehls, oft wider feine Ueberzengung widerrufenden ein (Befüht auferorbentlidjer Demüthigung, Befdjämung, Sränftung und $\mathfrak{A}$ ergerø herborrufen. Da jehen lvir benn, wie jidh audh hier, freilid beridieden und unab̧ängig von ben $\mathfrak{A r g u m e n t a t i o n e n ~ D e r ~ D o f t r i n , ~ b e r ~ S a d h e ~ j e l b j t ~}$

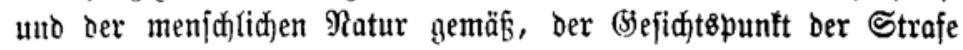
gettento zu madjen begann.

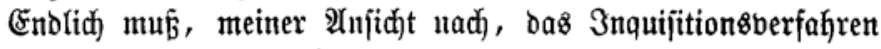
einen nidst unbedeutenden Einfluß auf die Einfüfrung bes Biber= ruff 8 in bie Seridjte unb feine allgemeinere Berbreitung geübt ha=

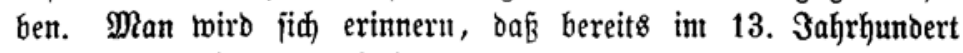
Der inquifitorifde Procé in oem Berfahren auf infamatio eine borlitändige (Entwidfelung gefunden hatte. ${ }^{32}$ ) $\Im n$ unb mit ben geift= fidjen (seridjten fam berfelbe nad) Dentfiflant, too er den Boden für feine $\mathfrak{A}$ ufnahme bereits burd) das Ridjten auf Reumunb bor= bereitet fand.

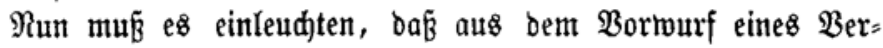
brechens im $\mathfrak{B}$ eifein Dritter, ober aus einer $\mathfrak{B}$ erläumbung für ben Зnjuriirten uno Bertäumbeten eine infamatio entjtehen tonnte, oie ihn jaflieflidy in eine criminelle Unterjudfung verwidelte. ${ }^{39}$ )

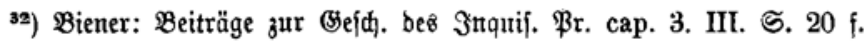

3s Ramentlid, gilt bies and für bie Sentgeriđjte, too bie testes sy-

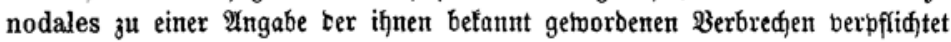
waren, unb bie baher ex officio genöthigt twaren einem curfirenben Bserüđjt

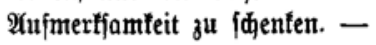


3war fonnte bei bem Mangel geeigneter Bemeisimittel ein folches Berfahren nur zu einer purgatio des アnquirirten führen; indeffen handelte $e \xi$ jid. in einem foldfen Fall, menn aud um feine (Sefahr, fo boch minteftens unt eine jehr unangenehme Störung und eine in jeder Bezief)ung peinlicte uno fränfenoe Situtation bes bor Beridyt Bseftellten. Nun hatte fich bereitz lange aud für (Sriminalfachen ber fugen. Diffamationsproze ${ }^{34}$ ) ansigebildet. Frei=

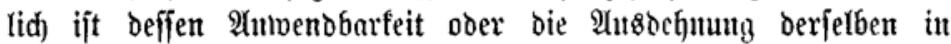
(Eriminalfden fehr beftritten resp. zweifelfaft (i. o. not.) 3noefien ift bieje (Sontroberje für uns ziemlid) indifferent. Denn too bas remedium ex leg. diff. gegeben tuuroc, äıñerte es boc) fidder feine Bairffamfeit nur dem $\mathfrak{B}$ eflagten gegenïber, injofern benfelben die impositio silentii traf. (Shegen oie obermähnte (5)efahr eines ex officio angefteflten inquifitorifaten \$roceffe mar ber Infamirte oder Diffamirte damit feinesiveg gejđüüßst, uno menn, wie es viel=

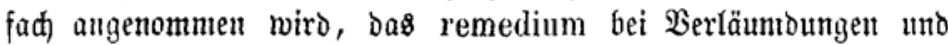

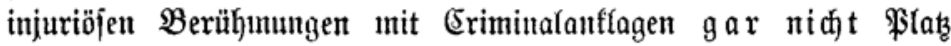
griff, fondern nur bie Snjurientfage angeftellt merben burfte, fo

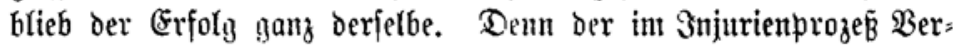
urtheilte fonnte nid)t mehr ats 2Antfäger bes borgetworfenen resp. berläumberijđ angedidteten Berbrechens auftreten, und es war ihu fomit indireft aud hier silentium imponirt. Dagegen äußerte

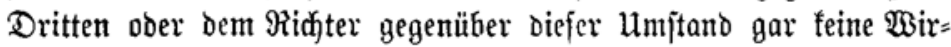
fung. - $\mathfrak{E}_{8}$ jteflte jïd alfo eine $\mathfrak{A}$ rt süde heraus, indem die

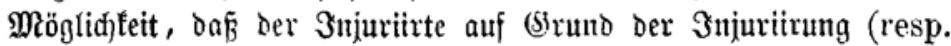

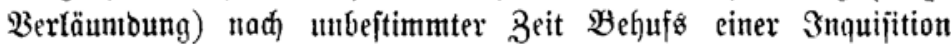
vor (5erid)t gezogen werden founte, unläugbar borthanden war,

34) Diefes (d,mierige Thema fann hier unmöglid meiter berfolgt merben. (E\& muß hier auf bie Sdrriftiteller, bie bajifelbe umfaffenb behandelt haben, ber. miefen merden, namentlid, Th. Muther: Die Diffamationsflage, in ben Beder

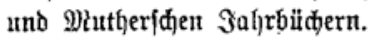

3twar toirb bas remedium ex L. diffamari in $\S 28$ auserïffid ba als

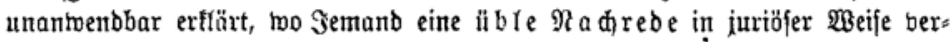

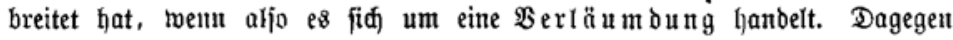
finb, und zumal in fritherer Beit mande 3tweifel erfoben. Fïr Berüfjmungen bie in judicio vorgebraht find, ift bie Antenbung bes remedii berbitrgt. Baldus in Der Margarita ad Innocentiam sub verb. Silenti um. - Si vero diffamo de crimine, et hunc . . in judicio aliquem diffamo, et debet mihi terminus assignari ad agendum. - - - 
ohne baß ihm zur Borbeugung berjelben irgento ein Mittel zu (Se= bot gejtanden hätte. - Eben diejes ßräjerbatio nun bot fid in

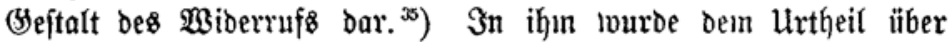

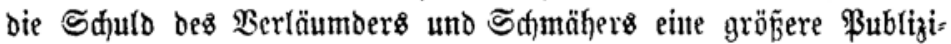
tät verliehen, und ben Beridtseingefeffenen bic Borftellung in= finuirt, baß̧ ber Berläumbete unf

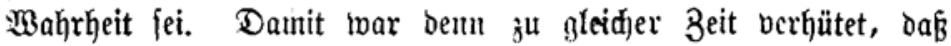
aus jener $\mathfrak{B e r}$ (äumoung ein (5erücht entitände, ober, two ein foldes bod) fdion aufgetaud̦t, demielben bei 3eiten vorgebeugt. - Man

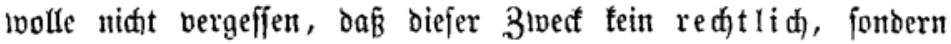
nur faftifd) anerfannter twar. (Es foll hier nicht etwa ber (bes jiatspuntt angegeben merden, bon bem aus bie Entftehung bes Wiberrufs zu beurtheilen fei, nod) felbịt ber (stumb zur Einfüh)= runty in bie (Serid)te; vielmehr joff in bem 2ngedeuteten lebiglid auf einen Buntt ljingewicfen werben, der bie Berbreitung, fo zu jagen bie Borliebe bes $\mathfrak{B}$ oltez für die Forderung auf $\mathfrak{W}$ iberruf ertlärtid) madte.

Nadjoem wir jo nod) biejenigen Umitände einer turzen $\mathfrak{B}_{e}=$ tradtung luntergogen haben, weldhe bei einer 21ufuahme unjeres

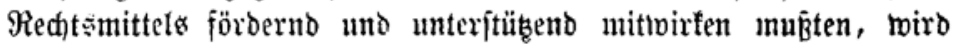

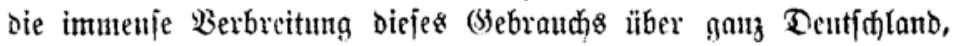

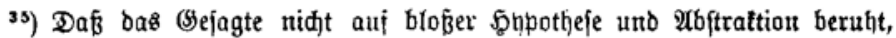
betweift menigftens eine Stelle: A b r. S awr: Straffbud, bas ift grünblide

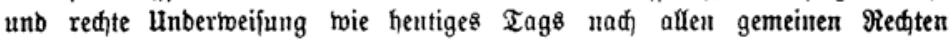

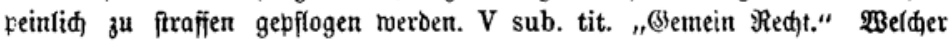
aud offentlid einen 2 ntbern mit 230 orten ober Berfen efremrithrig angreifit, fáilt, läf̧tert und fámähet :c. gegen ben fol gleidjergeftalt ex 1. diffamari C.

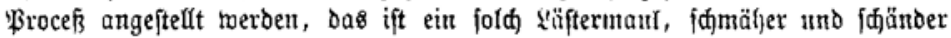

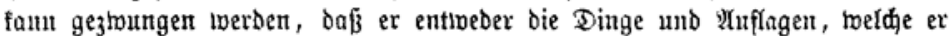
unter bie \{eute gebrađt, ljin unt wieber anşgeiprenget uno rüd,tig gemad, $2 c$. probice... wie Redt ift, oder aber, im Fall er bas nit thun tann, alobann einen öffentliden $23 i b e r r u f$ ober ent\{dulbigung bem Serleumboten thun, um Serzeilung bitte, und feil Maul zur lïgendajoe made."

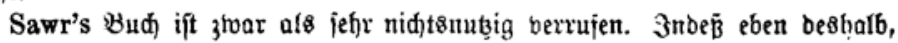

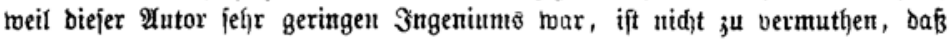

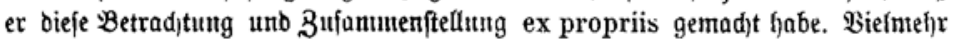

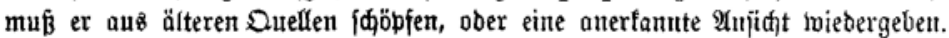

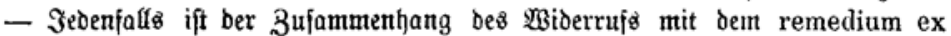
1. diffamari woht tlar uno entipridgt ber in Ter̨t gegebenen (Erlüuterung. 
Stalien, Spanien 2c. 4 3ahrhumberte hinourd) begreiflider er: fdjeinen.

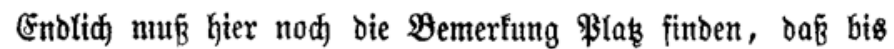
3u bem Ende des Zeitraums, bon bem wir bisher hantelten, bon einer feften Terminologie nod) nirgends bie Rebe ift. Die jesst

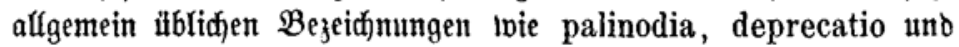
honoris declaratio finden fid gar nidt. Diefelben fino fpätern Uriprungs, uno erjt mit ber fpäteren Puffiellung von Unterichei: oungsimerfmalen in Bsebraud gefommen. Darüber unten. Das

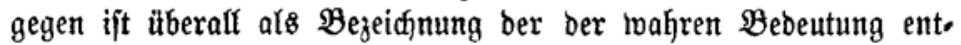
iprectjende und dem Uriprunge gemäß乃 eigentlich als technifd zu bezeidjnente $\mathfrak{A}$ usbrud restitutio famae und satisfactio famae (od. honoris) beibehalten.

Cap. IV.

Dokfrin und Öraxis von ber Garolina bis auf die getżtzeit. \$difuks.

Wenn aud in ber borliegenden 9 rrbeit bon bem Erfdeinent Der Carolina getwifiermaß̧en eine neue ßeriobe batirt werben faun, fo hat biejes bod feinesinegs barin feinen (Hrunto, baß etina neute

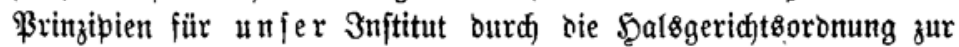
Bseltung gebradft toären, uno bamit eine neue Entlotcfelungsphaje für baffelbe heraufgeführt worben twäre; viełmehr fnüpft fid nur infofern ein befonderes 3ntereffe an bie constitutto criminalis, als burdf fie ber $\mathfrak{B i d e r r u f}$, ber bisher nur auf Betwohnheit bes ruhte, legalifirt wurbe. ${ }^{1}$ )

Dáa aber ber $\mathfrak{B}$ iderruf wirflich in ber Carolina eine Stelle gefunben hat uno anerfannt ift, unterliegt feinem 3meifel, wietwohl

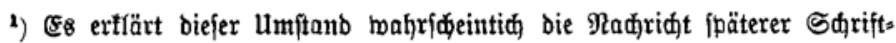

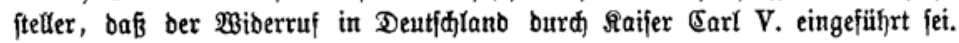
Qgl. bie Finl. a. (E. 
biefes Bielen nidt nur entgangen, fonbern fogar bon ihnen bes ftritten ift. ${ }^{2}$ ) Der $\mathfrak{A r t .} 216$ beftimmt $^{3}$ ):

So aber eyn foldder äberfahrer bejtimter Beld Been nit vermöd)t, ber foll im ferfer alfo lang geítrafft wer= ben bis er bem berresten nottürfftige entfdulbigang thuet, baß́ er jm an feinen efren bamit nit woll ge= fdimedit haben .... 2 .

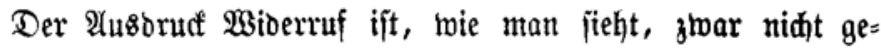

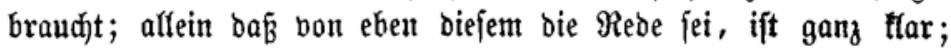
ein $\mathfrak{B l i c}$ auf bie Heferarbeitungen und Heberjekzungen ber C.C.C.

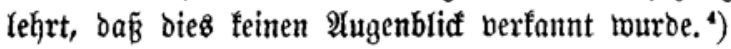

Freilid ifit in bem geoad)ten $\mathfrak{A r t}$. auf einen ganz ipezieflen Fall gerüufidtigt; betn im $\mathfrak{\text { Trt. }} 215$ fino Beftimmungeu über bie Erbauung bon Blalgen gegeben uno zugleid) eingefdärft, oaß̧ bieje

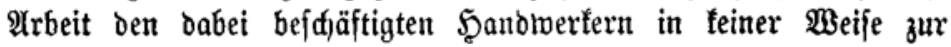
Unehre angeredjnet toerden folf. Unter ben ,"̈̈berfarern" in $\mathfrak{A}$ rt. 216 jint nun junädjit nur biejentigent berjtanden, lwelde jene ge:

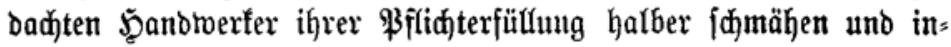

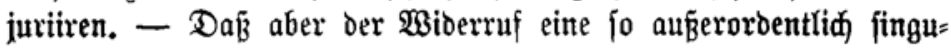
läre $\mathfrak{A n m e n t u n g ~ z u g e t w i e f e n ~ e r h a l t e n ~ h a b e n ~ f o l f t e , ~ i f t ~ g a n z ~ u n d e n t : ~}$

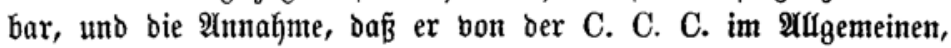
๖. h. audj für alle anbre Snjurienjadjen anerfannt fei, ijt getwi

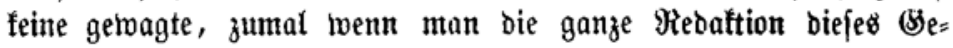

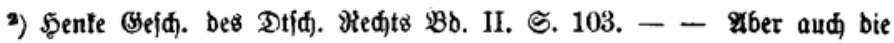
fpäter ïblidjen burd) Redtsgemohnheit mehr, ałs burd Brefes eingefïhrten, unb aus ber Sitte bes Ehrentampfes (?) felbft entiprungeneu Strafen bes

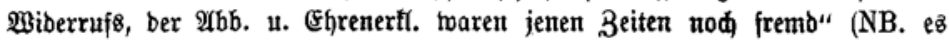
ift bon ben Strafbeftimmungen Der Carolina bie Rebe! -)

3) $\mathfrak{i n}$ ber Bambergensis finbet fich biefe Beftimmung nod nidgt. Sie murbe erft in bas 2. Brojeft bon 1529 (अrt. 224) hineinrebigirt.

4) So 3. B. bie :araphraje deళ Remus - : Si qui alteri furcam aedificanti aut reparanti factum exprobrarit .....

in vinculis tam diu detinebitur, donec laeso de injuria, quam pro more qui fecit revocabit, satisfaciat: et hoc protestetur, nolle se verba sua factave in ignominiam ejus qui aedificaverit, ullo modo cedere. - Daniel Classen. Commentarius in C. C. C. ad Art. 216 ... inque eo tamdiu detineri debet, donec laeso, per injuriae declarationem satisfecerit ....

- - S. F. v. Boehmer. Meditationes in C. C. C. art $216 \S 1 \ldots$. donec deprecatione judiciali innocenti satisfecerit . . 


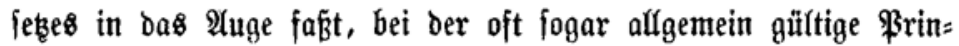
zipien gelegentlid) und in faheinbarer alleiniger $\mathfrak{B}$ zziehung auf einen befinmten Fafl abzuhandeln betiebt murben.

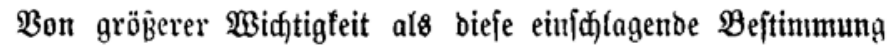
Der Carolina ijt entidjieben bie Alufnahme des $\mathfrak{B}$ iberrufs in bie Sädjiifden (Sonjtitutionen bon $1572,{ }^{5}$ ) injofern jid an biefelben bie Arbeiten breier bielgenannter Belehrten uno berühmten (Eom= mentatoren anfdifiểen: Die Berfe des Moller, Berlid uno Earpzob. Diefe aber werben loir baher einer etwas eingehen=

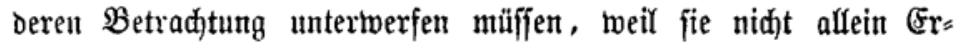
fenutniß̧quelfen für die Berhältniffe ihrer Zeit find, fondern utaß̧= gebenden Einflun auf viele forgente Decennien ausigeübt haben.

$\mathfrak{B}_{0}$ diejen breien num nimmt $\mathfrak{M o l l}_{\mathrm{er}}$ einen exceptionellen Stanopuntt ein, twähreno $\mathfrak{B e r f i d}$ uno (5arpzob, wie meiftens, in allen ivejentlidyen Bunften übereinftimmen. Der unlö\&bare

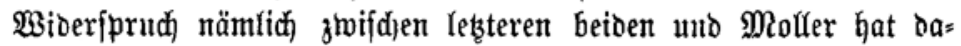
rin feinen (Srund, daß̧ biefer bie actio revocatoria für criminalis

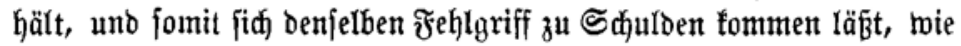
fđan meiland Maranta. Bon feinen $\mathfrak{A}$ rgumenten (beren er bei= läufig nur negatibe bietet) berbient ein einziges einige 2 Uufmert=

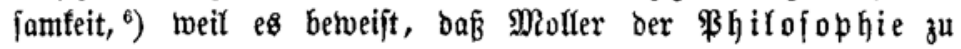

5) Pars IV Const. 42. Bon Sujurient. - "Radjbem trir bann erinnert,

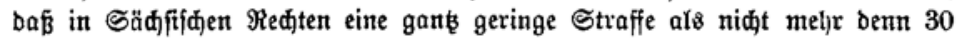

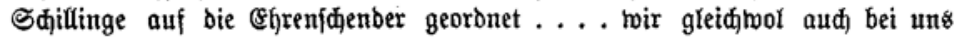
ertwogen, Daß̉ ber orbentlichen Dbrigteit gebühret efrrliebenben Seuten burd) ges orbnete Straff ihrer (E)re Ergetsung 3it thun (vers. lat. „ut legitimis poenis in injuriosos statutis existimationi virorum honestatem amantium sa-

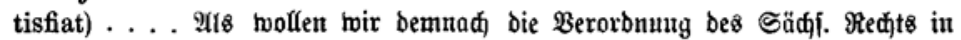

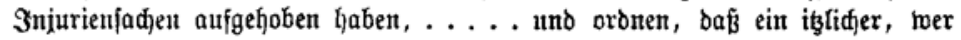
Der aud were, fo frebentlider und borfebelider tweife ben andern .... an Efren fđmähen, idjenten und injuriren und berhalben red,tid beflagt mürbe, Dem bejajmerten unb injurirten Theil, nad) Befindung ber unjchulb einent of fentlidjen wiederrufi für Beridjt ju thun fojulbig fein foll."

6) Daniel Molleri. Comment. in Ordin. et Constit. Saxon (gefdrieb. 1599) Pars IV Const. 42. in $\mathfrak{x}$. 6. - Nec me quicquam movet, si quis objiciat, imo cum, qui petit reum ad revocationen illatae injuriae condemnari, omnium id maxime agere, ut honor sibi ablatus, qui nullo pretio nummario aestimandus est, ante omnia restituatur etc.,

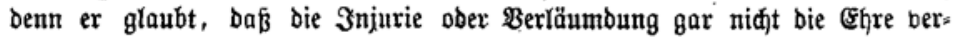
ringern fann. 
Riebe die Brefajidjte berläugnete. (Fr befanto fid nidjt mehr auf Dem Stanopunft ber Sdjolajtifer, weldye glaubten, honorem auf-

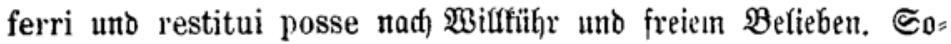

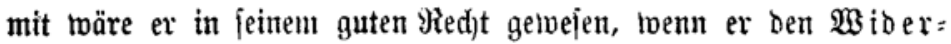

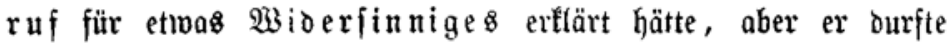
nidjt bie Ratur beffelben verläugnen, bie ihm in bem hijtorif́den Faftum jeiner Entftehung inprimirt tworben toar.

(5in widftiger ßunft, ber in Moller's Eommentar ebenfalls berührt ift, erforbert hier jeine (Erledigung, aber zugleid) hohe $\mathscr{A} u$ f: merffamfeit. ${ }^{7}$ )

Wir haben im Berlauf unjerer obigen Unterfuduung gejełen twie bie urfprünglid heterogenen uno felbiftîtänbigen EYemente ber

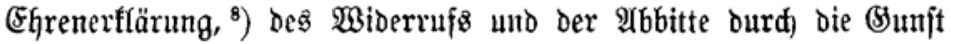
befonderer Berhältnifije in ein (S)anzes zujammenfloffen. IAber

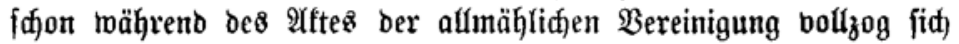
aud gradatim bereits eine neue Trennung, freilid nad) neuen Prinzipien. Dic iprengenden fieime jint in ber nationalen Ent=

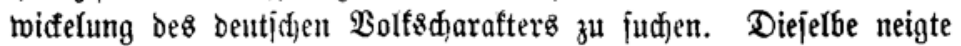
befanntfich bon früher Beit zu einer Stäntefeparation hin.

Auf dem $\mathfrak{B}$ oden bes focialen Berfefrrs mie auf Dem Bebiete

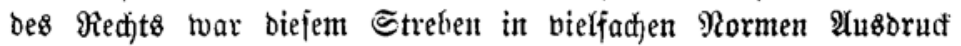
und Realität gegeben.

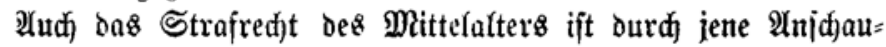
ungen reidflid beeinflust, uno nod) die Carolina 3 . $\mathfrak{B}$. unteriheibet bei ben meif́ten Strafbejtinmmungen forgfältią zmifinelt ßerfonen

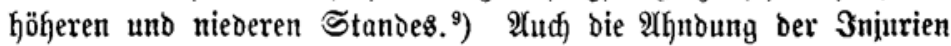
muşte nothwendig nad) biejem (Sepidjtzpuntt ljin eigenthümtidjen

$\left.{ }^{\tau}\right)$ Moller 1. c. Nr. 8. Quaestionis autem est, an poena recantationis, ut vocant, seu revocationis publicae in injuriantes ab Electore statuta in nobili locum habeat injuriarum convento a Plebejo - Nr. 9. 10. 12 . -

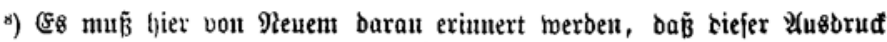

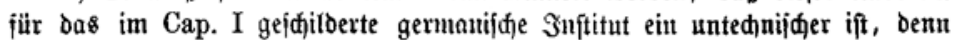

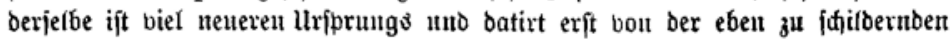

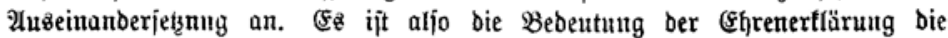
berfelbent in biejer 9 rrbeit bisher beigelegt murbe bon ber befounten unb unten oft vortommentent fiteng $3^{\text {u }}$ fondern. -

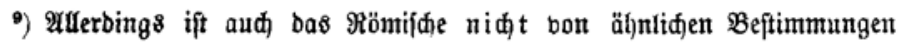
frei gebliebent, twie in Bejutg anf illustres, nobiles, liberi, servi etc. 
Modifitationen unterliegen. Atber hier war es gerabe, two bie Recttsbildoung nidft mit ben gefteigerten $\mathfrak{A}$ nfforberungen bes groß̧en Bolfsborurtheils Sdjritt halten fonnte. Dieje Differenz führte, twie ridftig bemerft worben, zu bem "Sultus bes Dueffs." Diefes Reparationsmittel, obgleid) nod) bis heutigen Tages nidjt außer Cours gejest, mußste bod) bon 2 nfang an mit bem $\mathfrak{B e j e n}$ ber Staat8oronung als unberträglid erifdeinen, uno Reaftionen ber Staatsgemalt herbeiführen. Diejelben bethätigten fid aber,nidht

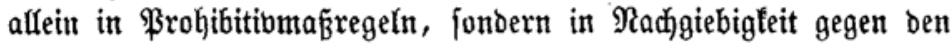
Drang der Nothmendigfeit, in 3 ugeftänoniffen. Snjofern bie

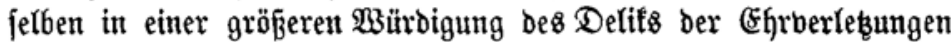

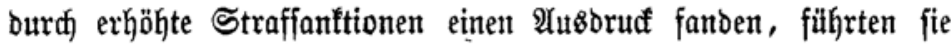
audh zu alfgemeinerer $\mathfrak{A}$ ufnahme und gefesfidjer $\mathfrak{A}$ nerfenmung bes

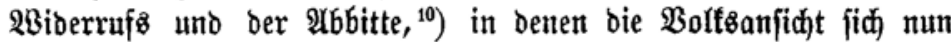
bod) einmal getwöhnt hatte, eine Strafe zul finben. Antorerjeits hätte aber bie gleidjmäßige und unterfajiebloje $\mathfrak{2} n$ twendung biejer Boen auf alle $\Re a n g=$ und Standesflaffen ber Bebölferung feine Befriebigung gewährt unb in ben feparatiftijđen $\mathfrak{B}$ ejtrebungen $\mathfrak{A} \mathfrak{n}=$

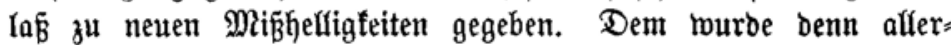
bings borgebengt, aflein burd, ein Mittel, meldjes nur zu jehr

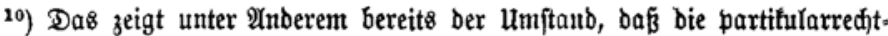

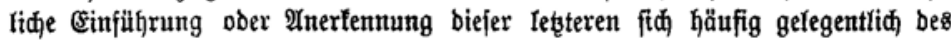
Erlaffes bon Duellberboten ausgejproden findet, fo 3. $\mathfrak{B}$. in ber Constitutio Ernesti, ducis Saxoniae. Sotha bom 4. Sept. 1646 - Ebilt Friebrid Bilhelm's, Marfgraf zu Branbenburg. (5egeb. Riönigsberg Den 22. Suni 1657. - Namentfich aud in bem, feiner Bebeutung fitr unjre \&efre nach ftet8

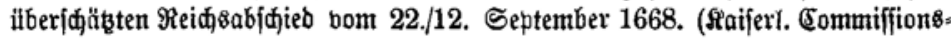
befret bei Sentenberg IV S. 56).

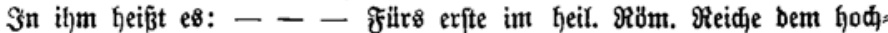

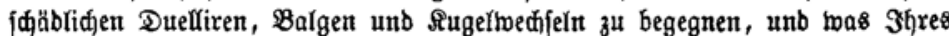

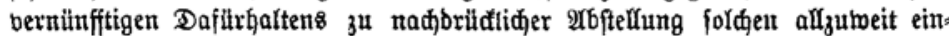
geriffenen undfriftliden Beginnens, fitr eine burdgehends ernftidje Berorbnung

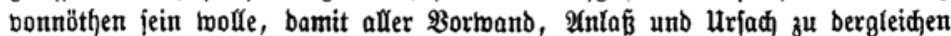
Erceiffen benommen unb bas frebelmitthige Sdqmähen und Snjurïren, als ber

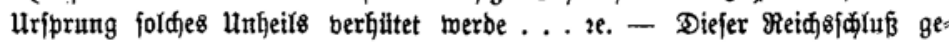
langte nidt zur ßromulgation (G. I. F. Meister princip. jur. crim § 184). Sebenfalfs if̣t er für bie Enthidelung unferes Snftituts bon gar teiner

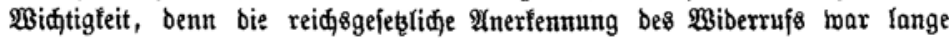
borher burd bie Carolina (f. ob.) forwie burd bie Rammergeridtsorbnung 1555 Th. II Tit. 28 \& 4 exfolgt, unb in ber Sadje felbft bietet er nidts Reues. 
geeignet war jene $\mathfrak{H m f o r m u n g}$ zur $\mathfrak{B}$ ollentoung fu bringen, bie fid im Rauf ber Beit mit ben uriprüngliçen Satisfaftionsmitteln bor bereitet und theilmeife bollzogen hatte. - Es beftand barin, då eine neute Tremung und genaue Sdjeibuta zwifhen Eghrenerflä= rung, Widerruf und Abbitte borgenommen murbe; aber weit ent fernt, daß biefelbe auf eine ridftige $\mathfrak{B}$ üroigung hiftorifaer Ent= jtehungsoata bajitt worden märe, fo boflzog man biefeltbe vielmehr mit Šintanfe(zung, nidjt allein genetifd)er Momente, fondern felbjt ber naturalis ratio, nur bem (Sefid)tzpunft einer prattifajen $3^{\text {toed }}=$ beftimmung zur 2ltsfülllung einer \&ülfe folgeno. -

(Es ijt oben in Cap. III gezeigt, wie ber $23 i d e r r u f$ fict auth in fofern Yeid)t mit ber altyermanifd)en (shrenterffärung bermijị̆te,

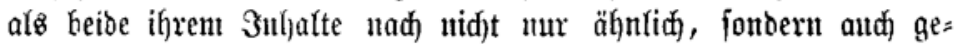

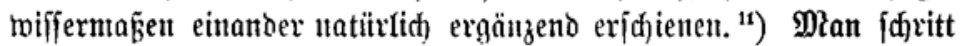
nun zu cimer neuen 2 frseinanderfebung, indem man beiben eine hejonbere Formel antwies, dic $\mathfrak{A b b i t t e ~ a l s ~ f e l b j t i t a ̈ n o i g e s ~ D r i t t e ~}$ daneben ftellte, uno jich jo bie Mlöglidffeit veridaffite eine getwiffe

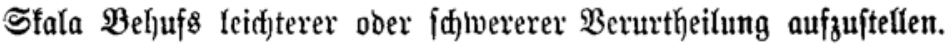

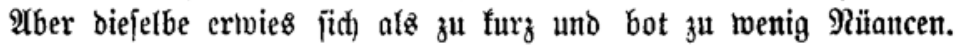
Man fanto aud) bafür eine $\mathfrak{A}$ tıfinnft. Bermittels gelviffer, bei ber Abreiftung ein ober bes andern jenter Satisfaftionsmittel zu beob= adftender Frormalitäten und Solennitäten erzielte man 2 (6jtufungen, bie fid) burd) (5ombitation beliebig vermehren ließen.

Run hatte ber Ridyter Spielraum genug, innerhalb beffent er

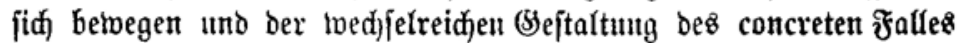

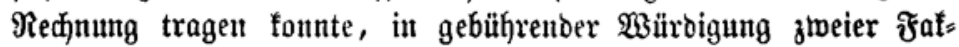
toren zugleid): ber Stanbesverificbenheit uno ber Sntenifi= bität ber Эnjurie.

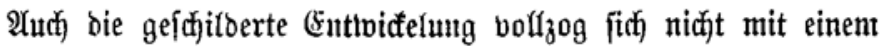

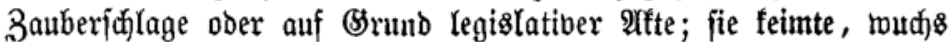

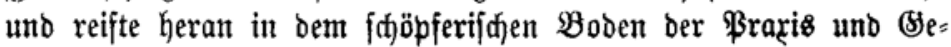
wohnheit. -

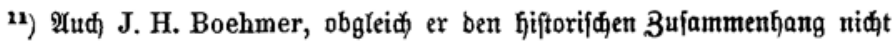

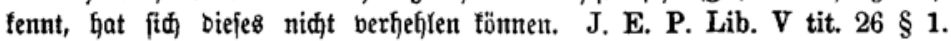
- Quamvis cuique deprecationi ut plurimum haec (sc. palinodia) tacite insit, non sine ratione tamen (?) creditum fuit, eam quandoque expresse deprecationi ... . addendum ut eo efficacius livida et mendax lingus mledicentis coerceatur. - 
Die erften Spuren babon finben fid bei Paris de Puteo $;^{12}$ ) bon ba an ift fie in ftetem Fortid)ritt begriffen. Dagegen greifen

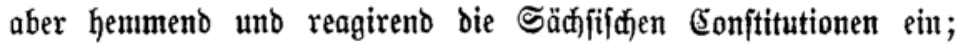

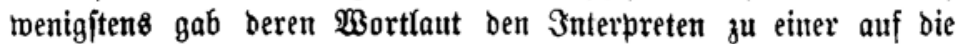

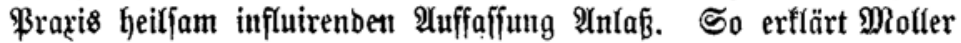
(a. a. D. $\Re$ r. 8.)

„Quaestionis autem est an poena recantationis, ut vocant, seu revocationis publicae in injuriantes ab Electore statuta in nobili locum habeat injuriarum convento a plebejo? ? $^{(13}$ )

Ex referirt nun, baß̧ biefes zloeifelhaft, an bielen Drten wie

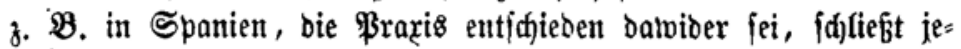

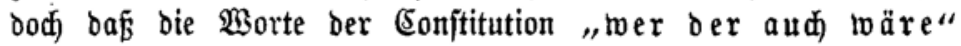
jeben Unterfajied ber ßerfon aufgehoben miffen wollten, unb ex finbet diejes baburd begründet, baß̧ mur bei arbiträren Strafen

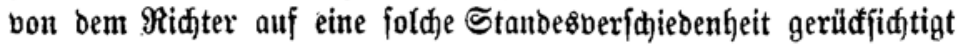
werden fann, nidft aber in poenis uniformiter, certe, determinate, indistincte et indiscriminatim impositis, ut est revocationis." Sontit war benn freifid) das Moment ber Standes"

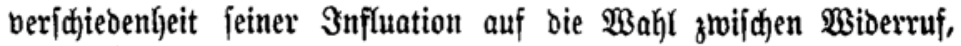
2bbitte unb (Ehrenerflärung beraubt; ${ }^{14}$ ) Damit war aber bie $\mathfrak{A n}=$

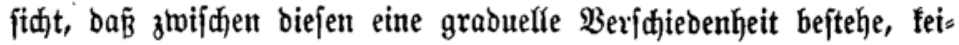
neต́weg̨ befeitigt; bielmefr wurbe beren $\mathfrak{B}$ edeutung ftets aufrecht

12) Paris de Puteo a. a. D. $\mathfrak{N}$. 6 in fine $--\ldots$ Ubi autem esset offensa personalis et enormis, ut quia quis fuisset pulsatus pugno quae gravis est injuria .... et vellet fieri satisfactio debet fieri cum ignominia ipsius offendentis et graviter sicut fuit delictum. $\Re$ r. 7. Nam quia poena est satisfactio delicti . . . . debet ipsa poena proportionari delicto .... erit ergo satisfactio quod delinquens juxta qualitatem injuriae satisfaciat. 9 r. 8 . Nam si fuit vir humilis qui nobilem verberavit fiet satisfactio curiae gravior, quia cum bastonevel cum laqueo in gula ad pedes offensi et per totam civitatem dicalciatus veniam petendo .... গr. 9. Si nobilis par et non provocatus non fiet cum tanta ignominia, sed flectere se debet ad illum cum corrigia in gula . . . etc. -

13) $3 g r$. au山 Mat. Berlich. Conclusiones practicabiles ad ord. Constit. Saxon Pars IV Const. 62. § 28-32.

16) D. 8. gefetglid. In praxi hat biejelbe fid trobzbem lange Beit hinburd weiter erhalten. 
erhalten unb bei ber Strafzume fijung in $\mathfrak{A}$ njiflag gebrad,t, ${ }^{13}$ ) nur

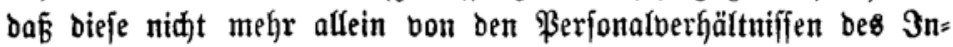
jurianten uno Эnjuriitten ab̧ängig war.

Rach den bielfadjen \$hajen, bie im Berlaufe ber Beiten unjer

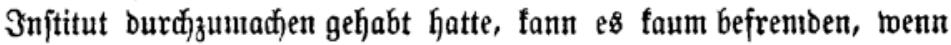
bie lekste Beftaltung deffelben bon ber primitiben fo abtweidfend fid) herausgebilbet hatte, baß bieje in jener nid)t mehr erfennbar war. Der regulären uno naturgemäß̈en Entwiđetunt nad, hätte bie altoeutidhe Ehrenertlärung mit Umgeftaltung Des alten ßroceß $=$

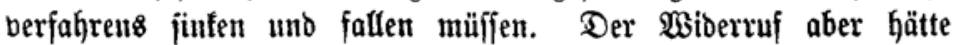
vielfeidgt ein längeres Dafein friften tönnen; mit einer befferen Renntnis auf philojophijder (S)runolage über bas wejen ber Ehgre

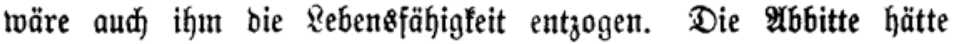
fid) nod) aut leidftejten bem mobernen Strafibitem eingefügt und Den Charafter, ihrer 3eit in groperer Mannigfaltigfeit bejtehender, Ehrenftrafen angenommen. Mit beren 2 uffhebung in bent neueren Bsejesbüchern toäre aud) über fie geridytet. Statt beffen bedurfte

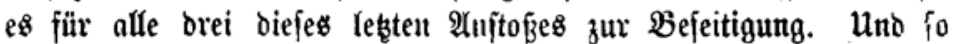
lange twaren 3 rtthümer Der beridiedeniten $\mathfrak{A}$ rt bie Träger eine\& auf fehlerhaftem Fundament erbauten (\$) bättoes! -

Die Theorie bout ben Brivatbeliften hat befanntlid in Deutid = lanb nie Eingantg gefunden. Dennod) ift nidht zu läugnen, bẩ grabe bie Snjurie in bem Strafredt cine anomale Stellung be= hauptet, die bon gewififen Momenten in ber Ratur eines Bribat=

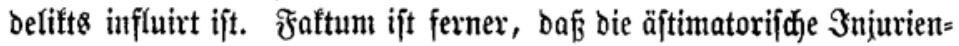

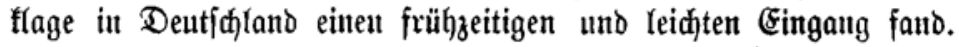

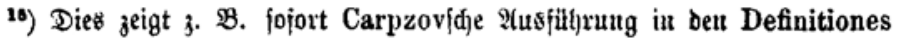

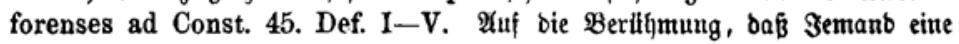

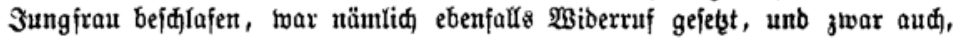
menn ber animus injuriandi jelfite (alfo eigentfid teine 3njurie borlag). Nur

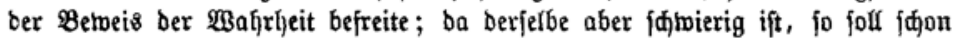
im Falle bie Sadje wahrideinlid) gemadjt ift, bie recantatio in eine depre-

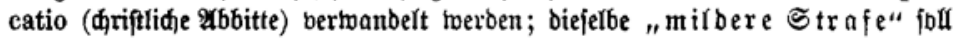

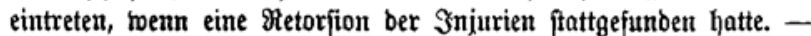


E\& fann hier nidjt ber Drt fein, um biejenigen Borbebingungen unb $\mathfrak{B} e r h a ̈ l t n i f f e ~ \jmath^{u}$ beleuthten, bie biefen $\mathfrak{A} f t$ ber Reception auf eine ungemeine $\mathfrak{W}$ eife erleidterten unb befofleunigten. Bsenug: fie bollzog fid , bamit berfnüpfte fid) aber eine weitere Folge:

Die $\mathfrak{B r i b a t j t r a f e}$ war für bas beutifje Strafredjt, twenn aud) nur für einen einzeluen Fall gegeben. Atber bie beutiche

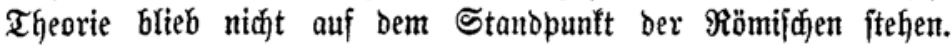
Sannte bie leştere als Objelt der Pribatitrafe nur bselb, fo ge=

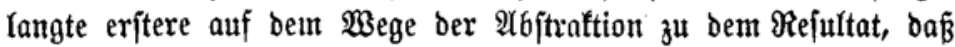
es auch anore Reiftungen geben fönne, bie, indem fie parti, n on fisco applicantur, fïr ben Reijtenden felbjt ben sharafter ber Pribatjtrafe annähme. ${ }^{16}$ )

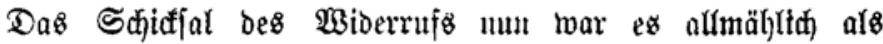
Pribatjtrafe aufgefaß̧t zu meroell, unt wenn bir bertäugnen

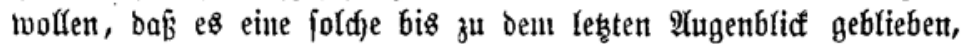

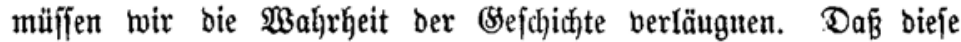

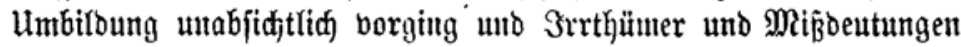
zu Urhebern gehabt hat, ifft rafhr, ändert aber am Picjultat Midutb. ${ }^{17}$ )

Bei theologifden Sdjriftitellern hat jidy bas Betwustipein ber

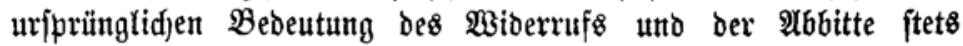
erhalten; ${ }^{18}$ ) aber aud bei ben 3 uriften hat fid bie Senntnif ober eine arfnumg bes Ridjtigen lä̈tger erhalten, als mau zu glauben geneigt fein follte, und erjt in bein lebeten $\Im a h$ hrhunbert ift in Folge

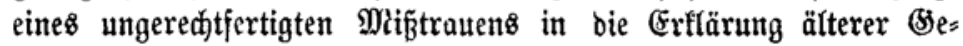
Yehrter ber Faben, ber zur Wahrheit leitete, berloren gegangen.

16) 3 in biejer Bezieh)ung berweife id auf bie fehr ridtige Bemerkung in Puther'\& Diffamationstlage a. a. D. S. 124.

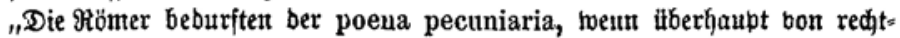
lidjer Berfolgung eires Bribatbelitts über ben Scjabenerfaţ hinaus . . . Die

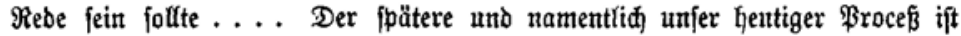
in biefer Beziehung freier entwiđelt, roir tönnen zu allen mögliđjen ફ̧andlun. gen - mögen fie einen Belblwerth haben ober niđjt - conbemniren."

${ }^{27}$ ) In eben biejem Rejultat ftimme id alfo mit Muther a. a. D. unb Den bort (Sitirten bollftändig Hberein. Nur ift niđjt zu bergeffen, baß̄ biefe

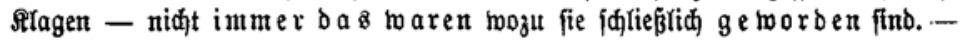

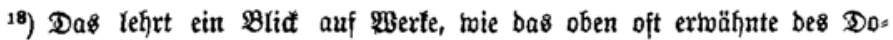
minicus Soto unb bie Roten bes Eajetanus zи Thomas b. Iquino. 
Bir müffen im Befits ber nummehr bißher gelvonnenen $\mathfrak{R e}=$

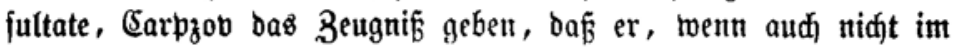

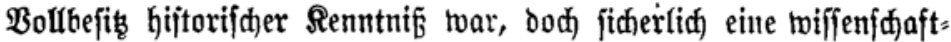
(id) ridtige $\mathfrak{B u ̈ r b i g u n g ~ b e r ~ S a d j l a g e ~ e n t m i d e l t ~ h a t , ~ b i e ~ i m ~ h o ̈ d ) = ~}$ ften Brabc auterfennenstwerth erfdeint. Bunädift verwirft er mit

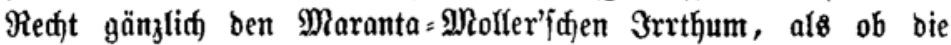
actio apalinodiam criminalis jei, inbem er jid für bie Matur ber Pribatitrafe erflärt. ${ }^{19}$ )

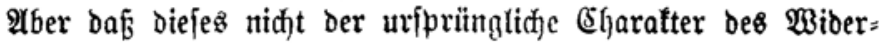
rufs gemejen, ift ihm nidht unbetautut; er bermeif't ausorüdflid

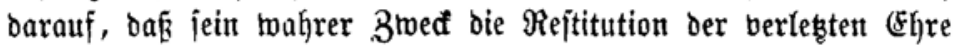

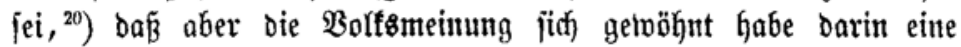
Strafe zu fehen.

$3_{\mathfrak{n}}$ einem Bunfte mur miiffen wir unfere 3 uffimmung zu ben bon Earpzob entwifelten \$rinzipien beriagen. Es ift bies bie Erledigung ber Sumulationsbedenten, bie über 3 Sahrhunberte

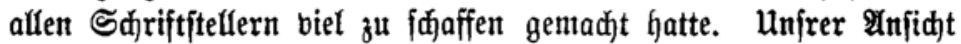
nact) fintet bie Frage in folgenter $\mathfrak{B}$ etradtung eine einfadje $\mathbb{R} 0$ = fung: So lange fid) ber $\mathfrak{w i d e r r u f}$ ben (Eharatter einer restitutio beffen, เoas dem 3niuriirten burd bas Delift entzogen war, bes wahrte, fonnte bie Mëglidffeit einer (sumulation jomohl mit ber öffentlidjen, als auth mit ber Bribatjtrafe ${ }^{21}$ ) teinem bejonderen $\mathfrak{B}_{e}=$

19) B. Carpzov. Practicae novae imper Saxon. rer. crim. II. Quaest. 94. No. 51. utpote quo omnis illa actio, qua poena petitur applicari parti non pro criminali, sed pro civili habetur. Quale et hanc actionem esse, negari nequit.

Ebenio Def. for. 6. IV. Concl. 42. Def. II. No. 1.

20) Carpzov l. c. No. 15. Haec. actio ad palinodiam proprie poenalis non est, ac licet ita appellitetur, interesse tamen privatum partis offensae concernit, cujus honor et existimatio per revocationem restituitur.

Nam qui petit reum ad revocationem illatae injuriae condemnari, omnium id maxime agit, ut honor sibi ablatus . . . restituatur.

Def. for. 1. c. Def I. No. 6. Def II. No. 1. Def. XVI. No. 11. Quin et per recantationem sive palinodiam famae existimationem restitui, nemo facile denegaverit, et probavi id modo ex h. ipsa Const. 42 verb. "Shrer ç冖ren Ergetzung zu thur."

21) Man menbe bagegen nidit ein - baß̧ in biefer bođf eigentlidf fđjott eine Bergïtigung für ben gehabten $\mathfrak{B e r t u f t}$ enthalten gemefen fei. Da fie

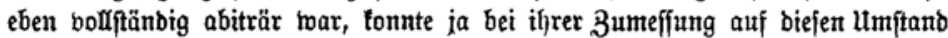


benfen unterfiegen, ba ber Sdabenerfaç ftets a ü Ber ber Beptra= fung zu berlangen ift. War biefer Egarafter aber eimmal in Den ber Bribatjtrafe übergegangen, fo muß̧ten nun comjequenter $\mathfrak{B s e i j e}$ aud bie allgemein gültigen $\Re$ egeln ïber die Cumulation in $\mathfrak{B i r}$ famfeit treten, b. h. ber $\mathfrak{B i b e r r u f}$ fonnte ber $r i d t i g e n$ Theorie nad) $\mathfrak{n} u r$ mit ber Pribat = nid) $t$ aber mit ber öffentlidjen Strafe cumulirt werben, ${ }^{22}$ ) ebenfo twie bie äftimatorijde 3njurienflage, von

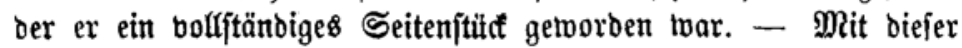
Entideidung iteht bie Earpzob's in Wiberiprud. (Er glaubt bie Eoncurrenz (und ztwar, fimobon nur bie Rebe, bie cumulatibe) mit ber äftimatorifajen uno ber (Eriminalflage gleid) zuläffíg. ${ }^{23}$ ) Man

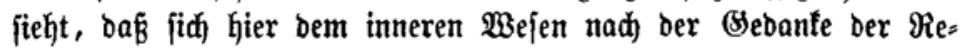

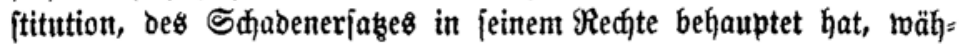
reno dod bas ftraflicje Moment äußierlid feitgehalten inerden follte.

um die in ber That unlö86are Differeng zu bejeitigen murbe ein Brincip aufgejtellt, bas gegen bie gemeinrecttidy anerfannten Yiegeln ber Slagcumulation verftöß̈t. Eine andere Auffaffung hat zlwar (5arpzob jelbit in ben Definitiones forenses niebergelegt, ${ }^{24}$ )

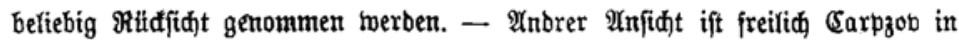
ben Def. for. 1. c. Def. XVI. Bgl. untent bef. not. 24.

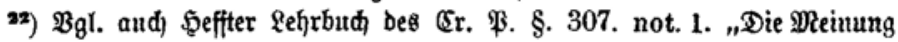

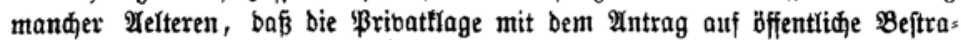

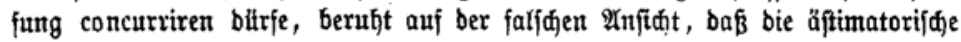
Intlage rein perfetutorifd fei." $\mathfrak{B g l}$. oie borige not. «. 1. 6. D. de injur.

23) Carpzov. Practic. nov. I. c. No. 32. Alterum, ad quod injurians obligatur, poena est. Non enim sufficit, reum injurias revocasse, sed et praeteria is poena pecunia vi vel carcere, vel relegatione pro arbitrio judicis puniatur. Cu i n on obstat, quod hac ratione injuriarum reus vis puniatur.... cum tamen nemo ab unum delictum poenis sit affligendus pluribus. -

No. 33. - Etenim istud tum demum verum est, quando utraque poena ad eundem tandem effectum, unaque poena delictum sufficienter est punitum. . Palinodia vero, si proprie poena appellanda est, privatum interesse offensae partis, existimationem scilicet et famam concernit, utramque igitur poenam subsistere atque concurrere haud mirum est.

$\left.{ }^{24}\right)$ Def. for. 1. c. Def. XVI. No. 5. sq. No. 9. - - Perinde ergo faceret injuriatus ad utrumque agens, ac si quis equi, sibi ablati restitutionem ac simul ejusdem aestimationem petere vellet! - Man bers gleiche bagegen 3. 28. ein Confitium in Responsor. sive consilir . . tomi duo (Tom. V. sub titulo Resp. sive consil. juris Dr. Laurentii Kirchovii 
bie aber teine glüffichere gettant toerben fann, ba fie fogar nod)

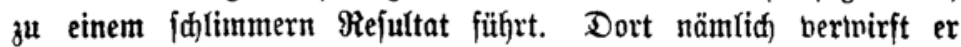
bie Cumulation mit ber actio a estimatoria, auf ausbrüf= lidje Berwahrung hin aber nidgt ats bem srunde, weil bie actio revocatoria poenalis fei, ,sed quia utraque petitio, palinodiae nempe et aestimationis privatum interesse concernit, satisfaction em nempe pro injuriis. E\& faun hier zur Ertwiberung auf bas oben in not. 21. 22. Ssefagte bertwiefen twerben.

$Z^{\mathfrak{u}}$ bemfelben Sajluf gelangt aud Berlic, ${ }^{25}$ ) obgleid auf einem andern - freilid be: quenteren Bege. Er modte bie Sdivierigfeit bei Enticheibung

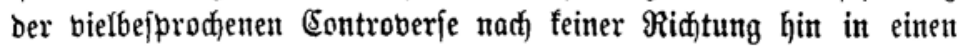
Biberiprud) zu gerathen, erfennen. Ebenfowenig lag es in feiner

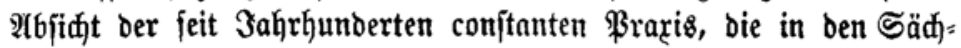

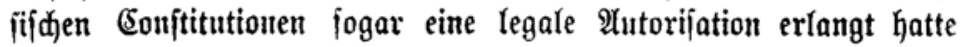
burd) eine neue (menn audf affein ridftige) Theorie bor ben Ropf

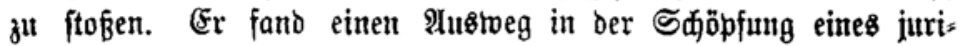
ftifden Unbings, bas leiber nad ifim nod in ben Seöpfen felbfft von Männern wie Feuerbaa ${ }^{26}$ ) gefpuft hat.

(Er erflärt nämlich, ber Streit über bie (Sumulation fei num fdjon lange geführt, ogne zu einem Rejultat geführt zu haben, in bent bie 2Anfidften nod immer getheilt jeien; und fährt bann fort: Verum mihi rem paulo penitius (?!) intuenti longe aliud sta-

Francof. ad Moenum 1578). Consil. IX. No. 32. 33. - - Actionem injuriarum reclamatoriam cum civili quoud aestimationem injuriae agitur, cumulari posse, tradit Jo. Berber in viatore seu directorio juris .... etc. Diefe Stelfe (Joan. Berberii Aurea practica sive viatorium jur. P IV. rubr. 1. de judic. No. 102.) ifit obelt in Cap. III. not. 25 bes reit\& miebergegebent. Sie enthält eit ßfagformular, in bem and äftimatorifđe

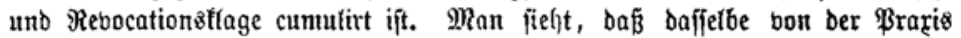

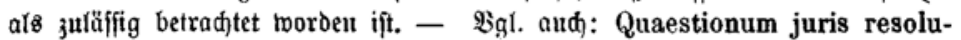
tiones et decisiones B. II. Ursellis. 1601. Pars IV. Quaest. 62 in fine.

2s) M. Berlich. Conclusiones practicab. 1. c. No. 13.

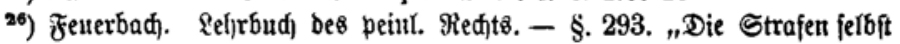

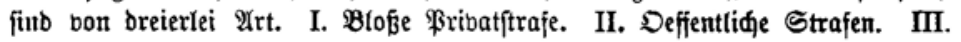
Bemifde ober refatib öffentlide Strafen."- - \&. Marzall. Das

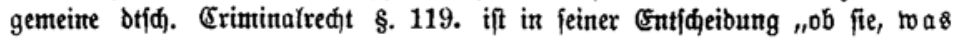
wo $\mathfrak{l}$ bas $\Re$ idtigere ift, eine reine Bribatgenugthuung für ben Snjuriirten bezweđten, ober gemifate öffentlide Strafen, aud zugleid eine öffentlidje Ufhnoung ber Injurie enthalten“ - nidht beftimmt. 
tuendum videtur, dicoque quod actio ad palinodiam sit a civili et criminali actione injuriarum prorsus separata, et quodammodo mixta, et cum utraque actione compatibilis. - - - quia ejusmodi recantatio injuriarum peculiari favore injuriati, propter restitutionem famae et honoris, in odium injuriantis est recepta. Quae autem peculiari favore sunt inducta, cum iis, quae a jure scripto sunt disposita, non sunt confundenda . . . . etc.

Es ijt $\delta a s$, wie man fieht, cin bifliges Raifonmement, $\delta a s$

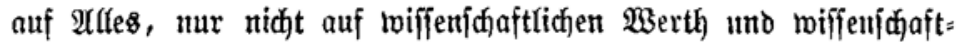

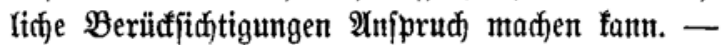

So war bent aljo burd) biele Bemithungen, burd) mandhes Fitr= nub Daribiderreden tweber bie Wiffenffdaft geförbert, nod) für bie leidjt betweglidje \$raris ein fejter Boden gejdaffent worden.

Aud burdh eine neute Terminologie, bie fid in jenen Zeiten ftabilirt hatte, war ber Sadje felbit mehr geidjadet als genïzst. ${ }^{27}$ )

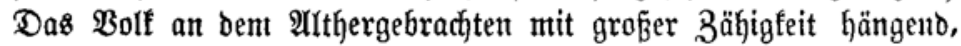

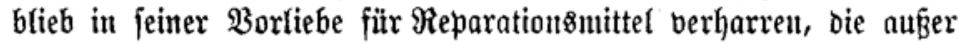

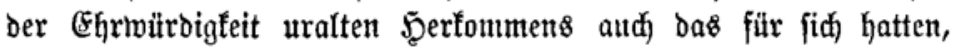

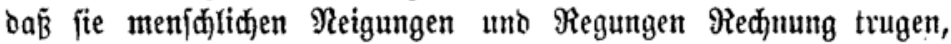
mentn biefelben aud bon bem Stanopunft ber Moral nidht haltbar genaunt werden tönnen. - Seit Rangem hatte man fid getwöhnt bas Moment ber Demilthigung in ber Atheiftung einer ber vorgejdriebenen Erflärungen, ठas boch ber $\mathfrak{B} e$ ftimmung gemäß gar nidyt barin lag, als bas Wejentlidjite jut betradjten, und bie viel= fadjen Sdjärfutugen ${ }^{28}$ ) bie man baz̆ erfunben, hatten nur gebient

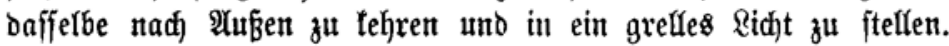
Diefe $\mathfrak{A n}$ idjaumg ift benn biejenige, bie fidh bis zulekzt erhalten

${ }^{2 r}$ ) Erf́t feit bem Entbe bes 16. Эahrhumberts mutrben nämlid bie nod heute alfgemein thbtiden Benennungen: actio ad palinodiam, ad deprecationem unb ad declarationem honoris als teduifde gebrautht. Bis bahin ift gemöhnlich nur bon einer restitutio honoris, einter satisfactio injuriae etc.

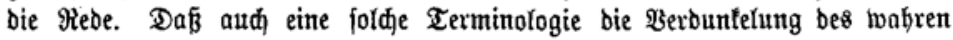

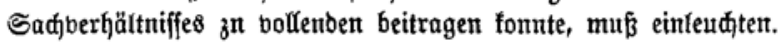

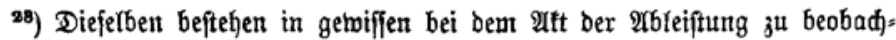

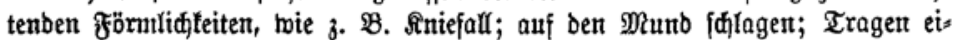

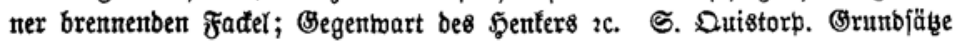
bes peint. Mecht8. §. 303. 
hat, und nod in $\mathfrak{B e b e r s}$ befannter Sdirift einen unberhohlenen

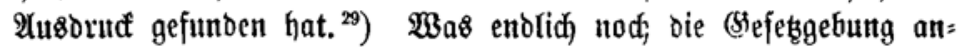
langt, bie fid) gerabe bamals auf bem (Sebiete bes Strafredts zu regen begonnen hatte, fo berhielt diefelbe fid unjerem Snjtitute gegenïber rein receptiv, wie aud) aus dem \$rototyp fpäterer $\mathfrak{B r o}$

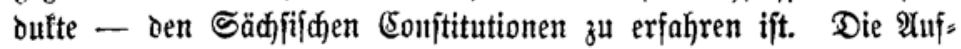
nahme des $\mathfrak{3 i b e r r u f s}$ in weitefter 2 tubdehnung empfahl jid aus red) toritifden Rüffidten, utuo jie erfolgte mit Reidtigteit,

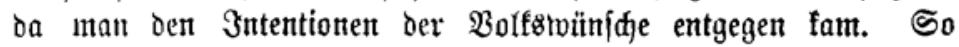
blieb bent $\mathfrak{A} 6$ fitte, Wiberruf und Egrenterflärung in leb̧aftem (stebrautch wit und neben öffentliçer uno \$ribatitrafe. ${ }^{30}$ )

Die lange traurige, unt für Entwicfelung des Strafredts mehr als indifferente $\mathfrak{Z}^{\text {eit, }}$, die bem epochemachenden literarijden unt funttioneflen Birfen (5arpzob's nadffolgte, fann uns nidit lange Bejchäftigung bieten. Der $\mathfrak{B e g}_{e g}$ ourd ein fo iteriles $\mathfrak{F}$ (ad)land, das jedes Yebensfrijden Triebes eiter inahren juriftifden Fortbil= bung baar ift, unb bas nur ben $\mathfrak{2}$ tublicf trauriger Berfümmerung einer = uno ungehemmter Berlundjerung andererfeits bietet, ift zu unerquicfliç, als baß bir ihn Sđjritt bor Sdjritt berfolgen follten.

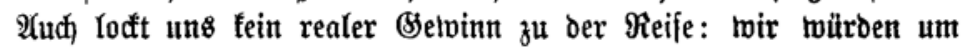
feine Erfahrung reiđjer das Ziel erreiđen. Die ßraz̧is ging ru= hig ifren $\mathfrak{B e g}$ meiter; bie Dottrin verharrte bei ihrem Brincipien= ftreit, ber im Brunde nur burd) Behauptungen gefüfrt trurbe, uno ohne gefdidftlidje Foridung feine Röjung finben fonnte. ${ }^{31}$ )

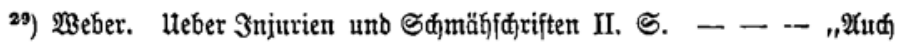
bleibt es immer widerfprechent (Ef)re, bie mant burd bie Snjurie nidt berYorent

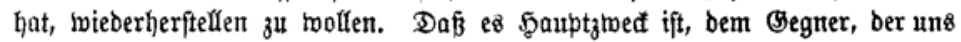
gefräntt hat, mehe zu thun, zeigt $\mathfrak{B}$ öhmer, de injustitia etc. cap. III. $\S .18$ ii. - - -". Damit, und auf ausbrïđfictes votum hin hält 2 Beber fireng

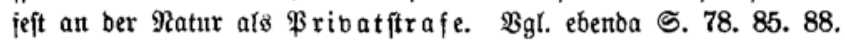

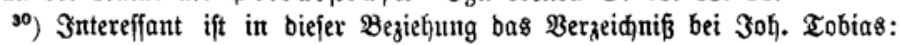

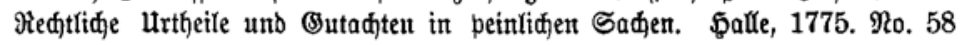
-61 unb anbertoürt8.

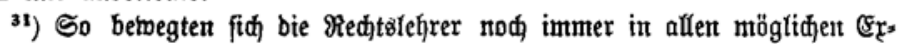
tremen. $\mathfrak{B a ̈ h r e n d ~} \mathfrak{B}$ öhnter a. a. $D$. 52 . ben $\mathfrak{2}$ Biberruf für criminaler $\mathfrak{R a t u r}$ 
Erit in bem neuen Fribfroth, bas Enbe bes vorigen $3 a$ hr $=$ hunderts heranbrad) bem Strafredt feine Regeneration burd $p$ hi= lofophifale unt hiftorifdje Erleuthtung verheifend unb getwäh= reno, fiel ein erwectender und belebender Straht aud auf unjer Inftitut. ऊener $\mathfrak{B a h n}$, ber burd einen vulgus error eingefüfhrt unb als foldjer fdjon bon einem Moller und bielen 2 noern erfannt war, bå̉ bie Ehre wie ein materiefles (S) nach Belieben entzo= gen und rwieber eritattet werben fönne, - ber fajon burd eine veränberte Bolfşauffaffing in ben Şintergruno georängt war,

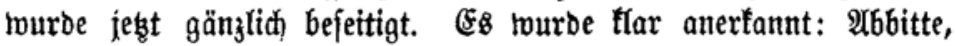
WBiberruf uno (Ehrenerflärungen fịı Strafen. ${ }^{32}$ )

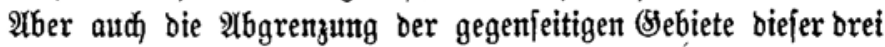
gegeneinander auf ber (Srunblage äufierer Berhältniffe, wie Stan= Desberfjiebentheit uno Brößße ber Snjurie, ftimmte meder mit ben 3ntentionen ber Beit, nod) fonte fie einer philofophifden $\mathfrak{B e t r a d}=$

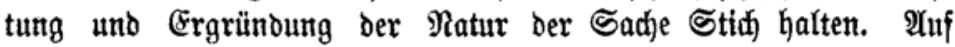

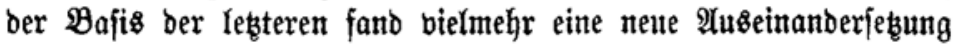
ftatt, $\left.{ }^{33}\right)$ bie, ausgehent bon bem $3 \mathfrak{n}$ alt ber formeln, bie

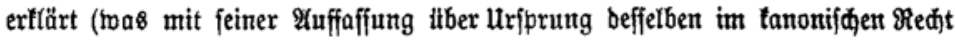
als einer ce ns ur a zufammenhängt), behauptet Sam. de Cocceji (Jus controversum civile. Francof. 1713. Lib. 47. Tit. X. Quaest. 20.) bie ftrenge Cibifität ber ferage unb betrađtet fte als rein reisperfefutorifd. (- - magis ad rei persecutionem accedere videtur, et sic ex interpretatione morum, quae vim legis habet, rei persecutorae censeri potest...) Er fteht alfo auf einem übermunbenen, nur hi ftorifd ridigen Stanopuntt, bon bem aus er bent freilidy alle meiteren Fragen, twie nad Eoncurrenz, afti= bem untb paffibem llebergang auf bie Exben (Qaest. 21. 22. 29.) in tabellofer (Sonfequenz beanthortet. Bertid's Borgang enblid) in ber $\mathfrak{A}$ mabme einer

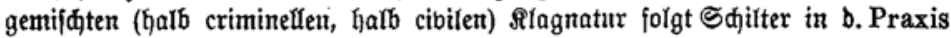
jur. Roman. Lib. 49. \$. XXXI. niđjt ohne anbre Эrrthitmer unb in fteter Berufung auf bie Braris, bie aber fo mentig conftant twar, baß̧ fie bon jeber

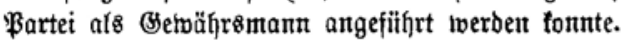

32) Damit fteht bie Forberung in teinem 2 iberfprüđ, baß̧ alle in Solen= nitäten beftebenden Erjamerungen fortfallen joflten. Denn bieje rourben als mit bem Beifte, Eharafter (unb wohl aud - 3međt) biejer Strajmittel mit

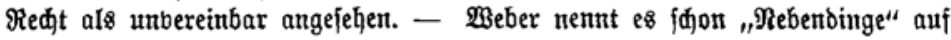

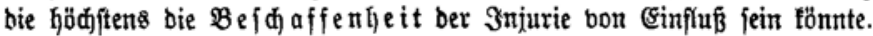

(Fine foldhe finbet fich nod bei Quistorp.

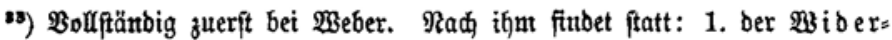

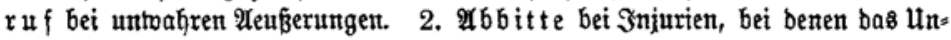


Sreife begränzte, innerhalb berer einer jeben einzelnen ber $\mathbb{L}_{0}$ gif

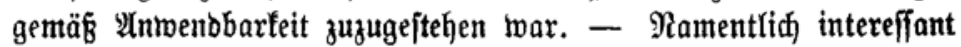
ift hierbei bie Eircumicription ber Eyrenerflärung. Die altgerma= nifdje Efrenerflärung war mit Berluft ihrer ganzen Bedeutung in

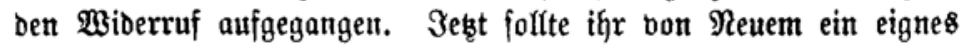
Shebiet zugetwiejen werben. Die Realifirung biefes Dejtrebens wurbe ourd einen Fehler auf Rojten juriftifjter $\mathfrak{B a h r h e i t e n ~ e r = ~}$ reidst, ${ }^{34}$ ) benn ofne animus injuriandi liegt teine Snjurie bor, und faum alfo aud nidjt gejtraft merden.

So war benn aus alten Material, uno aus Borliebe für Deffen Beibehaltung uno Berwenoung ein neues Bebäube aufge: ridjtet, über beffen nodernem Totaleinoruct ber Doftrin felbjt bie Sunde der Urefemente und ifhrer Formung und $\mathfrak{B}$ ujammenjeģung berloren ging. Hather aud eben biefes Bebäube war nidft geeig= ntet ben Stürmen ber geiftigen Reform zu twiberfteh)en, bielleidft eben weil das Miaterial unfaltbar uno bout ber Beit zu fehr zu= fammengeftoppelt uud übertündt war.

Sdjon $\mathfrak{T h o m a f i u}{ }^{35}$ ) hatte fidh gegen bie Antwentung biejer Ynjurienitrafen ausgefprodent gan bejonbers eiferte gegen fie aber $\mathfrak{B}$ öhmer in einer eignen Sdrift: de injustitia action injur. etc. Wietwohl num bei ihnent bie nidht itich haltige Argumentation

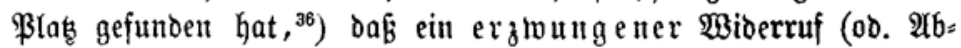

red)t in einer Unjittlidfeit beruht - (baher aud unter umfünben 2 Biberruf

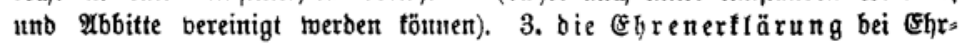
berleţungen, in benen man bie Mbjidjt 3 u beleibigen uidjt geljabt hat."

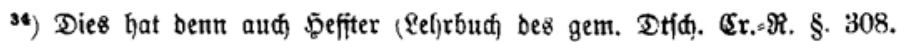

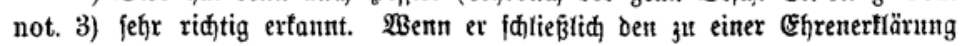

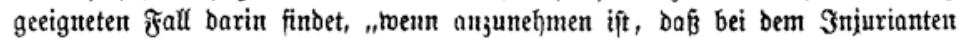

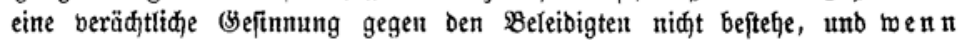
bejonber bie $\$$ njurie un im Born ober lebereilung begangen

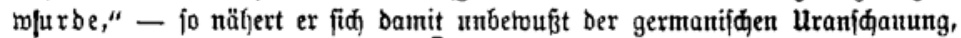
Der bas 3nftitut fein Dafein berbantt (f. Cap. I.). Freilid bleibt benn immer nod) bie Differenz beftehen, bie überhaupt zrifjen einem formellen (Broce B:) und materielren (Strafs) Mlt obtwaltet, - eime Differen, bie in bem vor:

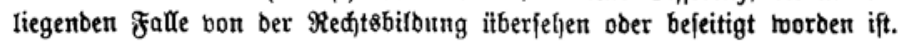

35) Dissertatio de actione injuriarum.

36) Daher nidt ftidhaltig, weil bie - Şerborbringung einte moras

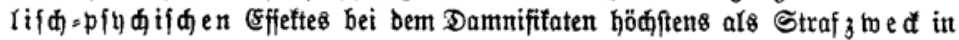
zmeiter Reike fteht. - 
bitte) twiberfinnig fei unb in feinen Birfungen mehr fdäblid) als

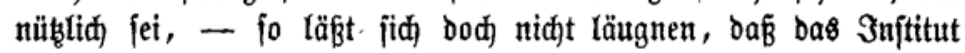
fid überlebt hat. Die Möglidffeit einer reiperjefutorifden (Ein= forberung gerautbter Eyre unterlag bereits, wie oben gezeigt, bor Sahrhumberten geredjten Bedenfen. Şentzutage ijt biefer $\mathfrak{B u n f t}$

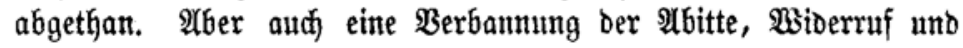
Ehrenerflärung aus ber Reihe ber Strafmittel mar auf Bruno ber neuten philofophifden Reform bes Strafrects und ber baraus refultirenden Bereinfadjung des Strafenfyitem \& unbermeiblid. Diejerbe ifit benn aud fucceffibe burd) bie neueren (Sobifitationen erforgt; mur Şantober (Strafgefę̧b. 266) uno Sarbinien (Codice penale bon 1839 Art. 629) erfennen heute nod biefe Strafe an; borausfictitlicy werben fie früher ober fpäter aud hier bem verän= berten Bseift ber Beit uno Biffenjafaft unterliegen müffen. Unnfer Inftitut wiro bamit in bie Reihe berer treten, oie ein rein hiftori. \{des aber beshalb nidyt für gering anzuldalagendes Sntereffe bar= bieten. - 